\title{
Clinical practice guidelines for hospital-acquired pneumonia and ventilator-associated pneumonia in adults
}

\author{
Coleman Rotstein MD FRCPC FACP ${ }^{1}$, Gerald Evans MD FRCPC ${ }^{2}$, Abraham Born MD FACP FCCP FRCPC ${ }^{3}$, \\ Ronald Grossman MD FACP FCCP FRCPC ${ }^{4}$, R Bruce Light MD ${ }^{5}$, Sheldon Magder MD FRCPC ${ }^{6}$, \\ Barrie McTaggart BSc $\mathrm{Phm}^{7}$, Karl Weiss MD MSc FRCPC ${ }^{8}$, \\ George G Zhanel PhD FCCP9,10
}

C Rotstein, G Evans, A Born, et al. Clinical practice guidelines for hospital-acquired pneumonia and ventilator-associated pneumonia in adults. Can J Infect Dis Med Microbiol 2008;19(1):19-53.

Hospital-acquired pneumonia (HAP) and ventilator-associated pneumonia (VAP) are important causes of morbidity and mortality, with mortality rates approaching $62 \%$. HAP and VAP are the second most common cause of nosocomial infection overall, but are the most common cause documented in the intensive care unit setting. In addition, HAP and VAP produce the highest mortality associated with nosocomial infection. As a result, evidence-based guidelines were prepared detailing the epidemiology, microbial etiology, risk factors and clinical manifestations of HAP and VAP. Furthermore, an approach based on the available data, expert opinion and current practice for the provision of care within the Canadian health care system was used to determine risk stratification schemas to enable appropriate diagnosis, antimicrobial management and nonantimicrobial management of HAP and VAP. Finally, prevention and risk-reduction strategies to reduce the risk of acquiring these infections were collated. Future initiatives to enhance more rapid diagnosis and to effect better treatment for resistant pathogens are necessary to reduce morbidity and improve survival.

\section{Des lignes directrices cliniques pour la pneumonie nosocomiale et la pneumonie sous ventilation assistée chez les adultes}

La pneumonie nosocomiale (PN) et la pneumonie sous ventilation assistée (PVA) sont d'importantes causes de morbidité et de mortalité, les taux de mortalité avoisinant les $62 \%$. Dans l'ensemble, la PN et la PVA constituent la deuxième cause d'infection nosocomiale en importance, mais la principale cause documentée à l'unité de soins intensifs. De plus, la PN et la PVA produisent le plus fort taux de mortalité imputable à une infection nosocomiale. C'est pourquoi on a préparé des lignes directrices probantes détaillant l'épidémiologie, l'étiologie microbienne, les facteurs de risque et les manifestations cliniques de la PN et de la PVA. De plus, une démarche axée sur les données disponibles, l'opinion d'experts et les pratiques courantes de prestation des soins au sein du système de santé canadien ont permis de déterminer les schèmes de stratification des risques afin de favoriser un diagnostic pertinent, la prise en charge antimicrobienne et la prise en charge non antimicrobienne de la PN et de la PVA. Enfin, on a colligé des stratégies de prévention et de réduction des risques afin de réduire le risque d'acquérir ces infections. De futures initiatives en vue de favoriser un diagnostic plus rapide et d'assurer le meilleur traitement des pathogènes résistants s'imposent pour réduire la morbidité et accroître le taux de survie.

Key Words: Guidelines; Hospital-acquired; Pneumonia; Ventilatorassociated

\section{EXECUTIVE SUMMARY}

$\mathrm{H}$ ospital-acquired pneumonia (HAP) and ventilatorassociated pneumonia (VAP) are important causes of morbidity and mortality in Canada, and they warrant a comprehensive management guideline. Furthermore, the economic impact of HAP and VAP is significant and has been a burden on health care resources. The present document, initiated and prepared jointly by the Association of Medical Microbiology and Infectious Disease Canada and the Canadian Thoracic Society, is an evidence-based guideline for the management of HAP and VAP. Group members represented the areas of infectious diseases, respirology, critical care and pharmacy. A standard grading system was used to classify each recommendation according to its strength (A-E) and quality of the evidence (1-3) (Table 1).

The present document covers the epidemiology, etiology, clinical manifestations of disease, risk factors for infection, strategies and approaches to diagnosis, antimicrobial and nonantimicrobial therapies in HAP and VAP and, finally, the role of prevention and risk reduction. Mention has also been given to the impact of antimicrobial resistance on pathogens associated with HAP and VAP, and future considerations that

${ }^{1}$ Division of Infectious Diseases and Department of Medicine, McMaster University and Henderson Site, Hamilton Health Sciences, Hamilton;

${ }^{2}$ Division of Infectious Diseases, Queen's University and Kingston General Hospital, Kingston; ${ }^{3}$ University of Toronto and North York General

Hospital, Toronto; ${ }^{4}$ University of Toronto, Toronto, Ontario and Credit Valley Hospital, Mississauga, Ontario; ${ }^{5}$ University of Manitoba and

St Boniface Hospital, Winnipeg, Manitoba; ${ }^{6} \mathrm{McGill}$ University Health Centre, Division of Critical Care and Department of Medicine, Royal

Victoria Hospital, Montreal, Quebec; ${ }^{7}$ McMaster University Medical Centre, Hamilton Health Sciences, Hamilton, Ontario; ${ }^{8}$ Department of

Microbiology and Infectious Diseases, Maisonneuve-Rosemont Hospital, University of Montreal, Montreal, Quebec; ${ }^{9}$ Department of Medical

Microbiology, Faculty of Medicine, University of Manitoba; ${ }^{10}$ Departments of Clinical Microbiology and Medicine, Health Sciences Centre,

Winnipeg, Manitoba

Correspondence and reprints: Dr Coleman Rotstein, University Health Network, Toronto General Hospital, NCSB 11-1212, 200 Elizabeth

Street, Toronto, Ontario M5G 2C4. Telephone 416-340-4800 ext 6663, fax 416-340-4242, e-mail coleman.rotstein@uhn.on.ca

Received for publication October 24, 2007. Accepted December 19, 2007 


\begin{tabular}{|c|c|}
\hline Category/grade & Definition \\
\hline \multicolumn{2}{|c|}{ Strength of recommendation } \\
\hline A & Good evidence to support a recommendation for use \\
\hline B & Moderate evidence to support a recommendation for use \\
\hline C & Poor evidence to support a recommendation \\
\hline $\mathrm{D}$ & $\begin{array}{l}\text { Moderate evidence to support a recommendation } \\
\text { against use }\end{array}$ \\
\hline $\mathrm{E}$ & Good evidence to support a recommendation against use \\
\hline \multicolumn{2}{|c|}{ Quality of evidence } \\
\hline 1 & Evidence from $\geq 1$ properly randomized, controlled trial \\
\hline 2 & $\begin{array}{l}\text { Evidence from } \geq 1 \text { well-designed clinical trial, without } \\
\text { randomization; from cohort or case-controlled analytic } \\
\text { studies (preferably from }>1 \text { centre); from multiple } \\
\text { time-series; or from dramatic results from uncontrolled } \\
\text { experiments }\end{array}$ \\
\hline 3 & $\begin{array}{l}\text { Evidence from opinions of respected authorities, based } \\
\text { on clinical experience, descriptive studies or reports of } \\
\text { expert committees }\end{array}$ \\
\hline
\end{tabular}

Adapted from reference 367

should be addressed regarding these two very important infectious diseases. Key issues and recommendations have been included at the end of each section.

The present guideline emphasizes rapid diagnosis, immediate empirical antibiotic therapy and avoidance of unnecessary use of antibiotics by way of streamlining and de-escalation. The use of patient risk stratification based on initial clinical presentation has been deemed an important feature in the treatment strategies described. Furthermore, these principles may not be applicable to immunosuppressed patients. However, this is a guideline and clinicians should always be cognizant of local epidemiology, antibiotic resistance issues and underlying immunosuppression. It should not replace the value of experienced clinical judgment.

The following are the highlights of the present document:

1. HAP and VAP together are the second most common cause of hospital-acquired infection and have been associated with a higher mortality than any other nosocomial infection.

2. HAP and VAP are associated with longer attributable lengths of stay in hospital and greater hospital expenditures compared with patients without HAP or VAP.

3. HAP and VAP may be caused by a variety of aerobic and anaerobic Gram-positive cocci and Gramnegative bacilli.

4. Many patients at risk for HAP and VAP have underlying medical conditions that put them at higher risk for acquiring antibiotic-resistant organisms (AROs).

5. The presence of specific host, environmental or pharmacological factors may enhance the propensity of patients to develop HAP and VAP.

6. HAP or VAP should be suspected in all patients, whether ventilated or not, if two or more of the following clinical features are present: temperature greater than $38^{\circ} \mathrm{C}$ or less than $36^{\circ} \mathrm{C}$; leukopenia or leukocytosis; purulent tracheal secretions and decreased partial pressure of oxygen in arterial blood $\left(\mathrm{PaO}_{2}\right)$.

7. Patient risk stratification based on clinical presentation, time of onset following admission to the hospital, and the potential for resistant pathogens can be applied to individuals with HAP and VAP.

8. Initial empirical antibiotic therapy for HAP and VAP should begin within $24 \mathrm{~h}$ of diagnosis and be modified accordingly as microbiological and clinical response data become available. Strong consideration should be given to abbreviating antibiotic courses to seven days for most pathogens to reduce the risk for the emergence of resistant organisms.

9. Attention to judicious use of fluids, nutritional support and careful management of mechanical ventilatory support can contribute to improved outcomes in patients with HAP and VAP.

10. An effective infection control program should be implemented to control the spread of AROs.

\section{INTRODUCTION}

HAP and VAP are important causes of morbidity and mortality in Canada and around the world. The economic impact of HAP and VAP is also significant and may be attributed to increased lengths of stay in the hospital.

HAP is defined as an inflammatory condition of the lung parenchyma caused by infectious agents not present or incubating at the time of hospital admission; that is, conditions that develop more than $48 \mathrm{~h}$ after admission $(1,2)$. For epidemiological purposes, the Centers for Disease Control and Prevention state that all patients older than 12 months of age who meet at least one of the criteria listed in Table 2 are considered to have HAP (3). HAP has been subdivided into pneumonias that occur on the ward and those that arise in the intensive care unit (ICU) (ICU HAP). The term 'early-onset' is used if HAP occurs within the first $96 \mathrm{~h}$ of admission to the hospital and 'late-onset' if HAP arises beyond this time $(4,5)$. Incidentally, it is this division that assists in the microbiological identification of pathogens that cause HAP (2). It has been suggested that patients with late-onset HAP are associated with an increasing prevalence of resistant nosocomial pathogens, although studies have contradicted this hypothesis.

VAP, on the other hand, is a subset of HAP and includes all patients receiving mechanical ventilation at the time of infection. VAP occurs almost exclusively in the ICU and represents approximately $86 \%$ of all ICU HAP (6). The American Thoracic Society criteria (2) for the diagnosis of VAP are pneumonia in a patient mechanically ventilated for greater than $48 \mathrm{~h}$ with at least two of the following criteria: fever (body temperature increase of greater than $1^{\circ} \mathrm{C}$ or body temperature greater than $\left.38.3^{\circ} \mathrm{C}\right)$, leukocytosis $(25 \%$ increase and a value greater than $10.0 \times 10^{9} / \mathrm{L}$ ) or leukopenia ( $25 \%$ decrease and a value less than $5.0 \times 10^{9} / \mathrm{L}$ ), and purulent tracheal secretions (greater than 25 neutrophils per high-power field). In addition, one or more of the following criteria must also be met: new or persistent infiltrates on chest radiographs, the 
TABLE 2

Centers for Disease Control and Prevention criteria for nosocomial pneumonia

\begin{tabular}{l} 
Pneumonia must meet one of the criteria (only in patients $>12$ months \\
of age) \\
\hline 1. Rales or dullness to percussion on physical examination of chest \\
and any of the following: \\
- new onset of purulent sputum or change in character of sputum; \\
- organism isolated from blood culture; \\
• isolation of pathogen from specimen obtained by transtracheal \\
aspirate, bronchial brushing or biopsy. \\
2. Chest radiographic examination shows new or progressive infiltrate, \\
consolidation, cavitation or pleural effusion and any of the \\
following: \\
- new onset of purulent sputum or change in character of sputum; \\
- organism isolated from blood culture; \\
• isolation of pathogen from specimen obtained by transtracheal \\
aspirate, bronchial brushing or biopsy; \\
- isolation of virus or detection of viral antigen in respiratory secretions; \\
- diagnostic single antibody titre (IgM) or four-fold increase in paired \\
serum samples (lgG) for pathogen. \\
\hline
\end{tabular}

Ig Immunoglobulin. Adapted from reference 3

same microorganism isolated from pleural fluid and tracheal secretions, or radiographic cavitation or histopathological demonstration of pneumonia and positive cultures obtained from bronchoalveolar lavage (BAL) (greater than $10^{4}$ colony forming units $[\mathrm{cfu}] / \mathrm{mL})(2)$.

The diagnosis of HAP and VAP is a challenge, and the precise role of testing, especially when using an invasive technique, is controversial (7). Although antimicrobials are the mainstay of the management of HAP and VAP, the optimal therapeutic agent(s) are controversial and numerous nonantimicrobial interventions such as fluid and nutritional support may also affect outcome.

The ultimate goal of the present guideline is to provide a framework to make informed decisions regarding the diagnosis and management of HAP and VAP. Diagnostic and treatment algorithms demonstrate that patient risk stratification based on the clinical presentation and risk for resistance organisms can promote successful outcomes and improve antimicrobial stewardship, curtailing the overuse of antimicrobials.

The present guideline and the recommendations provided, albeit evidence-based, should always be tempered by the judgment of a well-informed physician and only assist in the decisionmaking process.

\section{METHODOLOGY}

The present guideline was prepared by a working group comprised of individuals with expertise in the disciplines of infectious disease, respirology, intensive care medicine and pharmacy. Members were chosen based on their expertise and upon recommendation by the co-chairs who were members of the Association of Medical Microbiology and Infectious Disease Canada and the Canadian Thoracic Society, and were approved by the respective societies. Each member of the group was assigned a subject for review. For each subject, a literature search was undertaken of English-language peerreviewed papers and abstracts until December 2006, making use of relevant key words pertinent to that subject. Information was sorted and tabulated. All documents were

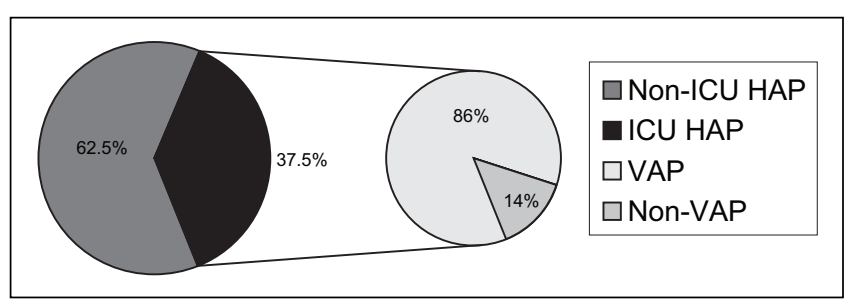

Figure 1) Breakdown of hospital-acquired pneumonia/intensive care unit (HAP/ICU) and HAP/ventilator-associated pneumonia (VAP). Information taken from references 6,12,13,22

merged and a working draft prepared for review by all members. The completed document was reviewed and approved by the aforementioned societies.

The grading system of the evidence used has been previously described and was based on the strength and quality of the evidence according to the Infectious Diseases Society of America (Table 1).

\section{Incidence and prevalence}

\section{EPIDEMIOLOGY}

HAP is the second most common nosocomial infection with a crude overall rate of 6.1 per 1000 discharges (8). By comparison, the infection rate for nosocomial urinary tract infection, the most common hospital-acquired infection, is 11 per 1000 discharges. The incidence of HAP varies depending on the hospital environment (Figure 1) $(9,10)$.

A Canadian descriptive study (11) of non-ICU HAP in a tertiary care hospital showed a mean $( \pm \mathrm{SD})$ age of $63 \pm 17$ years of which $55(65 \%)$ were male. The majority of HAP cases $(81 \%)$ were acquired on surgical wards.

The incidence of HAP is greater among patients in the ICU (Figure 1). Generally, approximately $30 \%$ of HAP occurs in critical care settings $(12,13)$.

The incidence of VAP from the National Nosocomial Infections Surveillance (NNIS) data is 7.6 cases per 1000 ventilator-days (14). However, it should be noted that rates vary depending on the method of assessment used (15). The incidence of the first episode of VAP was 22.8 per 1000 patient-days, 29.6 per 1000 patient-days at risk, 35.7 per 1000 ventilator-days, and 44.0 per 1000 ventilator-days at risk. The risk for VAP peaks at day 5 of mechanical ventilation (16). NNIS data showed that the incidence of VAP was highest for trauma ICUs (15.2 per 1000 ventilator-days) (14). The overall prevalence of VAP was $9.3 \%$ (17). In a Canadian cohort study of 1014 patients ventilated for $48 \mathrm{~h}$ or greater, 177 (17.4\%) developed VAP (18). The median duration from ICU admission to the onset of VAP in this study was seven days. Acute respiratory distress syndrome (ARDS) carries an increased risk for VAP $(19,20)$.

\section{Outcomes}

HAP has been shown to have the highest mortality rate of all nosocomial infections (4). In one study (10), the crude casefatality rate was $30 \%$, rising to $33 \%$ in cases attributable to an initial episode of HAP. In a Canadian study (11) of non-ICU HAP, overall mortality rate was $20 \%$, with a direct attributable mortality of $14 \%$. The mortality rate from HAP varied from $7 \%$ in patients on general wards to as high as $62 \%$ in patients in bone marrow transplant units (21). 


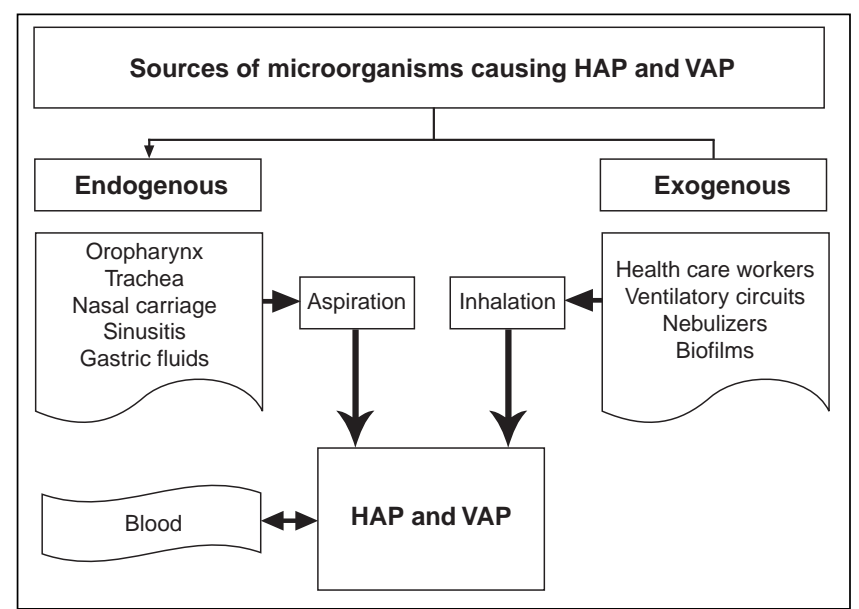

Figure 2) Endogenous and exogenous sources of microorganisms causing hospital-acquired pneumonia (HAP) and ventilator-associated pneumonia (VAP). Adapted from references 29,30

Death from bacteremic HAP occurred in $20 \%$ of patients within one week of their first positive blood culture, and Pseudomonas aeruginosa bacteremia was associated with the highest mortality rate (45\%) (22). The mortality rate in this study was similar for both the ICU $(22.2 \%)$ and non-ICU patients $(17.6 \%)$ (95\% CI 0.4 to 1.5$)$.

The mortality rate for VAP ranges from $24 \%$ to $50 \%$, and can reach as high as $76 \%$ in specific settings or when lung infection is caused by high-risk pathogens (23). The attributable mortality of VAP in a Canadian study (16) showed an increase in risk of death (absolute risk increase: 5.8\%). The attributable mortality was higher for medical patients than for surgical patients ( $R R$ increase of $65 \%$ versus $27.3 \%, P=0.04$ ). In a French study (20) of patients with ARDS, there was no difference in mortality rates between patients with VAP (28 of $49[57 \%])$ and without VAP (50 of 85 [59\%]) $(\mathrm{P}=0.8)$.

\section{Economic impact}

The costs of HAP are significant because it is associated with longer hospital stays (10). Similarly, VAP is associated with a significant increase in hospital costs. An American study (16) showed that the development of VAP was associated with an increase of $\$ 41,294$ in mean hospital charges per patient $(\$ 104,983 \pm \$ 91,080$ versus $\$ 63,689 \pm \$ 75,030, \mathrm{P}<0.001)$.

\section{Major points and recommendations for epidemiology}

1. The incidence of HAP and VAP together is between five and 10 cases per 1000 hospital admissions, depending on the case definition used and the study population.

2. Together, HAP and VAP are the second most common cause of hospital-acquired infection and are associated with a higher mortality than any other nosocomial infection.

3. Patients with late-onset HAP or VAP have a similar rate of mortality to those with early-onset disease.

4. Approximately $30 \%$ of HAP occurs in the ICU setting where the majority of cases (greater tham $85 \%$ ) occur in patients on mechanical ventilation.
TABLE 3

Microbiological causes of hospital-acquired pneumonia and ventilator-associated pneumonia (level A-2)

\begin{tabular}{lc}
\hline Microbiological diagnosis & $\begin{array}{c}\text { Frequency of isolation } \\
\text { (\% of patients) }\end{array}$ \\
\hline Gram-negative bacilli & $35-80$ \\
Escherichia coli & \\
Klebsiella species & \\
Enterobacter species & \\
Proteus species & \\
Serratia marcescens & \\
Pseudomonas aeruginosa & \\
Acinetobacter species & \\
Stenotrophomonas maltophilia & $9-46$ \\
Gram-positive cocci & \\
Streptococcus pneumoniae & \\
Streptococcus species & \\
Staphylococcus aureus (MSSA and MRSA) & \\
Polymicrobial & $9-80$ \\
Anaerobes & $0-54$ \\
Blood culture positive & $0-40$ \\
No growth & $2-54$ \\
\hline
\end{tabular}

MSSA Methicillin-susceptible S aureus, MRSA Methicillin-resistant S aureus Adapted from references 11,44-91

5. The costs of HAP and VAP are substantial and have been attributed to longer stays in hospital and greater hospital expenditures when compared with patients without HAP.

\section{MICROBIAL ETIOLOGY}

HAP and VAP occur if a large inoculum of organisms reaches the lower airways and thereby overwhelms host defenses. Alternatively, HAP and VAP can occur if a patient's host defenses are impaired or if they are infected with a highly virulent strain (5,24-38). To establish optimal empirical and pathogen-directed antimicrobial therapy, it is desirable to obtain sensitive, specific and rapid identification of the causative pathogen(s) of HAP and VAP. It is believed that establishing the correct etiological cause of HAP and VAP, followed by directed treatment based on susceptibility testing, will lead to improved outcomes (2,24,39-43). Unfortunately, establishing the etiological agent(s) of HAP and VAP may be difficult because distinguishing between mere colonization of the tracheobronchial tree versus true nosocomial pneumonia is often problematic $(24-26)$. Additional challenges, such as the fact that no organisms or alternatively, several organisms, may be isolated, hamper optimal antimicrobial therapy.

A common classification scheme, which aids in understanding the pathogenesis of HAP and VAP, has been developed. Infections are derived from either an endogenous or exogenous source (Figure 2) (24,29,30). Endogenous infection is the most frequent cause of HAP and VAP, and can occur with either community-acquired or hospital-acquired pathogens that colonize the host. Initial colonization of the respiratory tract occurs most commonly, followed by the microaspiration of oropharyngeal secretions $(29,30)$. In mechanically ventilated patients, leakage of endotracheal secretions around the endotracheal cuff results in aspiration of 
TABLE 4

Pathogens causing hospital-acquired pneumonia (HAP) and ventilator-associated pneumonia (VAP) (level A-2)

\begin{tabular}{|c|c|c|c|}
\hline Disease & Classification & $\begin{array}{l}\text { Diagnostic } \\
\text { features }\end{array}$ & Pathogens \\
\hline \multirow[t]{3}{*}{ HAP } & Group 1 & $\begin{array}{l}\text { No risk factors for } \\
\text { resistance }{ }^{\dagger} \text { AND mild to } \\
\text { moderate presentation }{ }^{\ddagger}\end{array}$ & Core pathogens* \\
\hline & Group 2 & $\begin{array}{l}\text { Risk factors for resistance }{ }^{\dagger} \\
\text { AND mild to moderate } \\
\text { presentation }{ }^{\ddagger}\end{array}$ & $\begin{array}{l}\text { Core pathogens* } \\
\text { plus MRSA and } \\
\text { Pseudomonas } \\
\text { aeruginosa }\end{array}$ \\
\hline & Group 3 & $\begin{array}{l}\text { Severe presentation }{ }^{\S} \pm \\
\text { risk factors for resistance }^{\dagger}\end{array}$ & $\begin{array}{l}\text { Core pathogens* } \\
\text { plus MRSA, } \\
\text { P aeruginosa and } \\
\text { Legionella species }\end{array}$ \\
\hline \multirow[t]{2}{*}{ VAP } & Group 4 & $\begin{array}{l}\text { No risk factors for } \\
\text { resistance }{ }^{\dagger} \text { AND mild to } \\
\text { moderate presentation }{ }^{\ddagger}\end{array}$ & Core pathogens* \\
\hline & Group 5 & $\begin{array}{l}\text { Risk factors for resistance }{ }^{\dagger} \\
\text { AND/OR severe } \\
\text { presentation } \S\end{array}$ & $\begin{array}{l}\text { Core pathogens* } \\
\text { plus MRSA, } \\
\text { P aeruginosa, } \\
\text { Legionella species, } \\
\text { Acinetobacter } \\
\text { species and } \\
\text { Stenotrophomonas } \\
\text { maltophilia }\end{array}$ \\
\hline
\end{tabular}

${ }^{*}$ Core pathogens include Streptococcus pneumoniae, Streptococcus species, Haemophilus influenzae, Enterobacter species, Escherichia coli, Klebsiella species, Proteus species, Serratia marcescens and methicillin-susceptible Staphylococcus aureus; tRisk factors for resistance include antimicrobial therapy in the past 90 days and late-onset during hospitalization ( $>5$ days); $¥$ Mild to moderate presentation: no hypotension, intubation, sepsis syndrome, rapid progression of infiltrates or end-organ dysfunction; §Severe presentation: hypotension, intubation, sepsis syndrome, rapid progression of infiltrates or end-organ dysfunction. MRSA Methicillin-resistant S aureus. Adapted from references 11,44-91

organisms into the lower airways. Gross aspiration of large volumes of either oropharyngeal or esophageal/gastric contents is not common. Exogenous infection with nosocomial pathogens acquired from the hospital environment is less common and generally occurs late in the ICU admission (Figure 2). Health care workers or medical equipment may harbour pathogenic flora that can prompt colonization of the tracheobronchial tree. Contaminated humidification reservoirs during mechanical ventilation may lead to aerosolization of pathogens and subsequent colonization and infection. Another potential route of infection in HAP and VAP is bacteremia. The hematogenous spread from distant sites of infection, although not a common cause, may also occur in postoperative patients as well as in patients with intravenous or urinary catheters.

Accurate data regarding the etiology of HAP and VAP are limited and may result from the lack of a gold standard for microbiological diagnosis. Microbiological diagnosis of HAP has been defined by samples collected from expectorated sputum, endotracheal suctioning, BAL, or protected specimen brushing (PSB) alone or in combination with blood cultures $(11,44-76)$. In general, the bacteriology of patients with HAP $(43,46,55,77)$ or VAP $(24,26,43,59,61,65,75,78)$ is similar, although Stenotrophomonas maltophilia and Acinetobacter species are found predominantly in VAP. Bacteriological

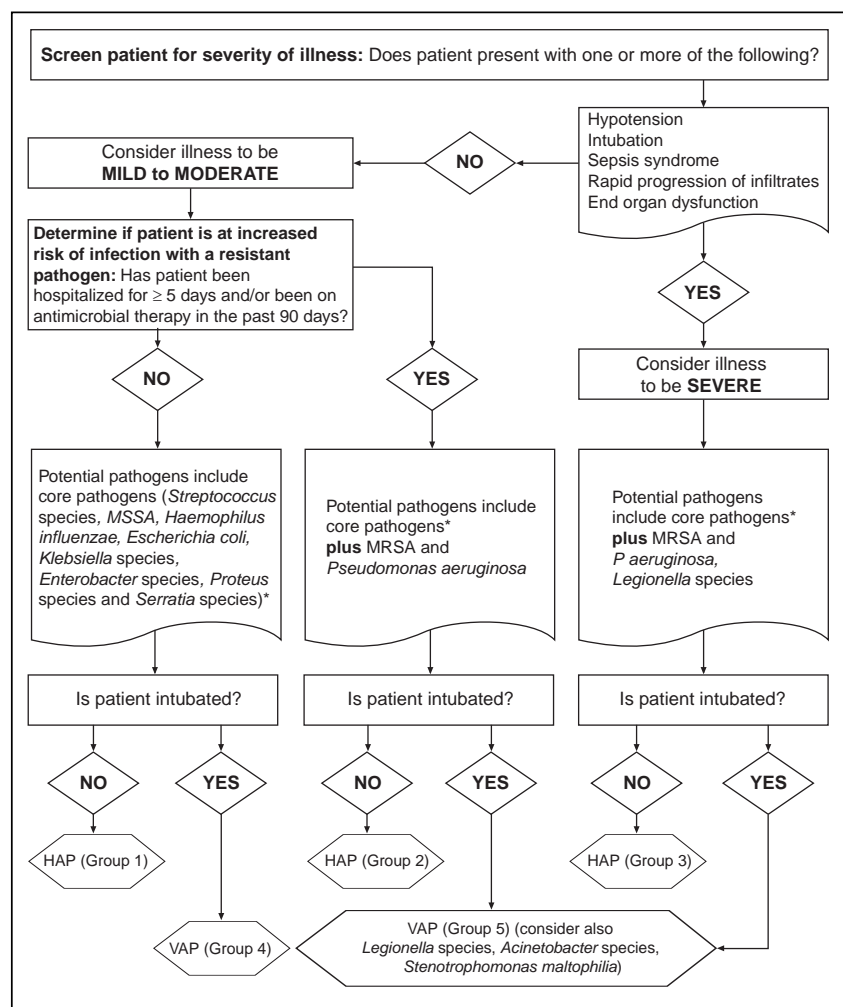

Figure 3) Algorithm for determining the microbiological cause of hospital-acquired pneumonia (HAP) and ventilator-associated pneumonia (VAP) using risk factors for resistance and severity of illness. MRSA Methicillin-resistant Staphylococcus aureus; MSSA Methicillin-sensitive S aureus. Data are from references 2,11,40,4491, and represent level A-2 data

analysis in patients with HAP or VAP has revealed that $35 \%$ to $80 \%$ of individuals are infected with Gram-negative bacilli, $9 \%$ to $46 \%$ with Gram-positive cocci and $0 \%$ to $54 \%$ with anaerobes (Table 3) (11,44-91). Studies report that $9 \%$ to $80 \%$ of patients with HAP or VAP have polymicrobial infection while the inability to isolate a pathogen was found to occur in $2 \%$ to $54 \%$ of patients (Table 3 ). Positive blood cultures have been reported in $0 \%$ to $40 \%$ of patients with HAP or VAP. The microbiology of HAP and VAP is supported by quality clinical studies.

Due to the predominance of certain virulent pathogens in HAP and VAP, the concept of 'core' pathogens was developed (Table 4 and Figure 3) (2,40,42). Core pathogens should be considered as potential causes of HAP or VAP in all patients. Core pathogens include Streptococcus pneumoniae, Streptococcus species, Haemophilus influenzae, Enterobacteriaceae such as Escherichia coli, Klebsiella species, Enterobacter species, Proteus species and Serratia marcescens, as well as methicillin-susceptible Staphylococcus aureus (Table 4) (11,44-101). In addition, severity of presentation of HAP or VAP (mild to moderate versus severe), as well as risk factors for resistant pathogens such as antimicrobial use in the preceding 90 days (for any reason), early-onset (less than five days of hospitalization) versus lateonset (five days or more of hospitalization) and immunosuppression affect the likely causative pathogens. Prior antimicrobial use and late onset are HAP risk factors for methicillin-resistant $S$ aureus (MRSA) and P aeruginosa (Figure 3) (27,41). Similarly, prior antimicrobial use and late onset are VAP risk factors for 
TABLE 5

In vitro antibiotic activity against common Gram-positive aerobes causing hospital-acquired pneumonia and ventilatorassociated pneumonia

\begin{tabular}{|c|c|c|c|c|c|c|c|c|c|c|c|c|c|c|c|c|c|c|c|c|c|c|}
\hline \multirow[b]{3}{*}{ Bacteria } & \multicolumn{22}{|c|}{ Susceptibility profiles } \\
\hline & \multicolumn{2}{|c|}{ Ceftazidime* $^{*}$} & \multicolumn{2}{|c|}{ Ceftriaxone $^{\dagger}$} & \multicolumn{2}{|c|}{ Ciprofloxacin } & \multicolumn{2}{|c|}{ Clindamycin } & \multicolumn{2}{|c|}{ Erythromycin $\ddagger$} & \multicolumn{2}{|c|}{ Gentamicin§ } & \multicolumn{2}{|c|}{ Levofloxacin } & \multicolumn{2}{|c|}{ Linezolid } & \multicolumn{2}{|c|}{ Meropenem $^{\star *}$} & \multicolumn{2}{|c|}{ Pip/Tazott } & \multicolumn{2}{|c|}{ Vancomycin } \\
\hline & Act & $\mathrm{MIC}_{90}$ & Act & $\mathrm{MIC}_{90}$ & Act & $\mathrm{MIC}_{90}$ & Act & $\mathrm{MIC}_{90}$ & Act & $\mathrm{MIC}_{90}$ & Act & $\mathrm{MIC}_{90}$ & Act & $\mathrm{MIC}_{90}$ & Act & $\mathrm{MIC}_{90}$ & Act & $\mathrm{MIC}_{90}$ & Act & $\mathrm{MIC}_{90}$ & Act & $\mathrm{MIC}_{90}$ \\
\hline $\begin{array}{c}\text { Staphylococcus } \\
\text { aureus (MS) }\end{array}$ & + & 32 & $++/+++$ & +4 & +++ & 0.5 & ++++ & 0.5 & +++ & 2 & ++ & 0.5 & ++++ & 0.25 & ++++ & 2 & ++++ & 0.12 & ++++ & 1 & +++ & 1 \\
\hline $\begin{array}{c}\text { Staphylococcus } \\
\text { aureus (MR) }\end{array}$ & - & 256 & - & 256 & - & 64 & $+/++$ & 4 & $-1+$ & $>128$ & + & 128 & - & 32 & ++++ & 2 & ++ & 64 & $-1+$ & 256 & ++++ & 1 \\
\hline $\begin{array}{l}\text { Staphylococcus } \\
\text { epidermidis (M }\end{array}$ & $\begin{array}{r}+ \\
M S)\end{array}$ & $32+$ & $++/+++$ & +4 & +++ & 1 & +++ & 2 & $+/++$ & 8 & + & 16 & +++ & 1 & ++++ & 2 & ++++ & 0.5 & ++++ & 1 & ++++ & 2 \\
\hline $\begin{array}{l}\text { Staphylococcus } \\
\text { epidermidis (M }\end{array}$ & MR) & 64 & - & 64 & + & 16 & + & 16 & $-1+$ & $>128$ & + & 16 & + & 8 & ++++ & 2 & ++ & 32 & $-/+$ & $>32$ & ++++ & 4 \\
\hline $\begin{array}{r}\text { Streptococcus } \\
\text { pneumoniae }\end{array}$ & ++ & 2 & ++++ & 0.5 & $+/++$ & 2 & ++++ & 0.12 & $+/++$ & 32 & $-/+$ & 16 & ++++ & 1 & ++++ & 1 & ++++ & 1 & ++++ & 0.12 & ++++ & 1 \\
\hline $\begin{array}{l}\text { Streptococcus } \\
\text { pneumoniae }(\mathrm{P}\end{array}$ & $\begin{array}{c}+++ \\
(P S)\end{array}$ & 0.25 & ++++ & 0.06 & $+/++$ & 2 & ++++ & 0.12 & ++++ & 0.06 & $-/+$ & 16 & ++++ & 1 & ++++ & 1 & ++++ & 0.016 & ++++ & $\leq 0.06$ & ++++ & 1 \\
\hline $\begin{array}{l}\text { Streptococcus } \\
\text { pneumoniae }(\mathrm{P}\end{array}$ & & 8 & ++++ & 1 & $+/++$ & 2 & ++ & 1 & ++ & 16 & $-1+$ & 16 & ++++ & 1 & ++++ & 1 & ++++ & 0.5 & ++++ & 1 & ++++ & 1 \\
\hline $\begin{array}{l}\text { Streptococcus } \\
\text { pneumoniae }(\mathrm{P}\end{array}$ & $\begin{array}{c}+ \\
(P R)\end{array}$ & 32 & +++ & 2 & $+/++$ & 2 & ++ & 1 & + & $>32$ & $-/+$ & 16 & +++ & 1 & ++++ & 1 & +++ & 1 & +++ & 4 & ++++ & 1 \\
\hline $\begin{array}{l}\text { Enterococcus } \\
\text { faecalis (VS) }\end{array}$ & - & $>64$ & - & $>64$ & + & $>32$ & ++ & 2 & + & 4 & + & $>2000$ & ++ & 4 & ++++ & 2 & +++ & 2 & ++++ & 1 & ++++ & 2 \\
\hline $\begin{array}{l}\text { Enterococcus } \\
\text { faecalis (VR) }\end{array}$ & - & $>64$ & - & $>64$ & - & $>32$ & + & 8 & $-1+$ & 16 & + & $>2000$ & - & 32 & ++++ & 2 & + & 8 & + & 64 & - & $>32$ \\
\hline $\begin{array}{l}\text { Enterococcus } \\
\text { faecium (VS) }\end{array}$ & - & $>64$ & - & $>64$ & + & $>32$ & + & 8 & + & 8 & + & $>2000$ & + & 32 & ++++ & 2 & + & 64 & + & 256 & ++++ & 2 \\
\hline $\begin{array}{l}\text { Enterococcus } \\
\text { faecium (VR) }\end{array}$ & - & $>64$ & - & $>64$ & $-1+$ & $>32$ & $-1+$ & 32 & - & 32 & + & $>2000$ & $-1+$ & $>32$ & ++++ & 2 & - & 64 & - & 256 & - & $>32$ \\
\hline
\end{tabular}

${ }^{*}$ Applies to ceftazidime and cefepime; ${ }^{\dagger}$ Applies to ceftriaxone and cefotaxime; $¥$ Applies to erythromycin and azithromycin; $\S$ Applies to gentamicin, netilmicin "Applies to ceftazidime and cefepime; Applies to ceftriaxone and cefotaxime; $¥$ Applies to erythromycin and azithromycin; $\$$ Applies to gentamicin, netilmicin,
tobramycin and amikacin; TApplies to levofloxacin, gatifloxacin and moxifloxacin; ${ }^{* *}$ Applies to meropenem and imipenem/cilastatin; ${ }^{+}$Applies to piperacillin/tazobactam (Pip/Tazo) and ticarcillin/clavulanate. Act Antibiotic activity: - poor activity, + limited activity and/or resistance $\geq 5 \%$, ++ moderate to good activity and/or resistance $10 \%$ to $14 \%,+++$ very good activity and/or resistance $5 \%$ to $9 \%,++++$ excellent activity and/or with resistance $\leq 4 \%$; MIC ${ }_{90}$ Minimum inhibitory concentration $(\mu \mathrm{g} / \mathrm{mL})$ of $90 \%$ of isolates; MR Methicillin resistant; MS Methicillin susceptible; PI Penicillin intermediate (MIC $0.12 \mu \mathrm{g} / \mathrm{mL}$ to $1 \mu \mathrm{g} / \mathrm{mL}) ; \mathrm{PR}$ Penicillin resistant (penicillin MIC $\geq 2.0 \mu \mathrm{g} / \mathrm{mL}$ ); PS Penicillin susceptible (MIC $\leq 0.06 \mu \mathrm{g} / \mathrm{mL})$, VR Vancomycin resistant (MIC $\geq 8 \mu \mathrm{g} / \mathrm{mL}) ; \mathrm{VS}$ Vancomycin susceptible $(\mathrm{MIC} \leq 4 \mu \mathrm{g} / \mathrm{mL})$. Antibiotic breakpoints from the Clinical and Laboratory Standards Institute approved breakpoints (368). Data presented in table were adapted from references (11,44-101) and represent level A-2 data

MRSA, P aeruginosa, Acinetobacter species and S maltophilia (Figure 3) (27,41). Unusual pathogens such as Aspergillus species, Candida species, Legionella pneumophila, Pneumocystis jiroveci (previously Pneumocystis carinii), Nocardia species and viruses such as cytomegalovirus are causes of HAP and VAP in patients who are immunosuppressed $(2,24,30,31,40,41,43,102$ 106). A discussion of these and other entities in immunosupressed patients goes beyond the scope of the present document but have been dealt with in other reports $(31,41,107)$.

Because HAP and VAP may be caused by a variety of aerobic and anaerobic Gram-positive cocci and Gram-negative bacilli, it is important to know the activity of commonly used antimicrobial agents against these pathogens (Tables 5 to 7 ) $(44,45)$. Third-generation cephalosporins (eg, cefotaxime, ceftriaxone and ceftazidime), broad-spectrum penicillins (eg, piperacillin/tazobactam), fluoroquinolones (eg, ciprofloxacin and levofloxacin), aminoglycosides (eg, gentamicin) and carbapenems (eg, imipenem and meropenem) have very broadspectrum activity against the common aerobic pathogens causing HAP or VAP (Tables 5 and 6). Other agents such as macrolides (eg, erythromycin and azithromycin) and lincosamides (clindamycin), linezolid and vancomycin have excellent activity against Gram-positive cocci, while demonstrating minimal activity against Gram-negative bacilli
(Tables 5 and 6). The most active antimicrobial against anaerobes include metronidazole, clindamycin, carbapenems and broad-spectrum penicillins combined with beta-lactamase inhibitors. Gatifloxacin and moxifloxacin have good activity against Bacteroides fragilis (Table 7) but adverse events associated with gatifloxacin preclude its use.

Impact of antimicrobial resistance

Many patients at risk for HAP or VAP are also at risk for acquiring AROs given that many of these patients have underlying medical conditions. In these patients, colonization by multi-resistant Gram-negative bacilli is often the forerunner of HAP or VAP. Further, inappropriate use of antibiotics in terms of indication, duration or spectrum choices promote the acquisition of AROs (108). Moreover, patients infected by AROs are at increased risk of morbidity and mortality (109-112), not only from the organisms themselves, but also due to complications of the antibiotic therapy.

MRSA is increasingly being recovered in ICUs and on general wards in North American institutions. Data from the NNIS in the United States have confirmed this finding (14). In Canada, the rate of MRSA increased from a mean of 0.95 per $100 \mathrm{~S}$ aureus isolates in 1995 to 5.97 per 100 isolates in 1999 (94). Moreover, one must be cognizant and wary not only of hospital-acquired MRSA, but also of the potential for 
TABLE 6

In vitro antibiotic activity against common Gram-negative aerobes causing hospital-acquired pneumonia and ventilatorassociated pneumonia

\begin{tabular}{|c|c|c|c|c|c|c|c|c|c|c|c|c|c|c|c|c|}
\hline \multirow[b]{3}{*}{ Bacteria } & \multicolumn{16}{|c|}{ Susceptibility profiles } \\
\hline & \multicolumn{2}{|c|}{ Ceftazidime* } & \multicolumn{2}{|c|}{ Ceftriaxone $^{\dagger}$} & \multicolumn{2}{|c|}{ Ciprofloxacin } & \multicolumn{2}{|c|}{ Erythromycin $\ddagger$} & \multicolumn{2}{|c|}{ Gentamicin§ } & \multicolumn{2}{|c|}{ Levofloxacin" } & \multicolumn{2}{|c|}{ Meropenem $^{* *}$} & \multicolumn{2}{|c|}{ Pip/Tazott } \\
\hline & Act I & $\mathrm{MIC}_{90}$ & Act & $\mathrm{MIC}_{90}$ & Act & $\mathrm{MIC}_{90}$ & Act & $\mathrm{MIC}_{90}$ & Act & $\mathrm{MIC}_{90}$ & Act & $\mathrm{MIC}_{90}$ & Act & $\mathrm{MIC}_{90}$ & Act & $\mathrm{MIC}_{90}$ \\
\hline Acinetobacter species & ++ & 16 & $+/++$ & 16 & +++ & 1 & - & $>32$ & +++ & 8 & +++ & 1 & +++ & 1 & +++ & 8 \\
\hline Citrobacter freundii & $++/+++$ & 32 & $++/+++$ & $>32$ & ++++ & 0.25 & - & $>32$ & ++++ & 1 & ++++ & 0.5 & ++++ & 0.12 & $+++/++++$ & 16 \\
\hline Enterobacter aerogenes & $++/+++$ & 16 & $++/+++$ & $>32$ & ++++ & 0.12 & - & $>32$ & ++++ & 1 & ++++ & 0.12 & ++++ & 0.12 & $+++/++++$ & 16 \\
\hline Enterobacter cloacae & $++/+++$ & 16 & $++/+++$ & 32 & ++++ & 0.5 & - & $>32$ & $++/+++$ & 8 & ++++ & 0.12 & ++++ & 0.25 & ++ & 64 \\
\hline Escherichia coli & ++++ & 1 & ++++ & 0.12 & +++ & 16 & - & $>32$ & ++++ & 2 & ++++ & 16 & ++++ & 0.03 & ++++ & 8 \\
\hline Escherichia coli (ESBL) & - & $>64$ & - & $>64$ & ++ & 32 & NA & NA & +++ & 4 & ++ & 32 & ++++ & 0.06 & $-1+$ & $>128$ \\
\hline Haemophilus influenzae & ++++ & 0.06 & +++ & 0.015 & ++++ & 0.008 & $+/++$ & 16 & +++ & 8 & ++++ & 0.03 & +++ & 0.12 & ++++ & 0.12 \\
\hline Haemophilus influenzae (BLP) & +++ & 0.06 & +++ & 0.015 & ++++ & 0.008 & $+/++$ & 16 & +++ & 8 & +++ & 0.015 & ++++ & 0.12 & ++++ & 0.25 \\
\hline Klebsiella pneumoniae & ++++ & 0.25 & ++++ & 0.06 & ++++ & 0.5 & - & $>32$ & ++++ & 0.5 & ++++ & 0.5 & ++++ & 0.03 & +++ & 8 \\
\hline Klebsiella pneumoniae (ESBL) & - & $>64$ & - & $>64$ & +++ & 0.5 & NA & NA & ++++ & 0.5 & +++ & 0.5 & ++++ & 0.06 & $-1+$ & $>128$ \\
\hline Klebsiella pneumoniae (AmpC) & ) ++ & $>32$ & ++ & $>32$ & ++++ & 0.5 & NA & NA & ++++ & 0.5 & ++++ & 0.5 & ++++ & 0.25 & $-1+$ & $>128$ \\
\hline Klebsiella species & ++++ & 0.25 & ++++ & 0.5 & ++++ & 0.03 & - & $>32$ & ++++ & 4 & ++++ & 0.06 & ++++ & 0.06 & ++++ & 8 \\
\hline Moraxella catarrhalis & ++++ & 0.5 & ++++ & 0.5 & ++++ & 0.03 & ++++ & 0.25 & ++++ & 2 & ++++ & 0.06 & ++++ & 0.008 & ++++ & 1 \\
\hline Morganella morganii & $++/+++$ & 16 & $++/+++$ & 8 & ++++ & 0.06 & - & $>32+$ & $+++/++++$ & +4 & ++++ & 0.12 & ++++ & 0.25 & ++++ & 4 \\
\hline Proteus mirabilis & ++++ & 0.12 & ++++ & 0.06 & $+++/++++$ & +0.12 & - & $>32$ & ++++ & 4 & $+++/++++$ & 0.12 & ++++ & 0.12 & ++++ & 1 \\
\hline Proteus vulgaris & ++ & $>32$ & ++ & $>32$ & ++++ & 0.03 & - & $>32+$ & $+++/++++$ & +4 & ++++ & 0.06 & ++++ & 1 & ++++ & 2 \\
\hline Providencia rettgeri & $++/+++$ & +4 & +++ & 2 & +++ & 1 & - & $>32$ & + & 32 & +++ & 4 & ++++ & 2 & ++++ & 4 \\
\hline Providencia stuartii & $++/+++$ & 4 & +++ & 2 & +++ & 2 & - & $>32$ & ++ & 16 & +++ & 1 & +++ & 2 & ++++ & 4 \\
\hline Pseudomonas aeruginosa & +++ & 32 & + & 128 & +++ & 16 & - & $>32$ & +++ & 64 & +++ & 32 & +++ & 32 & +++ & 64 \\
\hline Serratia marcescens & +++ & 4 & +++ & 0.5 & +++ & 2 & - & $>32$ & ++ & 16 & +++ & 2 & ++++ & 0.25 & ++++ & 8 \\
\hline Stenotrophomonas maltophilia & $-1+$ & 64 & - & 256 & + & 16 & - & $>32$ & + & 32 & $++/+++$ & 4 & - & 256 & + & 512 \\
\hline
\end{tabular}

${ }^{*}$ Applies to ceftazidime and cefepime; ${ }^{\dagger}$ Applies to ceftriaxone and cefotaxime; ${ }^{\ddagger}$ Applies to erythromycin and azithromycin; $\S$ Applies to gentamicin, netilmicin tobramycin and amikacin; TApplies to levofloxacin, gatifloxacin and moxifloxacin (gatifloxacin and moxifloxacin have only moderate activity against $\mathrm{P}$ aeruginosa), ${ }^{*}$ Applies to meropenem and imipenem/cilastatin; ${ }^{\dagger+}$ Applies to piperacillin/tazobactam (Pip/Tazo) and ticarcillin/clavulanate. Clindamycin, linezolid and vancomycin have not been included in the table because they have limited activity against Gram-negative bacilli. Act Antibiotic activity: - poor activity, + limited activity and/or resistance $\geq 5 \%,++$ moderate to good activity and/or resistance $10 \%$ to $14 \%$, +++ very good activity and/or resistance $5 \%$ to $9 \%$, ++++ excellent activity and/or with resistance $\leq 4 \%$; AmpC Chromosomal AmpC beta-lactamase; BLP Beta-lactamase positive; ESBL Extended spectrum beta-lactamase; MIC 90 Minimum inhibitory concentration $(\mu \mathrm{g} / \mathrm{mL})$ of $90 \%$ of isolates; NA Information not available. Antibiotic breakpoints from the Clinical and Laboratory Standards Institute approved breakpoints (368). Data presented in table were adapted from references 11,44-101 and represent level A-2 data

TABLE 7

In vitro antibiotic activity against common anaerobes causing hospital-acquired pneumonia and ventilator-associated pneumonia

\begin{tabular}{|c|c|c|c|c|c|c|c|c|c|c|c|c|c|c|c|c|c|c|c|c|c|c|}
\hline \multirow[b]{3}{*}{ Bacteria } & \multicolumn{22}{|c|}{ Susceptibility profiles } \\
\hline & \multicolumn{2}{|c|}{ Ceftazidime } & \multicolumn{2}{|c|}{ Ceftriaxone $^{*}$} & \multicolumn{2}{|c|}{ Ciprofloxacin } & \multicolumn{2}{|c|}{ Clindamycin } & \multicolumn{2}{|c|}{ Erythromycin } & \multicolumn{2}{|c|}{ Gentamicin $^{\dagger}$} & \multicolumn{2}{|c|}{ Levofloxacin $\ddagger$} & \multicolumn{2}{|c|}{ Linezolid } & \multicolumn{2}{|c|}{ Meropenem $\S$} & \multicolumn{2}{|c|}{ Pip/Tazo" } & \multicolumn{2}{|c|}{ Metronidazole } \\
\hline & Act & $\overline{\mathrm{MIC}_{90}}$ & Act & $\overline{\mathrm{MIC}_{90}}$ & Act & $\overline{\mathrm{MIC}_{90}}$ & Act & $\mathrm{MIC}_{90}$ & Act & $\overline{\mathrm{MIC}_{90}}$ & Act & $\overline{\mathrm{MIC}_{90}}$ & Act & $\overline{\mathrm{MIC}_{90}}$ & Act & $\mathrm{MIC}_{90}$ & Act & $\overline{\mathrm{MIC}_{90}}$ & Act & $\overline{\mathrm{MIC}}_{90}$ & Act & $\mathrm{MIC}_{90}$ \\
\hline $\begin{array}{l}\text { Bacteroides } \\
\text { fragilis }\end{array}$ & + & 64 & + & 64 & + & 16 & +++ & 2 & $-1+$ & 8 & - & $>16$ & + & 8 & ++ & 4 & ++++ & 0.5 & ++++ & 1 & ++++ & 2 \\
\hline $\begin{array}{l}\text { Bacteroides } \\
\text { fragilis group }\end{array}$ & $-/+$ & $>64$ & $-/+$ & $>64$ & $-/+$ & 32 & +++ & 4 & + & 4 & - & $>16$ & + & 16 & ++ & 4 & ++++ & 0.5 & +++ & 16 & ++++ & 1 \\
\hline $\begin{array}{l}\text { Fusobacterium } \\
\text { species }\end{array}$ & +++ & 4 & ++++ & 1 & + & 8 & +++ & 2 & $-/+$ & $>64$ & - & $>16$ & $+/++$ & 4 & ++++ & 0.5 & ++++ & 0.5 & ++++ & 0.12 & ++++ & 2 \\
\hline $\begin{array}{c}\text { Peptostrepto- }+ \\
\text { coccus specie }\end{array}$ & $\begin{array}{l}+1+++ \\
\text { es }\end{array}$ & & +++ & 8 & $+/++$ & 4 & ++++ & 1 & + & $>64$ & - & 16 & +++ & 2 & +++ & 2 & ++++ & 0.5 & ++++ & 2 & + & 32 \\
\hline
\end{tabular}

${ }^{*}$ Applies to ceftriaxone and cefotaxime; ${ }^{\dagger}$ Applies to gentamicin, netilmicin, tobramycin and amikacin; ${ }^{\ddagger}$ Applies to levofloxacin, gatifloxacin and moxifloxacin (gati-

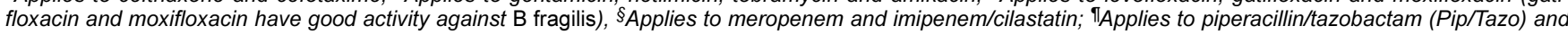
ticarcillin/clavulanate. MIC $\mathrm{g}_{0}$ Minimum inhibitory concentration $(\mu \mathrm{g} / \mathrm{mL})$ of $90 \%$ of isolates, Act Antibiotic activity: - poor activity, + limited activity and/or resistance $25 \%,++$ moderate to good activity and/or resistance $10 \%$ to $14 \%,+++$ very good activity and/or resistance $5 \%$ to $9 \%$, ++++ excellent activity and/or with resistance $\leq 4 \%$. Antibiotic breakpoints from the National Committee for Clinical Laboratory Standards approved and tentative breakpoints (369). Data presented in table were adapted from references 11,44-101 and represent level A-2 data

community-associated MRSA with its enhanced transmissibility, to cause HAP and VAP (113).

With respect to Gram-negative bacteria, S maltophilia represents a considerable challenge because of its natural intrinsic resistance to many commonly used antimicrobial classes (carbapenems, broad-spectrum beta-lactams, fluoroquinolones and aminoglycosides), thus limiting available therapeutic options (114). Patients with severe underlying medical conditions, 


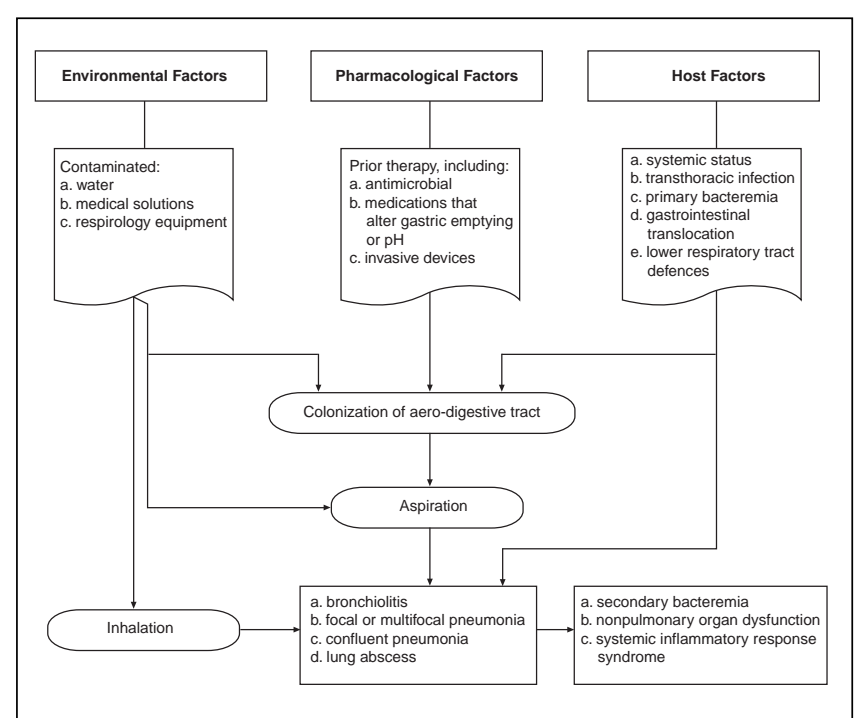

Figure 4) The pathogenesis of hospital-acquired pneumonia and ventilator-associated pneumonia. Adapted from reference 117

particularly those with cancer, are often infected with this organism. Furthermore, risk factors for colonization and infection with $P$ aeruginosa and Acinetobacter species include being elderly or immunocompromised, respiratory equipment used in ventilated patients and previous antibiotic therapy (115). In the case of Acinetobacter species, many outbreaks have occurred in the ICU, thereby putting patients with VAP at particular risk due to the limited antibiotic treatment options available. Extended-spectrum beta-lactamases are mostly present in Klebsiella species and E coli, and have been associated with increasing resistance to many commonly used antibiotics such as third-generation cephalosporins and trimethoprimsulfamethoxazole, as well as the fluoroquinolones. This plasmid-mediated resistance can easily be shared and transmitted to other Enterobacteriaceae (116).

Major points and recommendations for microbial etiology Patients with early- or late-onset HAP and VAP and who have recently received antibiotics or had an admission to a health care facility are at risk for colonization and infection with more antibiotic resistant pathogens.

\section{RISK FACTORS}

Not only are certain patient groups at greater risk for HAP or VAP, but the presence of specific host, environmental or pharmacological factors enhance the propensity of patients to develop pneumonia (117) (Figure 4). The identification of these risk factors allows the development of strategies for the prevention of HAP and VAP and the design of treatment protocols (23).

\section{Host factors}

The major factor predisposing patients to HAP or VAP is the colonization of the upper respiratory and digestive tract with pathogenic microorganisms (118). Factors enhancing airway colonization include previous and continuing antibiotic therapy, endotracheal intubation, smoking, malnutrition, general surgery, dental plaque and therapies that elevate the gastric $\mathrm{pH}(119-121)$. Adequate daily oral hygiene in the hospitalized elderly may reduce the risk of HAP (B-2). Other host-related factors reported in the literature that predispose to oropharyngeal colonization include renal dysfunction, diabetes, coma, shock, advanced age and underlying lung disease (119).

The risk of HAP and VAP increases after surgery (122). The risk of pneumonia is associated with preoperative smoking, longer preoperative admissions, longer surgical procedure times, and thoracic or upper abdominal surgery. Surgical patients admitted to the ICU after cardiothoracic surgery or head trauma were found to be more likely to develop nosocomial pneumonia (16). For ICU patients, the association of VAP and an elevated acute physiological assessment and chronic health evaluation (APACHE) score existed for surgical patients mechanically ventilated for two days and medical patients for more than two days (123).

Intubation and mechanical ventilation increase the risk of pneumonia by six- to 21 -fold $(1,124-126)$. The most important independent risk factors were male sex (OR 1.58), ICU admission for trauma (OR 1.75) and intermediate underlying disease severity (OR 1.47 to 1.70 ) (27). Longer time on ventilation and reintubation are important risk factors in development of VAP (41) (127). Other risk factors include body position during ventilation (OR 6.8), enteral feeding (OR 5.7), mechanical ventilation for more than seven days (OR 10.9) and Glasgow Coma Scale scores of less than 9 (128). Finally, chronic obstructive pulmonary disease, extensive burns, neurosurgical conditions, ARDS, witnessed aspiration and enteral nutrition have also been identified as risk factors for VAP (129).

Reducing the risk of VAP through early tracheostomy remains controversial, with some studies suggesting benefit (130) and others showing none (27). Endotracheal tubes can develop an internal bacterial biofilm and circumvent host defenses causing local trauma and inflammation that may lead to increased aspiration of nosocomial pathogens from the oropharynx in and around the tube (131). High volume, lowpressure cuffs may reduce pooling and aspiration of oral contents (C-3).

\section{Environmental factors}

Increased gastroesophageal reflux of stagnant oral secretions caused by indwelling nasogastric tubes has been shown to be an independent risk factor for HAP and VAP $(23,132,133)$. Most experts favour a distal nasogastric tube tip location, although this remains controversial (23).

Tubing associated with mechanical ventilation contains a condensate formed as a result of the temperature difference between inspired gas and ambient air. This condensate can easily be contaminated with patient secretions and high levels of microorganisms. Installing in-line devices with one-way valves can enhance secretion sequestration and decrease the risk of aspiration or inhalation of contaminated condensate. Oral tracheal intubation is associated with a decreased incidence of sinusitis and a lower incidence of VAP in ventilated patients. Concomitant sinusitis was predicted to increase the risk of VAP by a factor of $3.8(134,135)$.

Closed suctioning versus open suctioning and frequency of ventilator changes have not been shown to alter the risk of VAP in ventilated patients $(129,136)$.

Lastly, the movement of ICU patients for diagnostic and surgical procedures out of the ICU is an independent risk factor for VAP (OR 3.8) (137). 


\section{Pharmacological factors}

Various studies have produced contradictory outcomes with regard to antibiotic use as a risk for HAP and VAP $(16,138,139)$. Some experts suggest that prophylactic antibiotics in the ICU encourage the risk of superinfection by multiresistant bacteria but delay the onset of nosocomial infection (23).

Gastric bacterial colonization, which leads to contamination of tubing in mechanically ventilated patients, correlates with nonacidic gastric $\mathrm{pH}$ and consequently, drugs affecting the latter can have an impact on the risk of VAP (20,140-145). If stress ulcer prophylaxis is indicated, the risks and benefits of acid-suppression versus sucralfate should be weighed before prescribing (A-1). Administration of a paralytic agent to mechanically ventilated patients has also been documented as a risk factor for VAP (76).

\section{Major points and recommendations for risk factors}

1. Colonization of the oropharynx with pathogenic organisms is an important risk factor leading to subsequent HAP/VAP.

2. Host factors such as supine positioning, extensive burns, mechanical ventilation, cardiothoracic surgery, ARDS and head trauma are predisposing factors for VAP.

3. Nasogastric tubes and condensate in ventilator tubing are environmental factors that enhance the risk of developing VAP and should be avoided (A-2).

4. Acid-suppressing medications (eg, antacids and $\mathrm{H}_{2}$ blockers) that are employed to prevent stress ulcer bleeding in ventilated patients can increase the risk of developing VAP and careful consideration should be given to their use $(A-1)$.

\section{CLINICAL MANIFESTATIONS}

The clinical manifestations of HAP and VAP are nonspecific and there are no pathognomonic signs or symptoms that are unique to these conditions (146). The symptom constellation of fever, shortness of breath, chest pain, cough, sputum production, hypoxia and leukocytosis that comprise the clinical manifestations of HAP and VAP may be mimicked by other clinical entities such as pulmonary embolism, congestive heart failure and ARDS. The performance of a chest radiograph to confirm the presence of a pulmonary infiltrate may not provide definitive confirmation for HAP and VAP. Signs of pulmonary consolidation on a chest radiograph can be duplicated in congestive heart failure, pulmonary emboli, pulmonary hemorrhage and ARDS. Furthermore, there is no specific pulmonary radiographic pattern that is unique to a particular microorganism.

Similarly, laboratory investigations are not predictive of specific symptoms associated with HAP and VAP. Numerous clinical conditions produce leukocytosis and hypoxia. Although the presence of microorganisms with pus cells in respiratory secretions combined with the aforementioned symptoms should portend the presence of HAP or VAP, this is not the case. The presence of microorganisms in a respiratory sample without a pulmonary infiltrate on a chest radiograph has low specificity for the diagnosis of VAP $(147,148)$. This may merely represent colonization or tracheobronchitis and not pulmonary infection. On the other hand, overt symptoms as listed above and the presence of microorganisms in respiratory secretions with a pulmonary infiltrate are certainly not always specific for HAP or VAP.

HAP and VAP clinical manifestations run the gamut from asymptomatic disease to the sepsis syndrome with multiple organ dysfunction. Asymptomatic disease manifestations are indolent, and HAP and VAP may only become obvious after viewing a chest radiograph. However, asymptomatic disease is an uncommon clinical presentation of HAP and VAP. In contrast, the manifestations of hypotension, electrolyte derangement, lactic acidosis, and renal and hepatic dysfunction that comprise the cardinal signs and symptoms of the sepsis syndrome may also be produced by HAP and VAP. Both Grampositive and Gram-negative organisms can precipitate the sepsis syndrome, resulting in these clinical manifestations.

There is a paucity of evidence-based data on the presence of various symptoms in HAP and VAP. Shah and Stille (149), in reporting their randomized trial comparing cefotaxime versus ceftriaxone for the treatment of nosocomial pneumonia, actually described the frequency of symptoms at study entry. Fever was present in $82 \%$ of their patients, and chest pain was present in $46 \%$, cough with or without sputum present in $85 \%$, dyspnea in $72 \%$, pulmonary consolidation in $64 \%$, rales in $85 \%$ and a pleural friction rub in approximately $5 \%$. Other investigators have also described septic shock in less than $10 \%$ of their patients with HAP and VAP $(150,151)$.

Finally, the clinical presentation of patients with HAP and VAP varies from an illness of abrupt onset to one that is insidious and gradual in onset. An abrupt onset may be the harbinger of the sepsis syndrome, with rapid progression of pulmonary infiltrates and multiple organ dysfunction. On the other hand, a more insidious onset without hypotension, multiple organ dysfunction, sepsis syndrome, or rapid progression of infiltrates and the need for ventilation may also occur. These presentations are discussed in more depth in a later section describing the treatment of HAP and VAP.

Thus, the presentation and clinical manifestations of HAP and VAP may be nonspecific and mimicked by other clinical entities. Presentations may be gradual in onset or more abrupt, portending the development of the sepsis syndrome. Early recognition of HAP and VAP is imperative to ensure the initiation of appropriate antimicrobial therapy.

\section{Major points and recommendations for clinical manifestations}

The presentation and clinical manifestations of HAP and VAP are nonspecific and resemble other clinical entities.

\section{DIAGNOSTIC APPROACHES}

HAP and VAP present diagnostic challenges, and the precise role of diagnostic testing, especially when using invasive techniques, is controversial (7). Generally, a presumptive diagnosis of HAP or VAP is made on clinical grounds when a patient develops a clinical syndrome that includes fever, leukocytosis, purulent tracheobronchial secretions, and a new or changing pulmonary infiltrate. Unfortunately, this strategy has led to the overestimation of HAP and VAP because tracheobronchial colonization can lead to purulent tracheobronchial secretions. Moreover, there are other conditions that can result in fever and changing lung infiltrates. In addition, with increasing antimicrobial resistance, clinicians are more motivated to examine techniques that properly identify infected patients, thereby making attempts to minimize the indiscriminate use of 
TABLE 8

Clinical pulmonary infection score (CPIS) chart

\begin{tabular}{llll}
\hline & \multicolumn{1}{c}{$\mathbf{0}$} & \multicolumn{1}{c}{ CPIS points } & \multicolumn{1}{c}{$\mathbf{2}$} \\
\cline { 2 - 4 } Diagnostic feature & Rare & Abundant & Abundant and purulent \\
\hline Tracheal secretions & None & Diffuse & Localized \\
Chest $x$-ray infiltrate & $\geq 36.5$ and $\leq 38.4$ & $\geq 38.5$ and $\leq 38.9$ & $\geq 39$ or $\leq 36$ \\
Temperature $\left({ }^{\circ} \mathrm{C}\right)$ & $\geq 4.0$ and $\leq 11.0$ & $<4.0$ or $>11.0$ & $<4.0$ or $>11.0$ plus band forms $\geq 0.5$ \\
White blood cells $\left(\times 10^{9} / \mathrm{L}\right)$ & $>240$ or ARDS & & $\leq 240$ and no ARDS \\
$\mathrm{PaO}_{2} / \mathrm{FiO}_{2} \mathrm{mmHg}$ & Negative & Positive* & Positive plus positive Gram stain ${ }^{*}$
\end{tabular}

*Microbiology not relevant in the case of the modified clinical pulmonary infection score as described by Fartoukh et al (157); 'Determination is only 'positive' for the purpose of the modified clinical pulmonary infection score as described by Fartoukh et al (157). ARDS Acute respiratory distress syndrome; FiO 2 Fraction of inspired oxygen; $\mathrm{PaO}_{2}$ Partial pressure of oxygen in arterial blood

antibiotics, especially in the ICU. Confronted with a patient's changing clinical picture or radiographic parameters demanding specific therapy, clinicians have considered using an invasive testing strategy to supplement clinical judgment. Invasive techniques include PSB, BAL and blinded versions of these techniques.

\section{Clinical diagnosis}

The initial diagnosis of HAP or VAP is based on clinical suspicion and the presence of new or progressive radiographic infiltrates. The standard diagnostic clinical criteria for HAP and VAP, along with abnormal findings from chest radiographic studies, are comprised of at least two of the following three findings: fever, leukocytosis and purulent tracheal secretions. When these conditions occur, the likelihood of VAP is high (147). The presence of a radiographic infiltrate in a patient with fever, leukocytosis or purulent tracheobronchial secretions has high diagnostic sensitivity but low specificity. When all four criteria are present, specificity improves but sensitivity drops to below $50 \%$ (152). The only study examining interobserver diagnostic reliability found no major differences between individual physicians or those grouped by level of training (147).

The diagnosis of HAP or VAP based on the presence of alveolar infiltrates as determined by chest radiography has a sensitivity of $58 \%$ to $83 \%$ when using air bronchogram signs, and is $50 \%$ to $78 \%$ for new or worsening infiltrates when compared with invasive techniques or histological studies $(153,154)$. Unfortunately, the specificity is unknown because reports do not state the appropriate denominator (the number of ventilator-assisted patients without pneumonia and with normal findings on a chest radiograph). Chest radiographs are not a reliable diagnostic tool because there is only marginal reproducibility of the findings obtained from two readers for patients with HAP in the ICU (155). The presence of any one radiographic sign does not significantly increase the likelihood of VAP, because other potential causes of radiographic abnormalities occur in ventilated patients (154). The sensitivity and specificity of interpretation of chest radiographs have not been extensively evaluated, nor have the detrimental clinical and economic impacts of misinterpreting chest radiographs. Moreover, the incidence of pneumonia is unknown among immunocompetent patients with a normal chest radiograph and compatible clinical presentation using more advanced computed tomography imaging or invasive microbiological techniques (as seen in patients with P jiroveci pneumonia).
The presence of abnormal clinical manifestations combined with abnormal radiographic findings can be used for initial screening for VAP. However, the lack of specificity with this method suggests that additional procedures are needed, such as cultures of lower respiratory tract secretions. In 1991, Pugin et al (156) combined body temperature, white blood cell count, volume and appearance of tracheobronchial secretions, oxygenation, chest radiograph findings and tracheal aspirate cultures into a clinical pulmonary infection score (CPIS) for VAP (156). A total score greater than six out of a maximum of 12 correlated with high bacterial counts isolated from the lower respiratory tract and a sensitivity and specificity of $93 \%$ and $100 \%$, respectively, were demonstrated for this approach. More recently, Fartoukh et al (157) found that clinical prediction alone was inaccurate but a modified CPIS score, incorporating a Gram stain of respiratory tract secretions, improved diagnostic accuracy (Table 8) (157). The diagnostic accuracy was enhanced and the likelihood ratio for pneumonia based on a score greater than 6 increased from a baseline of 1.46 (using the CPIS) to 1.67 if a Gram stain of blind protected samples was obtained and to 1.77 if a Gram stain of a directed sample was obtained. Nonetheless, the authors cautioned that further refinement of the clinical scoring approach was necessary to improve the diagnostic accuracy in patients suspected of having VAP. Blot et al (158) reported that a positive Gram stain from a plugged telescoping catheter, with its high specificity, should prompt starting empirical therapy immediately. Conversely, a negative Gram strain of an endotracheal aspirate (that is highly sensitive) should lead to withholding of antibiotics (158).

\section{Microbiological diagnosis}

Qualitative cultures of endotracheal secretions are often used in lieu of invasive diagnostic testing, because health care workers can perform the aspiration procedure at the bedside with minimal training. Typically, qualitative cultures identify pathogenic organisms found by invasive tests and thereby suggest high sensitivity. Incidentally, such tests frequently identify nonpathogenic organisms as well, thereby reducing the positive predictive value of this procedure. If the culture results are negative for pathogens, VAP is very unlikely to be present, unless the patient has been treated with antibiotics (159).

The use of invasive diagnostic strategies for diagnosing HAP and VAP remains controversial. Procedures to quantitatively identify likely pathogens include endobronchial aspirates, nonbronchoscopic techniques (quantitative endotracheal aspiration, 
blinded bronchial sampling [BBS], mini-BAL, blinded PSB [BPSB]) and bronchoscopic techniques (BAL, PSB, protected BAL). Because these tests have a similar sensitivity, specificity, positive predictive value and likelihood ratio, the choice depends on local expertise, experience, availability and cost factors.

Growth above a certain threshold indicates the presence of HAP or VAP, whereas growth below this threshold suggests colonization or contamination. The results of quantitative cultures on specimens obtained by endotracheal aspiration vary depending on the bacterial load, the duration of mechanical ventilation and the prior administration of antibiotics. Sensitivity and specificity of the culture results obtained by these methods can range from $38 \%$ to $100 \%$ and $14 \%$ to $100 \%$, respectively $(160,161)$. Gram stain and culture of endotracheal secretions obtained by aspiration may be useful in diagnosing VAP. Neither bacterial antibody coating nor the presence of elastin fibres are diagnostically sensitive or specific for VAP (162-164), and they are not recommended for clinical diagnostic use (B-2).

Bronchoscopic BAL has been used diagnostically in VAP since 1988, but bronchoscopic and bacteriological methods have not been standardized. The sensitivity of quantitative BAL fluid cultures ranges from $42 \%$ to $93 \%$, with a mean of $73 \%$. The variability reflects the characteristics of the study population, prior administration of antibiotics (which reduces sensitivity) and the reference test used $(165,166)$. For quantitative cultures of BAL samples, most studies cite $10^{4} \mathrm{cfu} / \mathrm{mL}$ as a positive result; however, a finding of $10^{3} \mathrm{cfu} / \mathrm{mL}$ to $10^{5} \mathrm{cfu} / \mathrm{mL}$ is also considered positive. Sensitivity varies inversely with the cutoff point. Specificity ranges from $45 \%$ to $100 \%$, with a mean of $82 \%$ in most studies $(167,168)$. Detection of intracellular organisms by BAL is highly specific ( $89 \%$ to $100 \%$ ) and has a high positive predictive value. However, such a test is not highly sensitive (37\% to $100 \%$ ) $(164,169)$, thus indicating problems in sampling or laboratory techniques.

The PSB sampling technique was developed in 1987 by Wimberly et al (170), but the technique has not been standardized. As a result, few definitive, evidence-based recommendations have been reached. Reasons for this include concerns about diagnostic accuracy, reliability of findings, reproducibility of results, diagnostic thresholds, nonstandardized methodology, safety concerns and lack of data on clinical outcome $(171,172)$.

Most studies do not report the quality of the samples nor do they state whether secretions were cleared by using a separate bronchoscope before the test (173). The accuracy of PSB sampling has been determined and, in $25 \%$ of cases, a single bronchial brush determination led to a false-positive or falsenegative result (174). Specimens taken from an affected lobe have a much higher concentration of organisms than those taken from an unaffected lobe (173). Sensitivity for PSB tests ranges from $33 \%$ to $100 \%(175,176)$, with a median of $67 \%$. Specificity ranges from $50 \%$ to $100 \%$, with a median of $95 \%$. PSB sampling appears to be somewhat more specific than sensitive in diagnosing VAP.

Blinded invasive procedures have also been used to obtain lower respiratory tract samples. In BBS, a catheter is blindly wedged into a distal bronchus, and secretions are aspirated without instillation of fluid. In mini-BAL, a sterile, singlesheathed, $50 \mathrm{~cm}$, plugging, telescoping catheter is used and $20 \mathrm{~mL}$ to $150 \mathrm{~mL}$ of lavage fluid is instilled. In some instances, an unprotected catheter can be used instead. In BPSB, a sterile brush that is protected from contamination is used. Incidentally, none of these techniques have been standardized. The sensitivities of these tests is as follows: BBS, $74 \%$ to $97 \%$ $(165,177,178)$; mini-BAL, $63 \%$ to $100 \%(156,165,179)$; and BPSB, $58 \%$ to $86 \%$ (180-183). The specificities are: BBS, $74 \%$ to $100 \%$; mini-BAL, $66 \%$ to $96 \%$; and BPSB, $71 \%$ to $100 \%$. These specificity ranges are similar to those reported for BAL and PSB. Risks from blinded techniques are minimal and would appear to be no greater than those with fibre optic bronchoscopy.

In nonventilated patients, the use of invasive techniques appears to be too aggressive and costly and, therefore, a clinical approach is preferred. There is insufficient robust evidence to indicate that quantitative testing produces better clinical outcomes than empirical treatment. While invasive tests may avoid the use of antibiotics for clinically insignificant organisms in ventilated patients, no direct evidence or consensus indicates the superiority of one invasive test over another. Withholding antibiotic therapy when invasive tests do not confirm a clinical suspicion of VAP has not been found to be associated with recurrence of VAP or with increased mortality rates (184). Issues to consider in choosing a diagnostic test include sensitivity and specificity, ability to improve patient outcome, potential adverse effects, availability of the test, local expertise in performing the test and cost.

\section{Recommended diagnostic algorithms}

Based on the data from the clinical and invasive strategies reviewed above and their applicability to the Canadian environment, the following diagnostic algorithms are suggested when HAP or VAP is suspected (Figure 5). Specifically, an associated pneumonia should be suspected in patients whether ventilated or not, if two or more of the following clinical features are present: temperature greater than $38^{\circ} \mathrm{C}$ or less than $36^{\circ} \mathrm{C}$, leukopenia or leukocytosis, purulent tracheal secretions and decreased $\mathrm{PaO}_{2}$. In the absence of such findings, no further investigations are required and observation will suffice (Figure 5) (B-3).

The presence of two or more of the aforementioned clinical abnormalities and the absence of an alternative infective focus mandates that a chest radiograph be performed. If the findings are normal, other causes of the abnormal clinical features should be investigated. If the radiograph shows alveolar infiltrates or an air bronchogram sign, or if the findings have worsened, it is recommended that the CPIS be calculated regardless of whether the patient is in the ICU or mechanically ventilated. If the CPIS is less than 6 , infection is unlikely and the decision to treat with antibiotics should be carefully considered. Patients should have their CPIS recalculated daily and if it remains persistently below 6 , the decision to stop antibiotics or not start them in the first instance was correct (Figure 5) (A-1). In the case of ventilated patients, if the CPIS is between 4 and 6 , pneumonia should be considered if no alternative diagnosis for the findings can be obtained (Figure 5) because of the mortality associated with this disease (C-3). Therapy should be considered taking into account the Gram stain of tracheobronchial secretions. Again, the CPIS should be recalculated daily and cessation of antibiotic therapy should be considered if the CPIS remains below 6 by the third day (C-3). Although the only evidence that supports this approach is the study by Singh et al (185), 


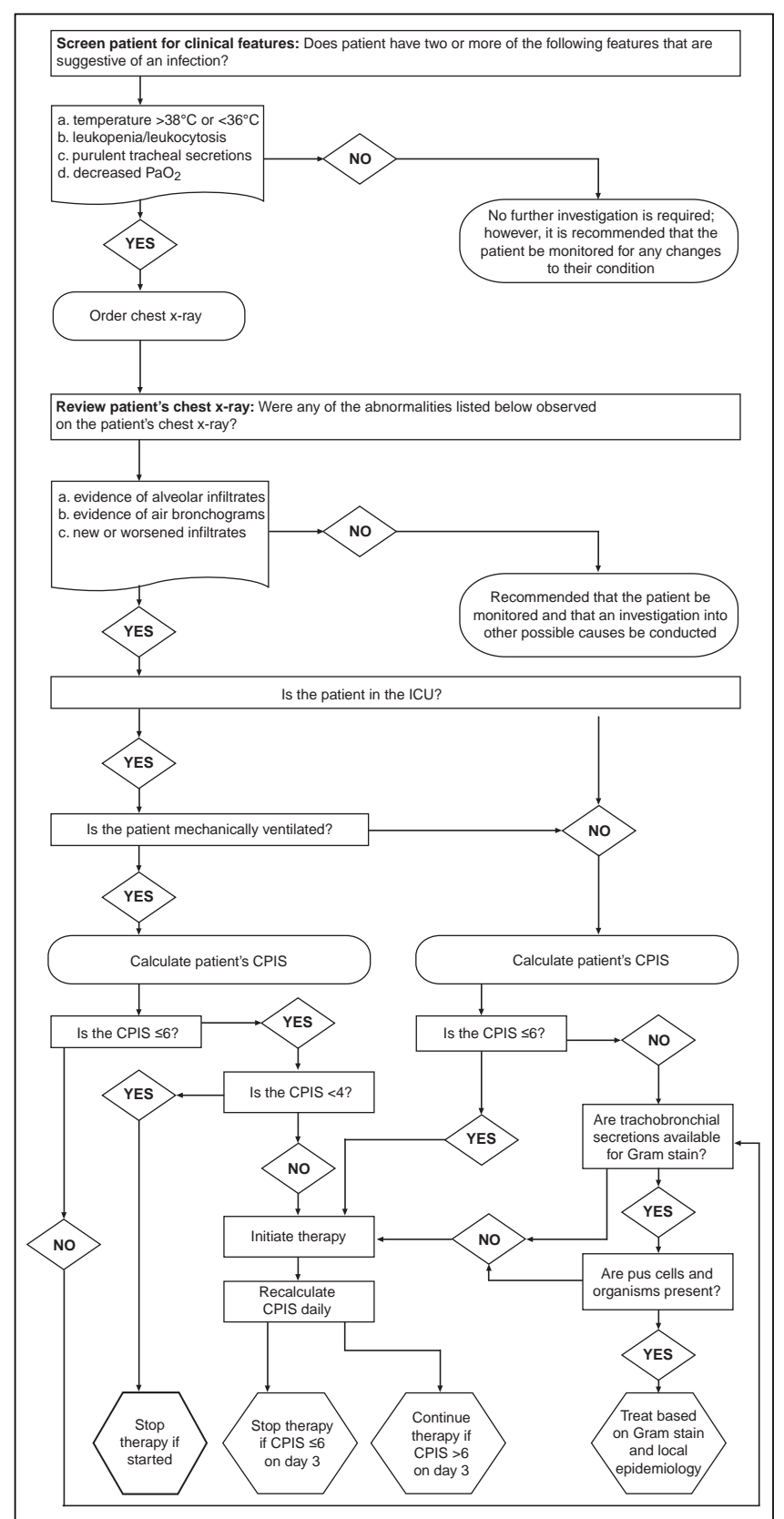

Figure 5) Diagnostic algorithm for hospital-acquired pneumonia and ventilator-associated pneumonia. Please note that there is no definitive scientific evidence or expert consensus that quantitative testing produces better clinical outcomes than empirical treatment. Scientific evidence of improved specificity, supplemented by expert opinion, supports the performance of invasive tests to avoid the use of antibiotics for clinically insignificant organisms, but there is no direct evidence or consensus regarding the superiority of one invasive test over another. Factors to consider in choosing an appropriate test include sensitivity and specificity, ability to improve patient outcome, potential adverse effects, test availability and cost. CPIS Clinical pulmonary infection score; ICU Intensive care unit; $\mathrm{PaO}_{2}$ Partial pressure of oxygen in arterial blood

it is a reasonable compromise given that the CPIS score on day 1 is not sufficiently accurate to drive all clinical decisions.
If the CPIS is greater than 6, a Gram stain of tracheobronchial secretions should be obtained and cultures of the secretions undertaken. Treatment should be started based on the findings of the Gram stain and consideration of local epidemiology. If the Gram stain does not reveal pus cells or organisms, antibiotic therapy should be considered at least initially. Thereafter, the CPIS score should be recalculated on a daily basis and antibiotics discontinued on the third day if the score is consistently less than 6 (C-3).

Treatment should be based on the results of diagnostic testing. Decisions about empirical therapy should be determined by the patient's clinical stability, risk factors for resistant pathogens and the local epidemiology, together with the results of preliminary tests. Many patients receive antimicrobial agents before testing is performed, thus making it difficult or even impossible to interpret test results. After the initiation of antibiotic treatment for suspected VAP, the diagnostic thresholds for numbers of organisms in the culture must be decreased to maintain accuracy. By contrast, ongoing antibiotic therapy for a pre-existing infectious disease does not affect the diagnostic accuracy of PSB or BAL (186). In addition, five randomized prospective clinical trials (187-191) comparing invasive techniques and noninvasive quantitative techniques in patients with VAP have been performed. In the first, invasive techniques led to more frequent changes in antibiotic therapy but did not change the mortality rate. In the second, invasive techniques reduced early (but not late) mortality, produced less multiorgan damage and led to less antibiotic use. Finally, the other three trials did not support the use of invasive techniques. Singh et al (185) demonstrated in a randomized trial that pneumonia could be reasonably excluded and empirical therapy stopped when the CPIS fell below 6 at baseline and again at three days. Overall, a substantial reduction in antibiotic use with no adverse outcomes was observed.

These investigations indicate that an approach to reduce antibiotic use is possible without using an invasive strategy. Because the costs of an invasive strategy are significant and not all institutions are adequately resourced to perform these procedures continuously, an alternative approach using clinical criteria supplemented by noninvasive microbiological investigations is feasible and welcomed (C-3).

\section{Major points and recommendations for diagnosis}

1. The clinical diagnosis for HAP and VAP is not sensitive or specific.

2. The CPIS score should be calculated to improve sensitivity and specificity for the diagnosis of HAP and $\operatorname{VAP}(\mathrm{B}-2)$

3. Invasive diagnostic testing has not been demonstrated to improve clinical outcomes and therefore is not recommended unless dealing with immunocompromised hosts (A-1).

4. It is recommended that for most patients a clinical approach supplemented by noninvasive quantitative cultures of respiratory tract samples is sufficient to guide appropriate antibiotic choices (C-3).

5. A low CPIS score may allow careful observation of the patient without antibiotics. 
6. By the third day of calculating the CPIS, a score below a threshold of 6 may allow early discontinuation of antibiotics.

\section{ANTIMICROBIAL THERAPY OF HAP AND VAP}

\section{PHARMACOKINETIC AND PHARMACODYNAMIC ISSUES}

Clinical outcome in HAP is dependent on an interplay of factors relating to the host (eg, immune status, comorbid conditions and severity of clinical presentation), the pathogen (eg, inoculum, virulence factors), as well as antimicrobial properties including the concentration at the site of the infection, pharmacodynamic properties and the intrinsic activity of the antibiotic against the offending pathogen(s). Only the choice and dosing of the antimicrobial regimen are modifiable by clinicians.

There are no data suggesting that the postantibiotic effect or the pharmacodynamic properties of an antibiotic, such as concentration or time-dependent killing, have an impact on outcomes in HAP. An important issue for consideration, however, is whether the infection is intracellular (eg, Legionella species) or extracellular (eg, typical Gram-negative and Grampositive bacteria). For intracellular pathogens, it is the concentration of drug within the alveolar macrophage that is believed to be most relevant. Because the majority of pathogens encountered in nosocomial pneumonia are extracellular, concentrations in the epithelial lining fluid (ELF) are thought to be more important (192). Drugs achieving concentrations in ELF greater than or equal to those in the serum include the fluoroquinolones (193-195), macrolides and linezolid (196-198), followed by the beta-lactams (194,199-201) and carbapenems $(202,203)$. The aminoglycosides and vancomycin achieve lower levels $(204,205)$. It is not clear whether these differences relate to clinical outcomes in patients with HAP, although Wunderink et al (206) have implied that superior levels of linezolid in the ELF may contribute to enhanced efficacy.

Plasma concentrations have been eveluated as predictors of microbiological and clinical outcome in patients with both community-acquired pneumonia and HAP. In patients with HAP, Forrest et al (207) found that for ciprofloxacin, an area under the curve/minimum inhibitory concentration (AUC/MIC) greater than 125 was associated with an increased probability of clinical success and more rapid eradication of gram negative bacteria (207), while for levofloxacin an AUC/MIC from 87 to 100 was associated with pathogen eradication (208). Pharmacokinetic modeling suggests that AUC/MIC may also predict outcomes with beta-lactams, and aminoglycosides in lower respiratory tract infection (209). For agents with relatively poor penetration into ELF such as aminoglycosides $(210,211)$ and vancomycin, there is also evidence supporting the concept that plasma concentrations may predict both clinical and microbiological success. With vancomycin, the currently accepted therapeutic range for peak and trough levels may be inadequate and more aggressive dosing strategies may enhance outcomes in patients with MRSA HAP (212).

\section{De-escalation and streamlining}

De-escalation or streamlining is one strategy that has been developed that allows for the initiation of appropriate broad-spectrum antibiotic therapy while limiting the risks for resistance and adverse effects associated with continuing unnecessary agents (213-218). Following this strategy, empirical broad-spectrum antibiotic therapy is initiated based on patient risk factors and clinical presentation. Patients are then re-evaluated at $24 \mathrm{~h}$ to $48 \mathrm{~h}$ of therapy based on clinical response and results from microbiological evaluations. Therapy can be tailored to the offending pathogen, ie, streamlining therapy to ensure appropriate coverage without antibiotic over-use. If cultures are negative for organisms, antibiotics may be discontinued (219).

\section{Institutional guidelines}

A number of publications have demonstrated the positive impact of institution-specific guidelines on the management of HAP patients (220-226). Demonstrated benefits include improved empirical therapy $(222,225,226)$, reductions in duration of therapy $(220,222,224)$, inappropriate antibiotic use with discontinuation of some initial antibiotic therapy (221-223,226), adverse drug reactions, exposure to medications to which patients were reported allergic (221), as well as reduced antibiotic costs $(220,221)$.

\section{Duration of therapy}

There are currently limited data concerning the optimal duration of therapy for patients with HAP and VAP. Traditionally, the majority of patients have received antibiotics for 10 to 14 days while those infected with nonlactose-fermenting organisms such as $P$ aeruginosa have been treated for 14 to 21 days. Recent evidence indicates that patients infected with susceptible pathogens experience rapid microbiological eradication and significant improvement in signs and symptoms of pneumonia within six days of receiving appropriate therapy (214). Luna et al (227) also demonstrated that signs and symptoms of pneumonia steadily improved according to the CPIS during the first seven days in patients responding to antibiotic therapy for VAP. These studies support the concept that patients treated with effective antibiotic therapy will respond within the first week of treatment.

Chastre et al (228) reported the results of a randomized double-blind trial of eight versus 15 days of antibiotics for patients with VAP. Patients randomly assigned to eight days of therapy achieved significantly more antibiotic-free days. No statistically significant differences were seen with respect to all-cause mortality or infection recurrence. Higher rates of pulmonary infection recurrence occurred in the eight-day arm for patients infected with non-lactose-fermenting bacteria, suggesting that infections with $P$ aeruginosa or Acinetobacter species may require longer courses of therapy. These results support the observations of Micek et al (224) and Ibrahim et al (222), who demonstrated that patients experienced resolution of their signs and symptoms of infection, with mean durations of therapy of 6.0 and 8.6 days, respectively, compared with patients treated for longer durations.

\section{Novel treatment of resistant nosocomial respiratory pathogens}

Colistin: Colistin, or polymyxin E, is an antibiotic originally isolated from Bacillus colistinus in 1950 (229), with activity against many Gram-negative bacteria including E coli, Klebsiella pneumoniae, $P$ aeruginosa, Enterobacter species and Acinetobacter species. There has been renewed interest in 
colistin despite concerns about its nephrotoxicity and neurotoxicity in light of the increasing numbers of infections caused by multi-drug-resistant (MDR) pathogens, particularly $P$ aeruginosa and Acinetobacter baumannii.

Currently, there are no randomized, controlled trials with colistin in the management of HAP or VAP, but case series with inhaled or intravenous colistin for the management of acute and chronic infections in patients with cystic fibrosis who developed nosocomial infections caused by MDR A baumannii and $P$ aeruginosa $(230,231)$, as well as other serious nosocomial infections (232-237), have been published. In patients with HAP or VAP, colistin at doses of $2.5 \mathrm{mg} / \mathrm{kg} / \mathrm{day}$ to $5 \mathrm{mg} / \mathrm{kg} /$ day has been associated with positive outcomes of $25 \%$ to $73 \%(233,235-237)$. Although resistance to colistin has not been identified, superinfections due to $S$ maltophilia and S marcescens have been noted (236).

\section{Local and inhalation therapy}

Direct local instillation or nebulization of antibiotics has been used to increase concentrations of antibiotics in the lower respiratory tract. The majority of experience and research in this area has involved the use of aminoglycosides or colistin for the management of chronic or recurrent infections in patients with bronchiectasis with or without cystic fibrosis (238-241). Data in patients with HAP and VAP are limited to small, randomized, controlled trials $(242,243)$ and case series (234). In a double-blind, randomized, controlled trial, adjunctive endotracheal instillation of tobramycin was shown to increase pathogen eradication compared with intravenous antibiotics alone ( $56 \%$ versus $25 \%, \mathrm{P}<0.005$ ); however, no significant differences in clinical outcomes were seen (242). Adjunctive once-daily, nebulized tobramycin was also associated with a nonsignificant trend toward extubation at day $10 \mathrm{com}$ pared with controls (35\% versus $18.5 \%, \mathrm{P}=0.18$ ) (243).

\section{Major points and recommendations for pharmacokinetic and pharmacodynamic issues in antimicrobial therapy of HAP and VAP}

1. Institutions should develop their own guidelines for the management of HAP and VAP that incorporate local resistance patterns. These guidelines should provide recommendations for empirical therapy as well as for de-escalation and duration of therapy (B-1).

2. It is recommended that for patients treated initially with appropriate antibiotics, seven to eight days of therapy for VAP should be considered appropriate except in those patients infected with non-lactosefermenting bacteria (A-1).

3. Based on the available evidence, intravenous colistin at a dose of $2.5 \mathrm{mg} / \mathrm{kg} /$ day to $5 \mathrm{mg} / \mathrm{kg} /$ day divided in two to three doses is a reasonable option for the management of HAP and VAP caused by P aeruginosa or A baumannii where no alternative antibiotics are appropriate.

4. Additional research including randomized, controlled trials involving larger numbers of patients is needed to delineate the role of inhaled antibiotics in the management of HAP and VAP. In the interim, it is recommended that they may be used as adjunctive therapy in selected cases of MDR Gram-negative pneumonia or in patients unresponsive to parenteral therapy (C-2).

\section{ANTIMICROBIAL SELECTION}

Antibiotic treatment of HAP and VAP is predicated on five overarching principles: early initiation of therapy, correlation of the severity of infection with the clinical presentation, reduction in mortality rates with appropriate therapy, association of late onset HAP and VAP with resistant pathogens and prudent use of combination therapy for certain resistant pathogens. The first of these principles suggests that treatment of HAP and VAP must be initiated as soon as the diagnosis is entertained. Iregui et al (244) demonstrated that the commencement of appropriate antibiotic therapy within $24 \mathrm{~h}$ of diagnosing VAP enhanced survival compared with waiting at least $24 \mathrm{~h}$ for therapy to begin. Hospital mortality was $28.4 \%$ (21 of 74) for early initiation versus $69.7 \%$ (23 of 33) for delayed initiation of therapy (244).

The second principle is that a more severe clinical presentation manifested by hypotension, organ dysfunction, electrolyte derangement (particularly hypophosphatemia) and hypoxia associated with the need for mechanical ventilation (low $\mathrm{PaO}_{2} /$ fraction of inspired oxygen ratios) implies a more severe nosocomial pneumonia often due to $P$ aeruginosa (227,245-247). VAP mortality rates have been predicted by the number of organ dysfunctions on the day of diagnosis (245,246), hypophosphatemia (247), and reduced $\mathrm{PaO}_{2} /$ fraction of inspired oxygen ratios (227). A more severe clinical presentation should dictate broader spectrum antibiotic therapy.

The third premise of importance is the concept that appropriate initial antimicrobial therapy providing adequate coverage for the potential pathogens will result in lower mortality rates in VAP compared with inappropriate therapy (248-252). Inadequate initial antibiotic therapy consistently conferred a statistically significant survival disadvantage. A corollary of this issue is that one must not only ensure appropriate selection of antibiotics to reduce the risk of inadvertently neglecting potentially resistant pathogens, but also appropriate dosing.

A natural segue to the aforementioned principle is the fourth concept. This concept dictates that resistant pathogens that may have greater potential to cause late onset HAP (MRSA, P aeruginosa) and VAP (P aeruginosa, MRSA and Acinetobacter species) should be adequately covered in the antimicrobial regimen employed $(245,253)$.

Finally, the issue of combination therapy compared with monotherapy for HAP and VAP must be addressed. Combination therapy with two or more antibiotics may appear advantageous from a clinical perspective because it provides security by reducing the risk of inadvertently neglecting potentially resistant pathogens. Although retrospective data on initial therapy using piperacillin-tazobactam for the treatment of VAP achieved lower in-hospital mortality compared with not including piperacillin-tazobactam in the therapeutic regimen (HR 0.41, $\mathrm{P}=0.009$ ) (254), combination therapy employing piperacillin-tazobactam with vancomycin, an aminoglycoside or ciprofloxacin resulted in no difference in mortality or length of hospital stay compared with monotherapy. Although these data did not focus on 
TABLE 9

Randomized clinical trials (RCTs) for hospital-acquired pneumonia (HAP)

\begin{tabular}{|c|c|c|c|c|c|c|}
\hline Reference & Regimen & Population & $\begin{array}{l}\text { Disease } \\
\text { severity }\end{array}$ & Setting & Response & Comments \\
\hline 370 & $\begin{array}{l}\text { Aztreonam (AZ) 1-2 g q6-12 h IV versus } \\
\text { tobramycin (T) IV; peaks } 4-10 \mathrm{mg} / \mathrm{mL} \\
\text { trough <2 } \mathrm{mg} / \mathrm{mL} ;+ \text { Gram-positive coverage }\end{array}$ & $\begin{array}{l}>50 \text { years old; } \\
\text { confirmed Gram- } \\
\text { negative infection }\end{array}$ & Mild-moderate & $\begin{array}{l}\text { NA } \\
\qquad(A Z) n=26 \\
(T) n=14\end{array}$ & $\begin{array}{l}\text { Clinical cure } \\
\text { (AZ) } 93 \% \\
\text { (T) } 50 \%, \quad P=0.05\end{array}$ & $\begin{array}{l}\text { Open label } \mathrm{RCT} \\
\text { 2:1 randomization }\end{array}$ \\
\hline 259 & $\begin{array}{l}\text { Cefoperazone (CPZ) } 2 \mathrm{~g} \text { q12 h IV versus } \\
\text { cefazolin 1-2 g q6 h IV or } \\
\text { clindamycin } 600 \mathrm{mg} \text { q8 } \mathrm{h} \text { IV + } \\
\text { gentamicin } 1-2 \mathrm{mg} / \mathrm{kg} \text { q8 h IV (COMB) }\end{array}$ & $\begin{array}{l}\text { MV } 27 \%(\mathrm{CPZ}) \\
\quad \mathrm{MV} 25 \% \text { (COMB) }\end{array}$ & NA & $\begin{array}{l}\text { Ward-ICU } \\
\qquad \begin{array}{l}(\mathrm{CPZ}) \mathrm{n}=46 \\
(\mathrm{COMB}) \mathrm{n}=61\end{array}\end{array}$ & $\begin{array}{l}\text { Clinical response } \\
(\mathrm{CPZ}) 89 \% \\
(\mathrm{COMB}) 72 \%, \mathrm{P}=0.052\end{array}$ & Open label RCT \\
\hline 260 & $\begin{array}{l}\text { Cefotaxime (CFT) } 2 \mathrm{~g} \text { q8 } \mathrm{h} \text { IV versus } \\
\text { antibiotic combination (AC) }\end{array}$ & NA & Mild-moderate & Ward & $\begin{array}{l}\text { Cure } \\
\qquad \begin{array}{l}\text { (CFT) } 79 \% \\
\text { (AC) } 71 \%, P=0.03\end{array}\end{array}$ & Open label RCT \\
\hline 149 & $\begin{array}{l}\text { CFT } 2 \mathrm{~g} \text { q12 } \mathrm{h} \text { IV versus } \\
\text { ceftriaxone (CRX) } 4 \mathrm{~g} \text { qd IV or } \\
2 \mathrm{~g} \mathrm{q12} \mathrm{h} \mathrm{IV}\end{array}$ & $>18$ years old & Mild-moderate & $\begin{array}{l}\text { Ward } \\
\qquad \begin{array}{l}(C F T) n=56 \\
(C R X) n=62\end{array}\end{array}$ & $\begin{array}{l}\text { Clinical response } \\
\text { at end of treatment } \\
\text { (CFT) } 80 \% \\
\text { (CRX) } 82 \%\end{array}$ & Open label RCT \\
\hline 264 & $\begin{array}{l}\text { Piperacillin/tazobactam } \\
\text { (P/T) } 3.375 \mathrm{~g} \text { q } 4 \mathrm{~h} \mathrm{IV} \text { or } \\
\text { ceftazidime (CTZ) } 2 \mathrm{~g} \text { q8 h IV with } \\
\text { tobramycin (T) } 5 \mathrm{mg} / \mathrm{kg} / \mathrm{d} \text { IV }\end{array}$ & $\begin{array}{l}>16 \text { years old } \\
\text { HAP } 87 \%(\mathrm{P} / \mathrm{T}) \\
\text { HAP } 72 \%(\mathrm{CTZ}+\mathrm{T})\end{array}$ & Moderate & $\begin{array}{l}\text { Ward } \\
\qquad \begin{array}{l}(P / T+T) n=70 \\
(C T Z+T) n=42\end{array}\end{array}$ & $\begin{array}{l}\text { Clinical response } \\
\text { at follow-up in } \\
\text { patients with pathogen } \\
(\mathrm{P} / \mathrm{T}+\mathrm{T}) 73 \% \\
(\mathrm{CTZ}+\mathrm{T}) 52 \%, \mathrm{P}=0.046\end{array}$ & Open label RCT \\
\hline 371 & $\begin{array}{l}\mathrm{P} / \mathrm{T} 4.5 \mathrm{~g} \text { q } 8 \mathrm{~h} \mathrm{IV} \\
\text { versus imipenem (I) } 500 \mathrm{mg} \mathrm{q6} \mathrm{h} \mathrm{IV}\end{array}$ & $\begin{array}{l}>16 \text { years old } \\
\text { MV } 47 \%(\mathrm{P} / \mathrm{T}) \\
\text { MV } 51 \%(\mathrm{I})\end{array}$ & Moderate & $\begin{array}{l}\text { Ward-ICU } \\
\qquad \begin{array}{l}\text { (P/T) } n=75 \\
\text { (I) } n=79\end{array}\end{array}$ & $\begin{array}{l}\text { Resolution of signs } \\
\text { and symptoms } \\
\text { (P/T) } 83 \% \\
\text { (I) } 71 \%, P=0.09\end{array}$ & Open label RCT \\
\hline 372 & $\begin{array}{l}\text { Cefepime (CPM) } 2 \mathrm{~g} \mathrm{q} 12 \mathrm{~h} \text { IV versus } \\
\text { CTZ } 2 \text { g q8 h IV }\end{array}$ & $>18$ years old & Mild-moderate & $\begin{array}{l}\text { Ward } \\
\qquad \begin{array}{l}(\text { CPM }) n=64 \\
(C T Z) n=65\end{array}\end{array}$ & $\begin{array}{l}\text { Clinical response at } \\
\text { end of therapy } \\
\text { (CPM) } 78 \% \\
\text { (CTZ) } 82 \%\end{array}$ & Open label RCT \\
\hline 373 & $\begin{array}{l}\text { Moxifloxacin (MOX) } 400 \mathrm{mg} \text { qd IV/po versus } \\
\text { ceftriaxone (CRX) } 2 \mathrm{~g} \text { qd IV } \rightarrow \text { cefuroxime } \\
500 \mathrm{mg} \mathrm{BID} \mathrm{po}\end{array}$ & $\begin{array}{l}>18 \text { years old } \\
\text { MV } 35 \% \text { (MOX) } \\
\text { MV 38\% (CRX) }\end{array}$ & $\begin{array}{l}\text { Mild-moderate } \\
\qquad(\text { APACHE }<20)\end{array}$ & $\begin{array}{l}\text { Ward-ICU } \\
\qquad \begin{array}{l}(\mathrm{MOX}) \mathrm{n}=72 \\
(\mathrm{CRX}) \mathrm{n}=73\end{array}\end{array}$ & $\begin{array}{l}\text { Clinical response } \\
7-10 \text { d post-therapy } \\
\text { (MOX) } 86 \% \\
\text { (CRX) } 84 \%\end{array}$ & $\begin{array}{l}\text { Pooled analysis } \\
\text { of two RCTs: } \\
\text { one double-blind, } \\
\text { one open label }\end{array}$ \\
\hline
\end{tabular}

Mechanical ventilation (MV) >75\% = ventilator-associated pneumonia (VAP); MV 50\% to 75\%= HAPNAP; MV <50\% = HAP. APACHE acute physiological assessment and chronic health evaluation; BID Twice daily; d Day; ICU Intensive care unit; IV Intravenous; NA Not available; po By mouth; $q$ Every

$P$ aeruginosa, nor substantiate the merit of combination therapy, a well-accepted practice has remained to treat $P$ aeruginosa with combination therapy. Bodey et al (255) previously demonstrated that combination therapy with an antipseudomonal beta-lactam and an aminoglycoside attained superior outcomes in $P$ aeruginosa bacteremia in cancer patients (255). Yet, clinical evidence and the in vitro synergy of such combination therapy were not parlayed into improved outcomes by Hilf et al (256), although mortality was reduced in the $P$ aeruginosa pneumonia and bacteremia subgroup treated with combination therapy. Combination therapy did not produce better outcomes in the $P$ aeruginosa VAP cases studied by Crouch Brewer et al (245). Moreover, a meta-analysis has evaluated all prospective randomized trials of beta-lactam/aminoglycoside combination regimens, including a group of patients who had HAP or VAP (257). No advantage for combination therapy compared with betalactam monotherapy for $P$ aeruginosa infections was realized. In addition, another meta-analysis assessing the effect of beta-lactam and aminoglycoside combinations compared with beta-lactam monotherapy on the emergence of antimicrobial resistance failed to show a beneficial effect for the combination (258). Thus, although beta-lactam-aminoglycoside combinations have been employed most commonly in $P$ aeruginosa infections, a clear benefit has not been documented. Other combinations, eg, beta-lactamfluoroquinolone and double beta-lactam combinations, need to be explored for the treatment of $P$ aeruginosa HAP and VAP, before one totally rejects the potential benefit of combination regimens.

It should be acknowledged that not all of the aforementioned treatment principles have been validated in both HAP and VAP. Evidence exists validating the applicability of early initiation of therapy (244), the clinical severity at onset $(227,245,246)$ and the advantage of appropriate initial therapy (248-252) for VAP; however, inclusion of HAP under the umbrella of these principles has not been verified. One must be cognizant that the principle of severity of presentation with organ dysfunction may also imply the presence of more resistant, harder to eradicate pathogens, and this issue is applicable to both HAP (247) and VAP and is associated with a poorer prognosis. Also, one can accept that combination therapy with appropriate initial agents may be preferred to attain a better outcome in $P$ aeruginosa HAP and VAP. 
TABLE 10

Randomized clinical trials (RCTs) for hospital-acquired pneumonia (HAP)/ventilator-associated pneumonia (VAP)

\begin{tabular}{|c|c|c|c|c|c|c|}
\hline Reference & Regimen & Population & Disease severity & Setting & Response & Comments \\
\hline 261 & $\begin{array}{l}\text { Ceftazidime (CTZ) } 2 \mathrm{~g} \text { q8h IV versus } \\
\text { ticarcillin (TIC) } 3 \mathrm{~g} \text { q4h IV + } \\
\text { tobramycin (T) IV with peak levels of } \\
5-7 \mathrm{mg} / \mathrm{mL} \text { and troughs of } 1.5-2.0 \mathrm{mg} / \mathrm{mL}\end{array}$ & $\begin{array}{l}>18 \text { years old, } \\
\text { neurosurgical } \\
\text { patients } \\
\text { MV NA }\end{array}$ & Moderate & $\begin{array}{l}\text { ICU } \\
\qquad(C T Z) n=17 \\
(T I C+T) n=18\end{array}$ & $\begin{array}{l}\text { Clinical cure } \\
\qquad(\mathrm{CTZ}) 88 \% \\
(\mathrm{TIC}+\mathrm{T}) 83 \%\end{array}$ & Open label RCT \\
\hline 374 & $\begin{array}{l}\text { Cefotaxime (CFT) } 2 \mathrm{~g} \mathrm{q6} \text { h IV with } \\
\text { aztreonam (AZ) } 1 \mathrm{~g} \mathrm{q8h} \mathrm{IV} \mathrm{or} \\
\text { amikacin (AM) } 500 \mathrm{mg} \mathrm{q} 12 \mathrm{~h} \mathrm{IV}\end{array}$ & $\begin{array}{l}\text { Adults (>20 years } \\
\text { old), MV NA }\end{array}$ & Moderate-severe & $\begin{array}{l}\text { ICU } \\
\qquad(C F T+A Z) n=13 \\
(C F T+A M) n=16\end{array}$ & $\begin{array}{l}\text { Clinical cure } \\
3, \quad(\mathrm{CFT}+\mathrm{AZ}) 77 \%, \\
6 \quad(\mathrm{CFT}+\mathrm{AM}) 75 \%\end{array}$ & Open label RCT \\
\hline 375 & $\begin{array}{l}\text { Ciprofloxacin (CIP) } 300 \mathrm{mg} \mathrm{q12h} \mathrm{IV} \\
\text { versus CTZ } 2 \text { g q8h IV }\end{array}$ & $\begin{array}{l}>18 \text { years old } \\
\text { MV } 59 \% \text { (CIP) } \\
\text { MV } 73 \% \text { (CTZ) }\end{array}$ & Moderate & $\begin{array}{l}\text { Ward-ICU } \\
\qquad \begin{array}{l}(\mathrm{CIP}) \mathrm{n}=17 \\
(\mathrm{CTZ}) \mathrm{n}=15\end{array}\end{array}$ & $\begin{array}{l}\text { Clinical response } \\
\text { (CIP) } 88.2 \% \\
\text { (CTZ) } 86.2 \%\end{array}$ & Double-blind RCT \\
\hline 262 & $\begin{array}{l}\text { Imipenem (I) } 500 \text { mg q6h IV or } \\
\text { I } 500 \mathrm{mg} \mathrm{q6h} \mathrm{IV} \mathrm{+} \\
\text { netilmicin (N) } 50 \mathrm{mg} \mathrm{q12h} \mathrm{IV}\end{array}$ & $\begin{array}{l}>16 \text { years old } \\
\text { MV } 52.7 \%(\mathrm{I}) \\
\text { MV } 56.9 \%(\mathrm{I}+\mathrm{N})\end{array}$ & Moderate & $\begin{array}{l}\text { Ward-ICU } \\
\qquad \begin{array}{l}\text { (I) } n=91 \\
(I+N) n=86\end{array}\end{array}$ & $\begin{array}{l}\text { Success } \\
\qquad \begin{array}{l}\text { (I) } 82.4 \% \\
(\mathrm{I}+\mathrm{N}) 83.7 \%\end{array}\end{array}$ & Open label RCT \\
\hline 263 & $\begin{array}{l}\text { CTZ } 2 \mathrm{~g} \text { q12h IV versus } \\
\text { ceftriaxone (CRX) } 2 \mathrm{~g} \mathrm{IV} \mathrm{qd} \mathrm{+} \\
\text { T 3-5 mg/kg/d IV }\end{array}$ & $\begin{array}{l}\text { Adults } \\
\text { ICU } 43 \% \\
\text { MV } 65 \%\end{array}$ & Moderate-severe & $\begin{array}{l}\text { Ward-ICU } \\
\qquad \begin{array}{l}(C T Z) n=159 \\
(C R X+T) n=138\end{array}\end{array}$ & $\begin{array}{l}\text { Clinical response } \\
\qquad \begin{array}{l}(\mathrm{CTZ}) 73 \% \\
(\mathrm{CRX}+\mathrm{T}) 65 \%, P=0.09\end{array}\end{array}$ & Open label RCT \\
\hline 376 & $\begin{array}{l}\text { CIP } 300 \mathrm{mg} \\
\text { q12h IV } \rightarrow 750 \mathrm{mg} \text { q12h po after } 72 \mathrm{~h} \\
\text { versus CTZ } 2 \mathrm{~g} \text { q8h IV }\end{array}$ & $\begin{array}{l}>18 \text { years old } \\
\text { MV } 52.8 \%(\text { CIP }) \\
\text { MV } 50.7 \%(C T Z)\end{array}$ & Moderate-severe & $\begin{array}{l}\text { Ward-ICU } \\
\qquad \begin{array}{l}(C I P) n=56 \\
(C T Z) n=68\end{array}\end{array}$ & $\begin{array}{l}\text { Clinical response at } 96 \mathrm{~h} \\
\text { (CIP) } 87.1 \% \\
\text { (CTZ) } 87.3 \%\end{array}$ & Open label RCT \\
\hline 91 & $\begin{array}{l}\text { Cefepime (CPM) } 2 \text { g q8h IV versus } \\
\text { I } 500 \mathrm{mg} \text { q6h IV }\end{array}$ & $\begin{array}{l}>16 \text { years old } \\
\text { MV } 66 \% \text { (CPM) } \\
\text { MV } 66 \% \text { (I) }\end{array}$ & Severe & $\begin{array}{l}\text { ICU } \\
\text { (CPM) } n=108 \\
\text { (I) } n=101\end{array}$ & $\begin{array}{l}\text { Clinical response } \\
\text { (CPM) } 70 \% \\
\text { (I) } 74 \%\end{array}$ & Open label RCT \\
\hline 270 & 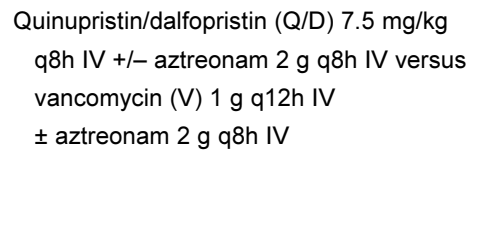 & $\begin{array}{l}>18 \text { years old, } \\
\text { MV } 74 \%(\mathrm{Q} / \mathrm{D}) \\
\text { MV } 68.9 \%(\mathrm{~V})\end{array}$ & Moderate-severe & $\begin{array}{l}\text { Ward-ICU } \\
\qquad \begin{array}{l}(Q / D) n=87 \\
(V) n=84\end{array}\end{array}$ & $\begin{array}{l}\text { Clinical response } \\
7-13 \mathrm{~d} \text { post therapy } \\
\text { in bacteriologically } \\
\text { evaluable patients, } \\
\text { (Q/D) } 56.3 \% \\
\text { (V) } 58.3 \%\end{array}$ & Open label RCT \\
\hline 268 & $\begin{array}{l}\text { Linezolid (L) } 600 \mathrm{mg} \text { q12h IV or } \\
\text { V } 1 \mathrm{~g} \text { q12h IV with } \\
\text { aztreonam } 1-2 \mathrm{~g} \text { q8h IV }\end{array}$ & $\begin{array}{l}>18 \text { years old, } \\
\text { MV } 50.5 \%(L) \\
\text { MV } 50.7 \%(\mathrm{~V})\end{array}$ & Moderate-severe & $\begin{array}{l}\text { Ward-ICU } \\
\qquad \begin{array}{l}(L) n=169 \\
(V) n=176\end{array}\end{array}$ & $\begin{array}{l}\text { Clinical response } \\
15-21 \text { d post-therapy } \\
\text { (L) } 67.9 \% \\
\text { (V) } 64.9 \%\end{array}$ & Double-blind RCT \\
\hline 269 & $\begin{array}{l}\text { L } 600 \mathrm{mg} \text { q12h IV or } \\
\text { V } 1 \mathrm{~g} \mathrm{q} 12 \mathrm{~h} \mathrm{IV} \mathrm{plus} \\
\text { aztreonam } 1-2 \mathrm{~g} \mathrm{q} 8 \mathrm{~h} \mathrm{IV}\end{array}$ & $\begin{array}{l}>18 \text { years old } \\
\text { MV } 58.2 \%(L) \\
\text { MV } 56.4(\mathrm{~V})\end{array}$ & Moderate-severe & $\begin{array}{l}\text { Ward-ICU } \\
\qquad \begin{array}{l}(L) n=107 \\
(V) n=91\end{array}\end{array}$ & $\begin{array}{l}\text { Clinical response in } \\
\text { evaluable patients with } \\
12-28 \mathrm{~d} \text { follow-up } \\
\text { (L) } 66.4 \% \\
\text { (V) } 68.1 \%\end{array}$ & Double-blind RCT \\
\hline 206 & $\begin{array}{l}\text { L } 600 \mathrm{mg} \mathrm{q} 12 \mathrm{~h} \text { IV or } \\
\text { V } 1 \mathrm{~g} \mathrm{q} 12 \mathrm{~h} \mathrm{IV} \mathrm{+/-} \\
\text { aztreonam } 1-2 \mathrm{~g} \text { q8h IV }\end{array}$ & $\begin{array}{l}>18 \text { years old } \\
\text { MV } 70.2 \%(L) \\
\text { MV } 66.7 \%(\mathrm{~V})\end{array}$ & Moderate-severe & $\begin{array}{l}\text { Ward-ICU } \\
\begin{array}{l}\text { S aureus } \\
\text { (L) } n=136 \\
\text { (V) } n=136 \\
\text { MRSA } \\
\text { (L) } n=61 \\
\text { (V) } n=62\end{array}\end{array}$ & $\begin{array}{l}\text { Clinical cure at end } \\
\text { of therapy } \\
\text { S aureus } \\
\text { (L) } 51.5 \% \\
\text { (V) } 43.4 \% \\
\text { MRSA } \\
\text { (L) } 59.0 \% \\
\text { (V) } 35.5 \%, P<0.001\end{array}$ & $\begin{array}{l}\text { Double-blind } \\
\text { RCTs with } \\
\text { (L) versus (V) } \\
\text { combined }\end{array}$ \\
\hline 88 & $\begin{array}{l}\text { Levofloxacin (LEV) } 750 \mathrm{mg} \text { q24h IV } \\
\text { then po versus } \\
\text { I 500-1000 mg q6-8h IV } \\
\text { then CIP } 750 \mathrm{mg} \text { BID po }\end{array}$ & $\begin{array}{l}>18 \text { years old } \\
\text { MV } 71.4 \%(\text { LEV) } \\
\text { MV } 70.6 \%(\mathrm{I})\end{array}$ & Moderate-severe & $\begin{array}{l}\text { Ward-ICU } \\
\qquad \begin{array}{l}\text { (LEV) } n=93 \\
\text { (I) } n=94\end{array}\end{array}$ & $\begin{array}{l}\text { Clinical response in } \\
\text { microbiological efficacy } \\
\text { patients at } 7-15 \mathrm{~d} \\
\text { post-therapy } \\
\text { (LEV) } 58.1 \% \\
\text { (I) } 60.1 \%\end{array}$ & Open label RCT \\
\hline 377 & $\begin{array}{l}\text { CPM } 2 \mathrm{~g} \mathrm{q} 12 \mathrm{~h} \mathrm{IV} \text { versus } \\
\text { CFT } 2 \mathrm{~g} \text { q } 8 \mathrm{~h} \mathrm{IV}\end{array}$ & $\begin{array}{l}>18 \text { years old } \\
\text { MV } 54 \% \text { (CPM) } \\
\text { MV } 62 \%(C F T)\end{array}$ & Moderate-severe & $\begin{array}{l}\text { Ward-ICU } \\
\qquad \begin{array}{l}(\mathrm{CPM}) \mathrm{n}=18 \\
(\mathrm{CFT}) \mathrm{n}=5\end{array}\end{array}$ & $\begin{array}{l}\text { Clinical response } \\
\text { at follow-up } \\
\text { (CPM) } 83 \% \\
\text { (CFT) } 40 \%\end{array}$ & $\begin{array}{l}\text { Open label } \\
\mathrm{RCT} ; 2: 1 \\
\text { randomization }\end{array}$ \\
\hline
\end{tabular}

Continued on next page 
TABLE 10 - CONTINUED

Randomized clinical trials (RCTs) for hospital-acquired pneumonia (HAP)/ventilator-associated pneumonia (VAP)

\begin{tabular}{|c|c|c|c|c|c|c|}
\hline Reference & Regimen & Population & Disease severity & Setting & Response & Comments \\
\hline 150 & $\begin{array}{l}\text { Meropenem (M) } 1 \mathrm{~g} \text { q8h IV } \\
\text { versus } 11 \mathrm{~g} \mathrm{q} 8 \mathrm{~h} \mathrm{IV}\end{array}$ & $\begin{array}{l}>16 \text { years old, } \\
\% \text { MV NA }\end{array}$ & Moderate-severe & $\begin{array}{l}\text { Ward-ICU } \\
\qquad \begin{array}{l}\text { (M) } n=36 \\
\text { (I) } n=44\end{array}\end{array}$ & $\begin{array}{l}\text { Clinical response at } \\
\text { end of therapy } \\
\text { (M) } 75 \% \\
\text { (I) } 75 \%\end{array}$ & Open label RCT \\
\hline 82 & $\begin{array}{l}\text { M } 1 \mathrm{~g} \text { q8h IV versus } \\
\text { CTZ } 2 \mathrm{~g} \text { q8h IV } \pm \\
\text { T } 1 \mathrm{mg} / \mathrm{kg} \text { q8h IV }\end{array}$ & $\begin{array}{l}>17 \text { years old } \\
\text { MV } 73 \%(\mathrm{M}) \\
\text { MV } 67 \%(\mathrm{CTZ}+\mathrm{T})\end{array}$ & Moderate-severe & $\begin{array}{l}\text { Ward-ICU } \\
\qquad(M) n=63 \\
\qquad(C T Z+T) n=58\end{array}$ & $\begin{array}{l}\text { Clinical response at } \\
\text { end of therapy } \\
\text { (M) } 89 \% \\
\text { (CTZ+T) } 72 \%, P=0.04\end{array}$ & $\begin{array}{l}\text { Open label RCT } \\
4\end{array}$ \\
\hline 378 & $\begin{array}{l}\text { M } 1 \mathrm{~g} \text { q8h IV } \\
\text { versus I } 1 \mathrm{~g} \text { q8h IV }\end{array}$ & $\begin{array}{l}>16 \text { years old } \\
\text { MV } 73 \%(\mathrm{M}) \\
\text { MV } 72 \%(\mathrm{I})\end{array}$ & Moderate-severe & Ward-ICU & $\begin{array}{l}\text { Clinical response at } \\
\text { end of therapy } \\
\text { (M) } 91 \% \\
\text { (I) } 78 \%\end{array}$ & Open label RCT \\
\hline
\end{tabular}

Mechanical ventilation (MV) >75\% = VAP; MV 50\% to 75\% = HAPNAP; MV <50\% = HAP. BID Twice daily; d Day; ICU Intensive care unit; IV Intravenous; NA Not available; po By mouth; q Every; MRSA Methicillin-resistant Staphylococcus aureus (S aureus)

\section{Randomized clinical trials for HAP and VAP}

The randomized clinical trials undertaken for the treatment of HAP and VAP are presented in Tables 9-11. These tables outline the antibiotic regimens, (monotherapy or combination therapy), the characteristics of the patient populations studied (percentage of patients receiving mechanical ventilation), the disease severity (mild, moderate or severe) as described in the clinical trial, the clinical setting (ward or ICU), the response rates for the respective regimens and pertinent comments about the trials.

A number of observations may be gleaned from these listings. First, the trials were often performed in heterogeneous patient populations containing both mechanically ventilated and nonventilated patients. This presents difficulties in determining the efficacy of a particular regimen for HAP compared with VAP. Therefore, in an effort to standardize the presentation of the data, populations in which the percentage of mechanical ventilation was less than $50 \%$ were considered to have HAP. Patient populations in which $50 \%$ to $75 \%$ of the patients were mechanically ventilated are presented as an amalgamation of HAP and VAP, while the patient population characterized by greater than $75 \%$ mechanical ventilation was considered to be VAP.

Second, the randomized clinical trials do not substantiate any advantage whatsoever for combination therapy compared with monotherapy (47,259-263). In fact, in two studies (for HAP [82,260] and VAP [82], respectively), the combination regimen was inferior to the monotherapy regimen.

Third, it would appear that the relatively small size of the prospective clinical trials in general precludes any statement demonstrating the superiority of one agent over another. There are, however, some exceptions. In a study of HAP comparing piperacillin-tazobactam to ceftazidime, each combined with tobramycin, the piperacillin-tazobactam arm achieved superior response rates ( $73 \%$ versus $52 \%, \mathrm{P}=0.046$ ) (264). Similarly, meropenem produced greater success in HAP and VAP compared with ceftazidime plus tobramycin (89\% versus $72 \%, \mathrm{P}=0.04)(82)$. Cefotaxime was superior to ceftriaxone in a small trial treating VAP (265). Moreover, in two studies, one in HAP and one in VAP, combined results from the two randomized clinical trials showed that linezolid produced higher response rates for MRSA $(191,266)$. Thus, one can only state that, in general, the comparative regimens listed in the tables were considered to be equivalent in efficacy for both HAP and VAP. The use of combination therapy for $P$ aeruginosa still remains theoretical at this time and is based on retrospective data and expert opinion $(255,267)(\mathrm{C}-3)$. Individual clinical trials have not demonstrated the superiority of combination therapy using a beta-lactam and an aminoglycoside. However, double beta-lactam or beta-lactam-fluoroquinolone combinations have not been studied adequately. Such combinations may have additive antimicrobial properties but their use is contingent on local susceptibility patterns.

Although individual trials have not found a distinct superiority of linezolid over vancomycin for MRSA HAP and $\operatorname{VAP}(268,269)$, superior efficacy of linezolid was demonstrated when the data from the two prospective randomized clinical trials were combined $(206,266)$. Noteworthy are the response rates for vancomycin found by Wunderink et al (206) and Kollef et al (266) that appear to be consistent with the vancomycin response rate reported by Fagon et al (270). Additional studies are warranted to advise clinicians of the optimal agents and dosages for treating $P$ aeruginosa and MRSA HAP and VAP.

\section{Risk stratification of patients with HAP and VAP}

Risk stratification schemata have evolved as important concepts in the treatment of patients with infectious diseases in the past 15 years. A risk stratification paradigm has been readily applied to the management of febrile neutropenic episodes in cancer patients, separating febrile episodes into low-risk febrile episodes in patients with short duration of neutropenia and no significant comorbid features versus higher risk febrile neutropenic episodes in those individuals who may have prolonged neutropenia associated with comorbid conditions $(271,272)$. Similarly, a risk stratification schema using clinical presentation as the paradigm may be applied to the management of HAP and VAP. Clearly, those individuals diagnosed with HAP who are hospitalized on wards or the ICU yet do not present with hypotension, multiple organ dysfunction, sepsis syndrome, rapid progression of infiltrates or the need for ventilation are far different from those individuals who require lifesupporting ancillary therapies such as mechanical ventilation, aggressive fluid management and vasopressors. As clinicians, it would also seem reasonable to adopt narrower spectrum therapy for the management of such patients provided resistant 
TABLE 11

Randomized clinical trials (RCTs) for treatment of ventilator-associated pneumonia (VAP)

\begin{tabular}{|c|c|c|c|c|c|c|}
\hline Reference & Regimen & Population & $\begin{array}{l}\text { Disease } \\
\text { severity }\end{array}$ & Setting & Response & Comments \\
\hline 265 & $\begin{array}{l}\text { Cefotaxime (CFT) } 2 \mathrm{~g} \text { q8h IV } \\
\text { versus ceftriaxone (CRX) } 2 \mathrm{~g} \text { q24h IV }\end{array}$ & $\begin{array}{l}>18 \text { years old } \\
\text { MV } 90 \%\end{array}$ & Moderate-severe & $\begin{array}{l}\text { ICU } \\
\qquad \begin{array}{l}(C F T) n=26 \\
(C R X) n=25\end{array}\end{array}$ & $\begin{array}{l}\text { Clinical response at } \\
\text { end of therapy } \\
\text { (CFT) } 73 \% \\
\text { (CRX) } 48 \%, P=0.04\end{array}$ & Open label RCT \\
\hline 379 & $\begin{array}{l}\text { Ceftazidime (CTZ1) } 1 \mathrm{~g} \text { q8h IV versus } \\
\text { ceftazidime (CTZ2) } 2 \mathrm{~g} \text { q8h IV }\end{array}$ & $\begin{array}{l}\text { Adults } \\
\text { MV 72\% (CTZ1) } \\
\text { MV } 92 \% \text { (CTZ2) }\end{array}$ & Moderate-severe & $\begin{array}{l}\text { ICU } \\
\qquad \begin{array}{l}(C T Z 1) n=25 \\
(C T Z 2) n=25\end{array}\end{array}$ & $\begin{array}{l}\text { Clinical response at } \\
\text { end of therapy } \\
\text { (CTZ1) } 80 \% \\
\text { (CTZ2) } 92 \%\end{array}$ & Single-blind RCT \\
\hline 60 & $\begin{array}{l}\text { Imipenem (I) } 1 \mathrm{~g} \text { q8h IV versus } \\
\text { ciprofloxacin (CIP) } 400 \mathrm{mg} \text { q8h IV }\end{array}$ & $\begin{array}{l}>18 \text { years old } \\
78 \% \text { (I)-HAP } \\
78 \% \text { (CIP)-HAP } \\
\text { MV } 80.6 \% \text { (CIP) } \\
\text { MV } 76.9 \% \text { (I) }\end{array}$ & Moderate-severe & $\begin{array}{l}\text { ICU } \\
\qquad \begin{array}{l}\text { (I) } n=76 \\
\text { (CIP) } n=83\end{array}\end{array}$ & $\begin{array}{l}\text { Primary end point } \\
\text { bacteriological response } \\
3-7 \text { d post Rx } \\
\text { (I) } 58 \% \\
\text { (CIP) } 69 \%\end{array}$ & $\begin{array}{l}\text { Double-blind RCT } \\
\text { se }\end{array}$ \\
\hline 151 & $\begin{array}{l}\text { Piperacillin/tazobactam } \\
\text { (P/T) } 4.5 \mathrm{~g} \text { QID IV or } \\
\text { CTZ } 1 \mathrm{~g} \text { QID IV } \\
\text { with amikacin } 7.5 \mathrm{mg} / \mathrm{kg} \text { BID IV }\end{array}$ & $\begin{array}{l}\text { Adults } \\
\text { MV } 100 \% \text { (P/T) } \\
\text { MV } 100 \% \text { (CTZ) }\end{array}$ & Moderate-severe & $\begin{array}{l}\text { ICU } \\
\qquad \begin{array}{l}(P / T) n=51 \\
(C T Z) n=64\end{array}\end{array}$ & $\begin{array}{l}\text { Clinical response } \\
\text { 6-8 d post-therapy } \\
\text { (P/T) } 51 \% \\
\text { (CTZ) } 36 \%\end{array}$ & Open label RCT \\
\hline 85 & $\begin{array}{l}\text { CIP } 800-1200 \mathrm{mg} \mathrm{IV} / \mathrm{d} \\
\text { versus I } 2-4 \mathrm{~g} \mathrm{IV} / \mathrm{d}\end{array}$ & $\begin{array}{l}>18 \text { years old } \\
\text { MV } 100 \%(\mathrm{CIP}) \\
\text { MV } 100 \%(\mathrm{I})\end{array}$ & Moderate-severe & $\begin{array}{l}\text { ICU } \\
\qquad \begin{array}{l}\text { (CIP) } n=41 \\
\text { (I) } n=34\end{array}\end{array}$ & $\begin{array}{l}\text { Clinical response } \\
\text { (CIP) } 71 \% \\
\text { (I) } 79 \% \\
\text { P aeruginosa } \\
\text { (CIP) } 71 \% \\
\text { (I) } 67 \%\end{array}$ & Open label RCT \\
\hline 47 & $\begin{array}{l}\text { P/T } 4.5 \mathrm{~g} \mathrm{q6h} \mathrm{IV} \\
\text { or CTZ } 2 \mathrm{~g} \text { q8h IV } \\
\text { with amikacin (A) } 7.5 \mathrm{mg} / \mathrm{kg} \mathrm{q12h} \mathrm{IV}\end{array}$ & $\begin{array}{l}>18 \text { years old } \\
\text { MV } 100 \%(P / T) \\
\text { MV } 100 \%(C T Z+A)\end{array}$ & Moderate-severe & $\begin{array}{l}\text { ICU } \\
\qquad(P / T) n=83 \\
(C T Z+A) n=26\end{array}$ & $\begin{array}{l}\text { Clinical response at } \\
\text { end of treatment } \\
\text { (P/T) } 63.9 \% \\
\text { (CTZ+A) } 61.5 \%\end{array}$ & Open label RCT \\
\hline 380 & $\begin{array}{l}\text { CTZ-CI (continuous infusion) } 3 \mathrm{~g} / \mathrm{d} \\
\text { or CTZ-II } 2 \mathrm{~g} \text { q8h IV plus } \\
\text { tobramycin (T) } 7 \mathrm{mg} / \mathrm{kg} \text { QD IV }\end{array}$ & $\begin{array}{l}>18 \text { years old } \\
\text { MV 89\% (CTZ-CI) } \\
\text { MV 94\% (CTZ-II) }\end{array}$ & Moderate-severe & $\begin{array}{l}\text { ICU } \\
\qquad \begin{array}{l}(C T Z-I I) n=17 \\
(C T Z-I I) n=18\end{array}\end{array}$ & $\begin{array}{l}\text { Clinical response } \\
14-21 \text { days } \\
\text { post-therapy } \\
\text { (CTZ-CI) } 83 \% \\
\text { (CTZ-II) } 94 \%\end{array}$ & Open label RCT \\
\hline 266 & $\begin{array}{l}\text { Linezolid (L) } 600 \mathrm{mg} \mathrm{q12h} \mathrm{IV} \mathrm{or} \\
\text { vancomycin (V) } 1 \mathrm{~g} \mathrm{q12h} \mathrm{IV} \\
\text { with aztreonam } 1-2 \mathrm{~g} \mathrm{q} 8 \mathrm{~h} \mathrm{IV}\end{array}$ & $\begin{array}{l}>18 \text { years old } \\
\text { MV } 100 \%(\mathrm{~L}) \\
\text { MV } 100 \%(\mathrm{~V})\end{array}$ & Severe & $\begin{array}{l}\text { ICU } \\
\text { (L) } n=282 \\
\text { (V) } n=262 \\
S \text { aureus } \\
\text { (L) } n=88 \\
\text { (V) } n=91 \\
\text { MRSA } \\
\text { (L) } n=37 \\
\text { (V) } n=33\end{array}$ & $\begin{array}{l}\text { ITT population clinical } \\
\text { cure } 12-28 \mathrm{~d} \\
\text { post-therapy } \\
\text { S aureus } \\
\text { (L) } 48.9 \% \\
\text { (V) } 35.2 \%, P=0.06 \\
\text { MRSA } \\
\text { (L) } 62.2 \% \\
\text { (V) } 21.2 \%, P=0.001\end{array}$ & $\begin{array}{l}2 \text { double-blind } \\
\text { RCTs }(L) \text { versus } \\
\text { (V) combined }\end{array}$ \\
\hline 381 & $\begin{array}{l}\text { Levofloxacin (LFX) } 750 \mathrm{mg} \text { q24h IV } \\
\text { versus I 500-1000 mg q6-8h IV }\end{array}$ & $\begin{array}{l}\text { Adults } \\
\text { MV } 100 \% \text { (LFX) } \\
\text { MV } 100 \% \text { (I) }\end{array}$ & Moderate-severe & $\begin{array}{l}\text { ICU } \\
\text { (LFX) } n=111 \\
\text { (I) } n=111\end{array}$ & $\begin{array}{l}\text { Response in } \\
\text { clinically evaluable } \\
\text { (LFX) } 56.1 \% \\
\text { (I) } 58.1 \%\end{array}$ & Open label RCT \\
\hline
\end{tabular}

Mechanical ventilation (MV) $>75 \%=$ VAP; MV 50\% to 75\%= hospital-acquired pneumonia (HAP)/VAP; MV $<50 \%=H A P$. BID Twice daily; d Day; ICU Intensive care unit; ITT Intention to treat; IV Intravenous; MRSA Methicillin-resistant Staphylococcus aureus; NA Not Available; P aeruginosa Pseudomonas aeruginosa; $q$ Every; QD Daily; QID Four times daily; Rx Treatment

microorganisms are not present. In fact, at times, oral rather than parenteral therapy may be sufficient for this group. On the other hand, the clinical presentation of HAP with multiple organ dysfunction, sepsis syndrome, rapid progression of infiltrates, need for mechanical ventilation and/or known colonization with resistant organisms should prompt more aggressive antibiotic management in concert with the use of life support measures. With these thoughts in mind, one may attempt to risk stratify patients with HAP into those patients who may be managed on the ward as opposed to those who should be managed in the ICU with or without mechanical ventilation and other life support measures. The former group may present with mild to moderate symptoms and clinical manifestations. In such patients, the infection may be early (four days or less after admission to the hospital) (group 1) or late (five or more days postadmission) in onset (group 2) (Figure 6). Finally, there is a group of patients with HAP initially hospitalized on the ward who must be transferred to the ICU due to the need for mechanical ventilation and other life supporting measures because of the severity of their clinical presentation with HAP. These individuals require more aggressive initial antibiotic therapy for fear of potential resistant pathogens that produce a more severe clinical presentation (group 3) (C-3). 


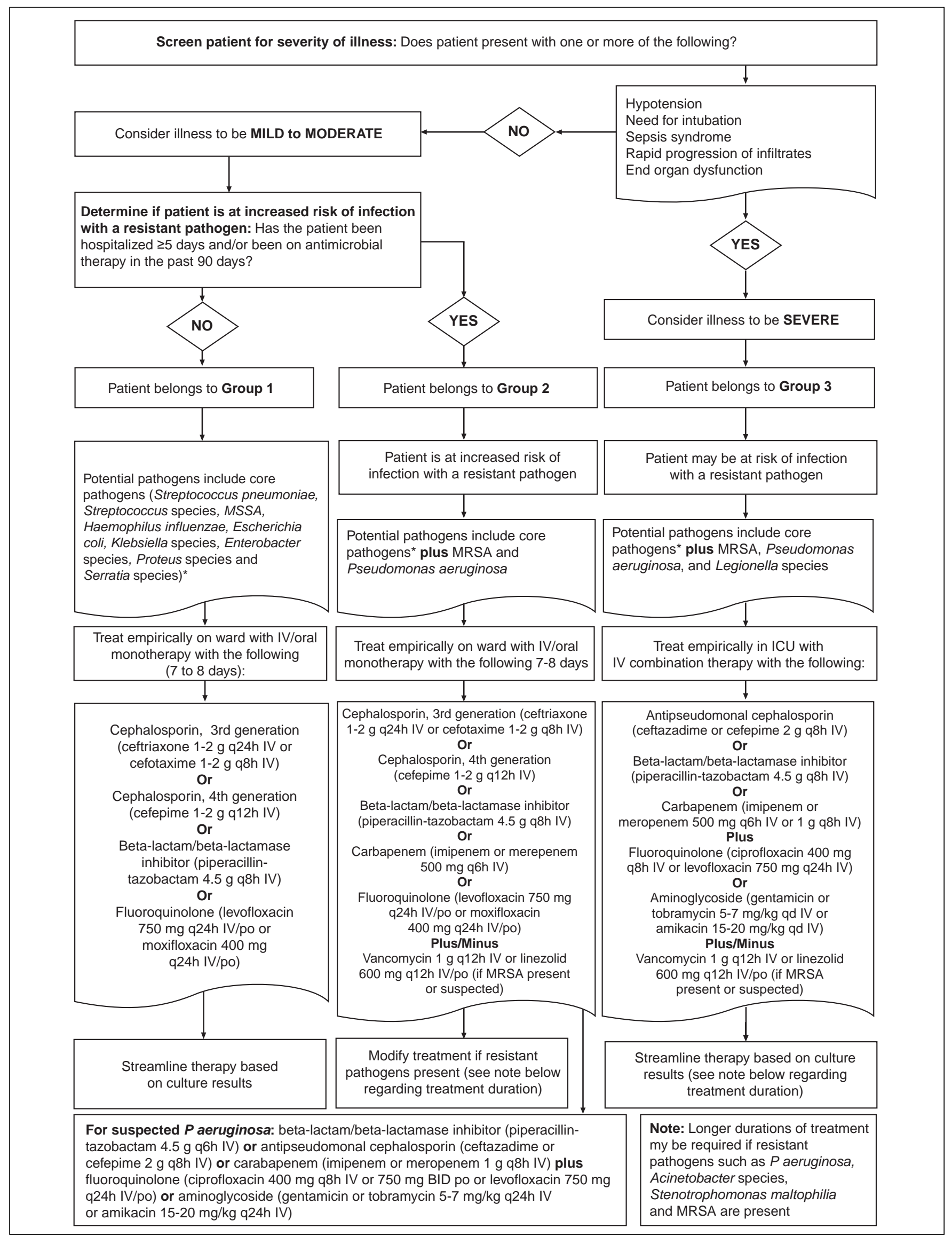

Figure 6) Treatment algorithm for hospital-acquired pneumona. BID Twice daily; ICU Intensive care unit; IV Intravenous; MRSA Methicillinresistant Staphylococcus aureus; MSSA Methicillin-susceptible S aureus; q Every; po By mouth 
Other considerations in the risk stratification schemata for HAP and VAP are the time of onset after admission to the hospital and the predilection for the presence of resistant pathogens due to antecedent antibiotic exposure. Early-onset HAP (less than five days after the patient's admission to the hospital), without prior antibiotic exposure, is usually caused by susceptible organisms. The late-onset time frame of HAP (five or more days after admission) often associated with prior exposure to antimicrobial agents in the preceding 90 days are risk factors that predispose patients to the acquisition of more antibiotic-resistant microorganisms $(5,43)$. Therefore, HAP of early-onset with no risk factors for resistant organisms and a mild to moderate presentation (group 1) may be treated with a third-generation (ceftriaxone or cefotaxime) or a fourthgeneration cephalosporin (cefepime), a beta-lactam/beta lactamase inhibitor combination (piperacillin-tazobactam) or a fluoroquinolone (levofloxacin or moxifloxacin) on the ward as outlined in Figure 6. Thereafter, HAP therapy may be streamlined according to available pathogen susceptibilities. However, although the presentation may be mild to moderate, the presence of risk factors for resistance, ie, previous antibiotic therapy and/or onset five or more days after admission to the hospital (group 2) should prompt more potent therapy for potentially resistant pathogens, ie, a beta-lactam/betalactamase inhibitor combination (piperacillin-tazobactam), a carbapenem (imipenem or meropenem), a fluoroquinolone (ciprofloxacin, levofloxacin or moxifloxacin) or a third- or fourth-generation cephalosporin with either vancomycin or linezolid if MRSA is suspected as an etiologic agent (Figure 6). Moreover, if there is concern about $P$ aeruginosa, a betalactam/beta-lactamase inhibitor combination, antipseudomonal cephalosporin (ceftazidime or cefepime), or a carbapenem with an antipseudomonal fluoroquinolone (ciprofloxacin or levofloxacin) or an aminoglycoside are warranted as therapy. Furthermore, a severe presentation with hypotension, need for intubation, rapid progression of infiltrates, sepsis or multiple organ dysfunction (group 3) mandates aggressive combination therapy with an antipseudomonal cephalosporin, betalactam/beta-lactamase inhibitor combination, or carbapenem plus a fluoroquinolone (ciprofloxacin or levofloxacin) or an aminoglycoside with either linezolid or vancomycin if MRSA is a potential pathogen (Figure 6). Once more, the regimen may be streamlined with the availability of organism identification and susceptibility.

Similar risk stratification schemata may also be applied to VAP (Figure 7). In individuals who are in the ICU for less than five days within five days of admission to the hospital, with no risk factors for resistant pathogens (ie, no antibiotics in preceding 90 days leading to colonization of the respiratory tract with resistant pathogens) and develop VAP with a mild to moderate clinical presentation (group 4), therapy is consistent with that of group 1 . Therefore, a third- or fourth-generation cephalosporin, a beta-lactam/beta-lactamase inhibitor, a carbapenem or a fluoroquinolone (levofloxacin, moxifloxacin or ciprofloxacin) monotherapy are all appropriate therapy (Figure 7). One must recognize, however, that resistance in $S$ aureus can emerge more readily with ciprofloxacin (273). The local epidemiology of microorganism susceptibilities must be taken into account with a willingness to adopt the use of other antimicrobial agents based on resistance patterns.

The final cohort of patients with VAP (group 5) may present with a severe clinical presentation of VAP and/or risk factors for resistant organisms due to the late onset of VAP and/or prior antibiotic exposure. This group should be treated with an antipseudomonal cephalosporin, a beta-lactam/beta-lactamase inhibitor, or a carbapenem plus a fluoroquinolone with antipseudomonas activity or an aminoglycoside with or without vancomycin or linezolid if the presence of MRSA is present or suspected (Figure 7).

Adjustments to these initial antibiotic regimens for HAP and VAP should be undertaken based on the diagnostic approach as outlined above, using the CPIS to re-evaluate the need for antibiotics. Antibiotics may be discontinued based on a low clinical probability of HAP or VAP. All initial regimens may be streamlined following the availability of microbiological data. The duration should also be dictated by the aforementioned recommendations. In addition, failure of a patient to respond to a seemingly appropriate regimen should prompt concerns about resistant organisms, poor host response due to the presence of complications such as a lung abscess or empyema or, potentially, a diagnosis other than HAP or VAP to account for the patient's clinical problems.

\section{Major points and recommendations for antimicrobial treatment}

1. It is recommended that antibiotic therapy for $\operatorname{HAP}(\mathrm{C}-3)$ and VAP (B-2) should commence within $24 \mathrm{~h}$ (or earlier) of diagnosis.

2. Patient risk stratification schemata based on clinical presentation (B-2), time of onset (B-2) and potential for resistant pathogens based on antibiotic exposure (B-2) should be applied to individuals with HAP and VAP.

3. Initiation of appropriate therapy and dosing in VAP will produce improved clinical outcomes.

4. A more severe clinical presentation implies infection with more resistant pathogens.

5. Randomized clinical trials do not show a benefit of any regimen over another with the exception of poorer outcomes with ceftazidime.

6. Combination therapy was not found to be superior to monotherapy.

7. A short course of therapy of seven to eight days should suffice for most cases of HAP and VAP (C-3 and A-1).

8. It is recommended that combination therapy be used for the treatment of $P$ aeruginosa HAP and VAP for more prolonged periods of time (14 days) (C-3).

9. Combination therapy should be prescribed for a severe presentation of HAP and VAP and streamlined based on culture results (C-3).

\section{NONANTIMICROBIAL APPROACH TO MANAGEMENT}

Although antimicrobial agents are the mainstay of the management of HAP and VAP, nonantimicrobial therapeutic interventions can also alter outcome. These interventions include hemodynamic management, ventilation strategies, immunological treatments, fluid and nutritional management, and administrative issues. 


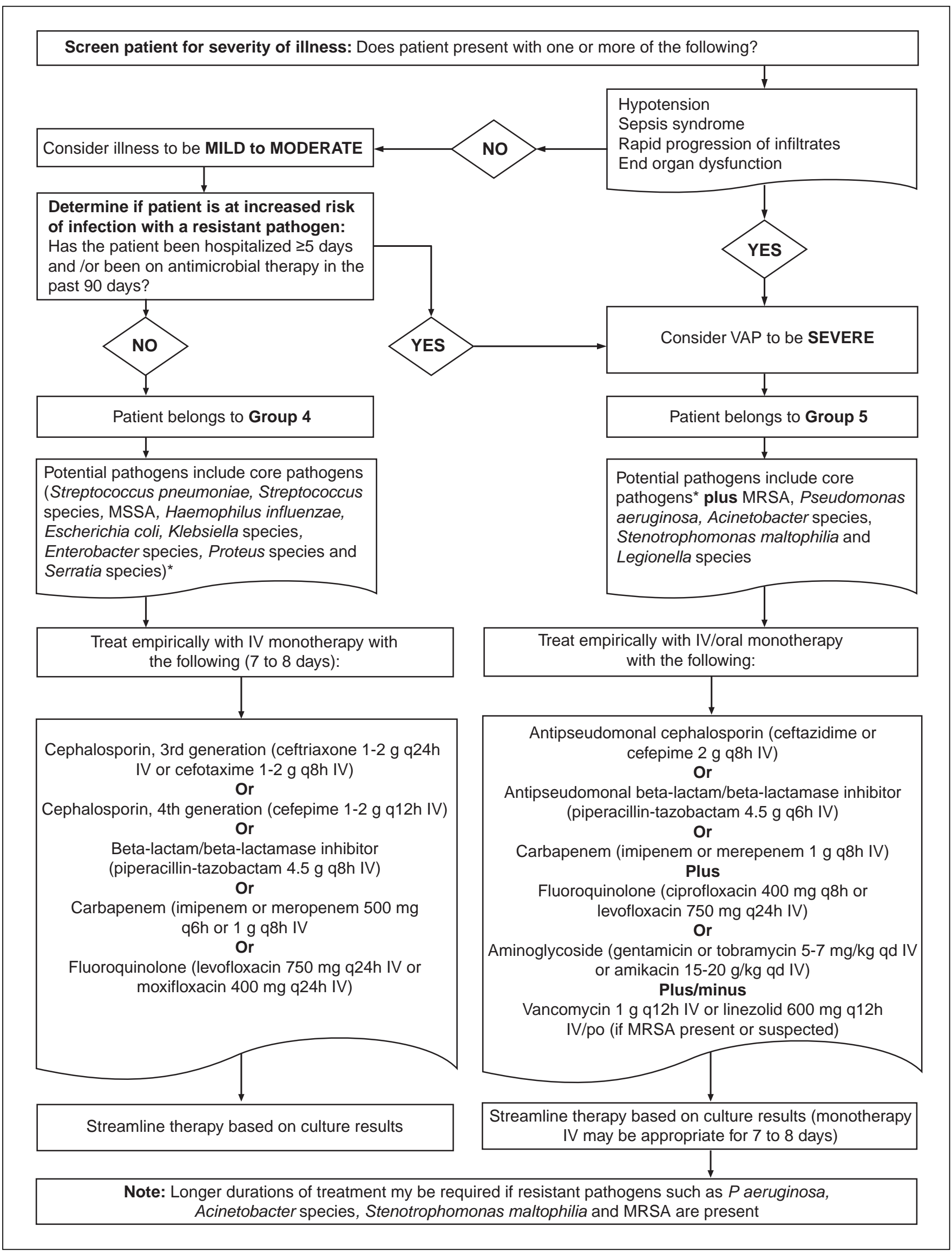

Figure 7) Treatment algorithm for ventilator-associated pneumonia (VAP). d Day; IV Intravenous; MRSA Methicillin-resistant Staphylococcus aureus; MSSA Methicillin-sensitive S aureus; q Every 


\section{Hemodynamic support}

Although no data in humans indicate that hemodynamic support alters outcome in patients with HAP and VAP, improved survival has been demonstrated in patients with severe sepsis presenting to the emergency department and managed with early goal-directed hemodynamic support (274). These data support the importance of early aggressive resuscitative measures directed at maintaining an appropriate hemodynamic response for all patients with sepsis, including those with HAP or VAP. Sepsis management should include the placement of a central venous catheter, noninvasive or invasive measurement of cardiac output, measurement of oxygen extraction as assessed by central or mixed venous oxygen saturation, and transfer to the ICU.

\section{Ventilator support}

Ventilator use in the management of HAP is relevant (119); however, it is not apparent which mechanical ventilation strategy is superior, nor under what circumstances should such strategy be employed. The management of HAP patients with noninvasive ventilation has been associated with a lower incidence of complications and shorter stays in the ICU (275), but no such association was reported in another study (276). Nonetheless, the use of early, noninvasive ventilation to circumvent the need for intubation has been effective in immunocompromised patients. Patients who received such support had less serious complications (277).

Ventilation with reduced lung volumes has improved survival (278). This approach, while suitable for patients with bilateral diffuse lung disease, has not been proven for patients with localized lung disease.

\section{Immune modulation}

Attempts at improving the clinical outcome of septic patients by immune modulation have been unsuccessful using antiendotoxin antibodies $(279,280)$, tumour necrosis factor-alpha (281), interleukin-1 (282,283), high-dose corticosteroids $(284,285)$ and nonsteroidal anti-inflammatory agents (286). Cheng et al (287) also reported that boosting the leukocyte response with granulocyte colony stimulating factor as an adjunct to antibiotics did not improve outcome. Interestingly, Bernard et al (286) showed that treatment of septic patients with intravenous ibuprofen decreased fever but was not associated with a clinical benefit. In contrast, treatment with activated protein-C (drotrecogin-alpha) reduced the absolute mortality of patients with sepsis by $6.1 \%$ compared with patients treated with placebo; unfortunately, such treatment was also associated with an increased risk of bleeding (288). Although Laterre et al (289) showed that treatment with drotrecogin-alpha improved the survival of patients with severe sepsis caused by community-acquired pneumonia, a less impressive benefit was observed in patients with sepsis caused by HAP (289). It is recommended that treatment with drotrecogin-alpha be confined to those HAP patients with concomitant severe sepsis (B-1).

\section{Fluids}

There are limited data on the effect of the amount of volume infused on lung function. Increased capillary leak caused by inflammatory processes, when combined with excessive fluid administration, leads to greater increases in pulmonary lung water and thereby poorer gas exchange. Greater fluid intake was found to produce progression of radiographic pneumonia (290). Furthermore, in patients with acute lung injury, high tidal volume and positive fluid balance are associated with a worse outcome (291). More recently, a large randomized trial by the ARDS network showed that conservative use of fluid in patients with acute lung injury decreases the time to extubation and time in the ICU (292). Excess fluid volume replacement should be avoided in the management of patients with pneumonia (B-2).

\section{Nutritional issues}

A number of investigations have examined the role of nutritional support on the outcome of critically ill patients with pneumonia, but none have specifically addressed this issue in HAP and VAP. Evidence indicates that there is no advantage of total parental nutrition over enteral nutrition. When safety, cost and feasibility are considered, the latter is favoured (293), as is the early introduction of feeding (B-2). By contrast, peptidebased formulas compared with intact proteins do not improve outcomes. There is no evidence to suggest that supplementation with arginine, fish oil or glutamine improves outcome.

\section{Administrative issues}

Though the administrative structure of the ICU is fundamental to the management of severely ill patients, there are no data on the issue as it relates to the management of patients with HAP and VAP. However, clinical outcomes of patients treated in a 'closed' ICU with dedicated physicians are improved compared with those of patients treated in an 'open' setting $(294,295)$. In addition, the surveillance of microorganisms in an ICU, including susceptibility testing to assess resistance trends, can enhance outcome by promoting the selection of more appropriate empiric regimens $(1,296,297)$. The calculation of infection rates per 100 ICU days or per 1000 ventilatory days may also verify the success of prevention strategies. Finally, computer-assisted antimicrobial management may reduce overall antibiotic usage (221). The collection of routine cultures is not recommended, because these cultures are not predictive of subsequent invasive organisms (reviewed in [23]).

\section{Major points and recommendations for nonantimicrobial} issues related to the management of HAP and VAP

\section{Attention to judicious use of fluids and nutritional} support, and careful management of mechanical ventilator support, can contribute to improved outcomes in patients with HAP and VAP.

2. Computerized antibiotic management systems and systems for monitoring the incidence and susceptibility of local hospital microbial flora are useful.

3. Establishing a closed ICU staffed by dedicated intensivists may improve outcomes.

4. Optimizing hemodynamic management with judicious use of fluids, inotropic and vasopressor agents should be instituted early in patients who develop sepsis in association with VAP and HAP (B-2).

5. Patients who develop HAP and sepsis outside of the ICU should be transferred to the ICU for optimal management (A-2). 
6. The use of drotrecogin-alpha in patients with severe sepsis and HAP can improve survival although the data in VAP is less clear.

\section{PREVENTION AND RISK REDUCTION}

Risk factors for the development of HAP can be differentiated into modifiable and nonmodifiable conditions (43,298). Nonmodifiable risk factors may be patient-related, such as male sex, pre-existing pulmonary disease or multiple organ system failure. However, although patient-related risk factors are nonmodifiable, long-term primary prevention or general health maintenance, such as exercise, weight reduction, and use of influenza and pneumococcal vaccines, are modifiable and recommended in patients at risk $(299,300)$. Smoking cessation should also be encouraged in all patients, particularly those who have had HAP or VAP.

Modifiable risk factors for HAP and VAP are crucial targets for prevention that can reduce patient mortality and morbidity, and also promote the cost-effective use of health care resources. Effective prevention strategies include the use of strict infection control, hand hygiene, microbiological surveillance with availability of data on local drug resistant pathogens, monitoring and early removal of invasive devices, and programs to reduce or alter antibiotic prescribing practices $(1,117,125,221,244,299,301-303)$.

Excellent, detailed, evidence-based guidelines for the prevention of HAP and VAP have been published by the Centers for Disease Control and Prevention and the Hospital Infection Control Practices Advisory Committee (1), as well as the Nosocomial and Occupational Infections Section of the Public Health Agency of Canada (304). Prevention strategies are also discussed in a number of more concise review articles $(23,124,298,305)$.

\section{Infection control}

Effective targeted surveillance for high-risk patients coupled with staff education and use of proper infection control practices is the cornerstone for prevention of nosocomial pneumonia $(117,125,298,306)$. Cross infection is an important source of AROs, and hands or gloves of hospital personnel are potential reservoirs for spread (307). No single infection control measure is efficient in reducing the threat of AROs. It is rather a combination of interventions coupled with the judicious use of antibiotics that will ultimately have a clinical impact. A comprehensive hand hygiene program has been shown to decrease the overall incidence of MRSA, extended-spectrum beta-lactamaseproducing Klebsiella species and vancomycin-resistant enterococci $(308,309)$. The lack of easily reachable appropriate physical facilities (sinks, bathrooms) has led many institutions to turn to alcohol-based gels, and clinical data have indicated that rates of all nosocomial infection may be significantly reduced by the use of alcohol-based hand disinfection $(125,303,306)$.

Contact precautions, including gowns and gloves, patient cohorting and staff cohorting, have been recommended as methods of limiting the transmission of AROs (108). Infection control measures have so far been the best weapon to curb rates of spread of AROs.

\section{Intubation and invasive devices}

The use of endotracheal tubes bypasses the natural defense mechanisms of the upper respiratory tract and impairs the host's capability to fend off infection (129). Endotracheal tubes also favour the development of bacterial biofilms that may contribute to the occurrence of VAP. Noninvasive positive pressure ventilation (NIV) using a face mask is an alternative to intubation $(277,310-315)$. The use of NIV has been shown to decrease the incidence of VAP and even mortality; however, most of these studies were small, not blinded and included selected patients $(129,312,314,316,317)$. Strategies to reduce the duration of mechanical ventilation are also recommended, such as improved methods of sedation and the use of protocols to facilitate and accelerate weaning (318-322). Reintubation should be avoided because it increases the risk of VAP (126). NIV to avoid reintubation after initial extubation can be attempted (310).

The major drawback of NIV is the inability to easily obtain patients' secretions, thus hindering the clinical diagnosis of VAP. When using mechanical ventilation, oral endotracheal and orogastric tubes reduce the frequency of nosocomial sinusitis and possibly HAP $(135,323)$. Oral intubation has been associated with a lower incidence of VAP $(129,316,324)$.

Efforts to reduce the likelihood of aspiration of oropharyngeal bacteria around the endotracheal tube cuff and into the lower respiratory tract include maintaining endotracheal cuff pressure at greater than $20 \mathrm{cmH}_{2} \mathrm{O}$, and limiting the use of sedative and paralytic agents that depress cough and other host protective mechanisms $(325,326)$. Continuous aspiration of subglottic secretions, through the use of a specially designed endotracheal tube, has been shown to significantly reduce the incidence of early-onset VAP in several studies, but may be a less effective strategy for prevention of late onset disease that carries a greater risk of infection with AROs, and higher mortality and morbidity (107,327-331).

\section{Pulmonary aspiration, body position and enteral feeding} Supine patient positioning facilitates aspiration; semirecumbent positioning decreases it (332-334). Infection in patients in the supine position was associated with the simultaneous administration of enteral nutrition and an increased risk of aspiration of gastric contents $(1,335)$. Gastroesophagal reflux occurs less frequently in the semirecumbent position. Thus, it is recommended that intubated patients should be managed in a semirecumbent position, particularly during feeding (A-2).

\section{Kinetic beds}

Kinetic beds or continuous lateral rotational therapy is a technique using a continuous movement of the bed along its longitudinal axis within a certain range $\left(-40^{\circ}\right.$ to $\left.+40^{\circ}\right)(129,316)$. This movement improves secretion drainage, and thus may decrease the risk of VAP. Two small studies showed some benefits in terms of decreasing VAP rates, and a meta-analysis concluded a significant reduction in the risk of VAP, but no reduction in mortality or duration of mechanical ventilation $(129,316,336)$.

\section{Circuit changes, humidifiers and ventilator equipment}

Bacterial colonization of condensates in ventilatory circuits plays a role in the pathogenesis of VAP (328). Vigilance is needed to prevent inadvertently flushing the condensate into the lower airway or into in-line medication nebulizers when the patient turns or the bedrail is raised (16,328,337-339). Frequent changes of ventilator circuits should theoretically lower the risk of initial bacterial colonization. However, a 
study by Craven et al (340) and at least three other welldesigned studies showed no advantage to change circuits less than once a week (337-339). In fact changing circuits more often was only associated with a higher cost $(339,341)$.

A heat and moisture exchanger (HME) recycles heat and moisture exhaled by the patient, and with a bacterial filter acts as an additional protection for the airways (342). HMEs seem to be associated with a decreased incidence of VAP (343).

\section{Chest physiotherapy}

No data exist to support the use of chest physiotherapy as a standard therapy for intubated patients.

\section{Suctioning catheters}

There are two types of suctioning catheters: open single-use and closed multiuse. Only a handful of studies with a limited number of patients have compared these two options. There is no significant difference in the incidence of VAP. A closed suction catheter changed between each patient is more advantageous in terms of cost and maintenance $(129,316,324)$.

\section{Antimicrobial modulation of host bacterial colonization}

Oropharyngeal colonization, either present on admission or acquired during the ICU stay, is an independent risk factor for the development of ICU-acquired HAP caused by enteric Gram-negative bacteria and P aeruginosa (344). In a randomized trial, DeRiso et al (345) demonstrated that the use of the oral antiseptic, chlorhexidine, significantly reduced rates of nosocomial infection in patients undergoing coronary artery bypass surgery.

Modulation of oropharyngeal colonization, by combinations of oral antibiotics, with or without systemic therapy or selective decontamination of the digestive tract (SDD) is also effective in reducing the frequency of HAP, although the methodological study quality appeared to be inversely related to the magnitude of the preventive effects (141,302,346-351).

Higher ICU survival has been noted among patients receiving SDD $(352,353)$. In the former study (352), patients had a lower ICU mortality, although ICU mortality rates of all patients included did not differ significantly. In the largest study performed so far, SDD administered to 466 patients in one unit was associated with relative risk for ICU mortality of 0.65 and of hospital mortality of 0.78 , when compared with 472 patients admitted in a control ward (353). In addition, infections due to AROs occurred more frequently in the control ward. Importantly, levels of AROs were low in both wards, with complete absence of MRSA. The preventive effects of SDD for HAP have also been lower in ICUs with high endemic levels of antibiotic resistance. However, SDD may increase the selective pressure for antibiotic-resistant microorganisms (354-360) and should be discouraged.

\section{Major points and recommendations for prevention and risk} reduction of HAP and VAP

1. To control the spread of AROs, an effective infection control program must be implemented in all institutions (A-1).

2. Oral intubation should be the preferred way for invasive mechanical ventilation (B-2).
3. Patients should be nursed in a semirecumbent position $\left(30^{\circ}\right.$ to $45^{\circ}$ angle) (A-2).

4. Kinetic beds may be useful in some carefully selected groups of patients.

5. Circuit changes should be performed not more than once a week, except if visibly soiled (A-1).

6. If not contraindicated, HME should be used and changed on a weekly basis (B-2).

7. The regular use of subglottic secretion drainage should be encouraged in intubated patients (A-2).

8. A closed suction catheter should be used for each new patient (B-2).

9. Routine prophylaxis of HAP with oral antibiotics (SDD), with or without systemic antibiotics, reduces the incidence of ICU-acquired VAP, has helped contain outbreaks of MDR bacteria, but is not recommended for routine use, especially in patients who may be colonized with MDR pathogens (B-3).

10. Modulation of oropharyngeal colonization by the use of oral chlorhexidine can prevent ICU-acquired HAP in selected patient populations (345).

\section{FUTURE DIRECTIONS}

The guidelines for HAP and VAP have helped to highlight deficiencies in our knowledge and by doing so have served to point the way for future studies and investigations. There are issues in diagnosis, treatment and prevention that still require more data and definitive answers.

\section{Diagnosis}

Historically, the detection of pathogens has relied on the staining and growth of microorganisms. Molecular diagnostics offer the opportunity for the rapid and accurate identification of specific etiological agents. The most widely employed of the molecular tests involves detection of nucleic acid molecules and nucleic acid amplification. Other advances such as matrixassisted laser desorption ionization - time of flight (MALDITOF) mass spectrometry and Raman and Fourier transformed infrared spectroscopy are also being developed $(361,362)$. The former has been used for the identification of proteins and separation of DNA fragments and the latter two for the rapid identification of pathogens in blood cultures. The further development of genomics, proteomics, glycomics and metabolomics should allow the development of inventories of bacterial genes and their proteins to help in the identification and virulence profiling of potential pathogens (363).

\section{Treatment}

One of the main issues in treatment is how to best deal with $P$ aeruginosa and MRSA. The two main questions in the treatment of pseudomonal HAP and VAP are whether one should use mono- or combination therapy, particularly in nonbacteremic cases; and how long to treat. Appropriately designed randomized controlled trials with sufficient sample sizes are needed to answer the former question.

How long to treat pseudomonal HAP or VAP is also an unknown. Physicians have often treated for up to two weeks 
and sometimes longer, but there are data suggesting that this may be too long. In a study of VAP patients, it was found that by day 6 , the specified criteria indicating clinical response had been satisfied (214). Administration of antibiotics for a second week not only did not improve clinical response, but was associated with colonization by other pathogens. However, $P$ aeruginosa VAP was associated with higher relapse rates when treated for only eight days (228). While eight days of treatment may be too short for $P$ aeruginosa, it is not clear for how long to extend therapy. Similar issues are applicable to HAP and VAP caused by MRSA.

\section{Aerosolized antibiotics for VAP}

Not all antibiotics achieve reasonable levels in the lung. Aerosolization of antibiotics allows greater access to the lower respiratory tract with higher levels being achieved in the ELF. Pseudomonal VAP unresponsive to systemically administered agents subsequently responded to aerosolized aminoglycosides or polymyxin, and aerosolized aminoglycosides have been used in cystic fibrosis patients for some time (234). Unfortunately, very few antibiotics have formulations developed specifically for administration by this route and often an intravenous formulation of a drug is used. Adverse effects such as bronchospasm may result when such an approach is tried. A nebulizer that delivers the appropriate particle size $(1 \mu \mathrm{m}$ to $5 \mu \mathrm{m})$ is also required. The use of aerosolized vancomycin may be worth exploring for treatment of MRSA HAP and VAP.

\section{Prevention}

Recent appreciation of the concept of quorum sensing has shown that this same mechanism may be involved in the production of biofilms (364). Two different approaches have been

\section{REFERENCES}

1. Tablan OC, Anderson LJ, Besser R, Bridges C, Hajjeh R. Guidelines for preventing health-care-associated pneumonia, 2003: Recommendations of CDC and the Healthcare Infection Control Practices Advisory Committee. MMWR Recomm Rep 2004;53:1-36.

2. Hospital-acquired pneumonia in adults: Diagnosis, assessment of severity, initial antimicrobial therapy, and preventive strategies. A consensus statement, American Thoracic Society, November 1995. Am J Respir Crit Care Med 1996;153:1711-25.

3. Garner JS, Jarvis WR, Emori TG, Horan TC, Hughes JM. CDC definitions for nosocomial infections, 1988. Am J Infect Control 1988;16:128-40. (Erratum in 1988 Aug;16:177.)

4. Ibrahim EH, Ward S, Sherman G, Kollef MH. A comparative analysis of patients with early-onset vs late-onset nosocomial pneumonia in the ICU setting. Chest 2000;117:1434-42.

5. Trouillet JL, Chastre J, Vuagnat A, et al. Ventilator-associated pneumonia caused by potentially drug-resistant bacteria. Am J Respir Crit Care Med 1998;157:531-9.

6. Richards MJ, Edwards JR, Culver DH, Gaynes RP. Nosocomial infections in medical intensive care units in the United States. National Nosocomial Infections Surveillance System. Crit Care Med 1999;27:887-92.

7. Grossman RF, Fein A. Evidence-based assessment of diagnostic tests for ventilator-associated pneumonia. Executive summary. Chest 2000;117:177S-81S.

8. Nosocomial infection rates for interhospital comparison: Limitations and possible solutions. A report from the National Nosocomial Infections Surveillance (NNIS) System. Infect Control Hosp Epidemiol 1991;12:609-21. tried to minimize or prevent this process and thus have an impact on the development of VAP. Altered surface characteristics of the endotracheal tube through the use of silver-coated or hexetidine-impregnated tubes, or oxygen-plasma treatment of the polyvinyl chloride interfere with the ability of bacteria to adhere to the tubes. Another approach is to use nebulized antibiotics such as gentamicin (365). Clinical studies are needed to show whether they actually have an impact on the development of VAP.

Also, nebulized ceftazidime for prevention has been shown to produce fewer VAP cases at day 14 and cytokine levels such as tumour necrosis factor-alpha, interleukin-1 beta and interleukin- 8 were lower in the ceftazidime group than in the placebo group (366). Such preventive approaches are worth pursuing with appropriately designed trials.

Through expansion of our knowledge of the epidemiology, risk factors, diagnosis, treatment and prevention of HAP and VAP, reductions in the morbidity and mortality of these significant infections will hopefully be realized.

ACKNOWLEDGEMENTS: The authors gratefully acknowledge Dr Donald E Craven, Professor of Medicine at Tufts University School of Medicine and Chair of the Department of Infectious Diseases at the Lahey Clinic Medical Center, Burlington, Massachusetts, USA, for his help in the preparation of this manuscript. The authors also acknowledge the administrative assistance of Core Health Inc. Financial support for preparation for the development of these guidelines was generously provided in the form of arm's length grants-in-aid from Bayer Canada Inc, Janssen-Ortho Inc, Pfizer Canada Inc and Wyeth Pharmaceuticals Canada Inc. The sponsors were not involved in any aspect of the development of the guidelines, the decision of submission for publication or the publication process.

9. Horan TC, White JW, Jarvis WR, et al. Nosocomial infection surveillance, 1984. MMWR CDC Surveill Summ 1986;35:17SS-29SS.

10. Leu HS, Kaiser DL, Mori M, Woolson RF, Wenzel RP. Hospitalacquired pneumonia. Attributable mortality and morbidity. Am J Epidemiol 1989;129:1258-67.

11. Greenaway CA, Embil J, Orr PH, McLeod J, Dyck B, Nicolle LE. Nosocomial pneumonia on general medical and surgical wards in a tertiary-care hospital. Infect Control Hosp Epidemiol 1997;18:749-56.

12. Kampf G, Wischnewski N, Schulgen G, Schumacher M, Daschner F. Prevalence and risk factors for nosocomial lower respiratory tract infections in German hospitals. J Clin Epidemiol 1998;51:495-502.

13. Lizioli A, Privitera G, Alliata E, et al. Prevalence of nosocomial infections in Italy: Results from the Lombardy survey in 2000. J Hosp Infect 2003;54:141-8.

14. National Nosocomial Infections Surveillance (NNIS) System Report, data summary from January 1992 through June 2004, issued October 2004. Am J Infect Control 2004;32:470-85.

15. Eggimann P, Hugonnet S, Sax H, Touveneau S, Chevrolet JC, Pittet D. Ventilator-associated pneumonia: Caveats for benchmarking. Intensive Care Med 2003;29:2086-9.

16. Cook DJ, Walter SD, Cook RJ, et al. Incidence of and risk factors for ventilator-associated pneumonia in critically ill patients. Ann Intern Med 1998;129:433-40.

17. Rello J, Ollendorf DA, Oster G, et al. Epidemiology and outcomes of ventilator-associated pneumonia in a large US database. Chest 2002;122:2115-21. 
18. Heyland DK, Cook DJ, Griffith L, Keenan SP, Brun-Buisson C. The attributable morbidity and mortality of ventilatorassociated pneumonia in the critically ill patient. The Canadian Critical Trials Group. Am J Respir Crit Care Med 1999;159:1249-56.

19. Chastre J, Trouillet JL, Vuagnat A, et al. Nosocomial pneumonia in patients with acute respiratory distress syndrome. Am J Respir Crit Care Med 1998;157:1165-72.

20. Markowicz P, Wolff M, Djedaïni K, et al. Multicenter prospective study of ventilator-associated pneumonia during acute respiratory distress syndrome. Incidence, prognosis, and risk factors. ARDS Study Group. Am J Respir Crit Care Med 2000;161:1942-8.

21. Wiblin RT. Nosocomial pneumonia. In: Wenzel RP, ed. Prevention and Control of Nosocomial Infection, 3rd edn. Baltimore, MD: Williams and Wilkins, 1997.

22. Taylor GD, Buchanan-Chell M, Kirkland T, McKenzie M, Wiens R. Bacteremic nosocomial pneumonia. A 7-year experience in one institution. Chest 1995;108:786-8.

23. Chastre J, Fagon JY. Ventilator-associated pneumonia. Am J Respir Crit Care Med 2002;165:867-903.

24. Craven DE, Driks MR. Nosocomial pneumonia in the intubated patient. Semin Respir Infect 1987;2:20-33.

25. Garrouste-Orgeas M, Chevret S, Arlet G, et al. Oropharyngeal or gastric colonization and nosocomial pneumonia in adult intensive care unit patients. A prospective study based on genomic DNA analysis. Am J Respir Crit Care Med 1997;156:1647-55.

26. Vincent JL. Ventilator-associated pneumonia. J Hosp Infect 2004;57:272-80

27. Leroy O, Soubrier S. Hospital-acquired pneumonia: Risk factors, clinical features, management, and antibiotic resistance. Curr Opin Pulm Med 2004;10:171-5.

28. Bruchhaus JD, McEachern R, Campbell GD Jr. Hospitalacquired pneumonia: Recent advances in diagnosis, microbiology and treatment. Curr Opin Pulm Med 1998;4:180-4.

29. Craven DE, Barber TW, Steger KA, Montecalvo MA. Nosocomial pneumonia in the 1990s: Update of epidemiology and risk factors. Semin Respir Infect 1990;5:157-72.

30. Young PJ, Ridley SA. Ventilator-associated pneumonia. Diagnosis, pathogenesis and prevention. Anaesthesia 1999;54:1183-97.

31. Diaz O, Diaz E, Rello J. Risk factors for pneumonia in the intubated patient. Infect Dis Clin North Am 2003;17:697-705.

32. Barcenilla F, Gascó E, Rello J, Alvarez-Rocha L. Antibacterial treatment of invasive mechanical ventilation-associated pneumonia. Drugs Aging 2001;18:189-200.

33. Leroy $\mathrm{O}$, Jaffré $\mathrm{S}$, D’Escrivan $\mathrm{T}$, et al. Hospital-acquired pneumonia: Risk factors for antimicrobial-resistant causative pathogens in critically ill patients. Chest 2003;123:2034-42.

34. Costa SF, Newbaer M, Santos CR, Basso M, Soares I, Levin AS. Nosocomial pneumonia: importance of recognition of aetiological agents to define an appropriate initial empirical therapy. Int J Antimicrob Agents 2001;17:147-50.

35. Niederman MS. Nosocomial pneumonia in the elderly patient. Chronic care facility and hospital considerations. Clin Chest Med 1993;14:479-90.

36. Levison ME, Kaye D. Pneumonia caused by gram-negative bacilli: An overview. Rev Infect Dis 1985;7(Suppl 4):S656-65.

37. Chastre J. Antimicrobial treatment of hospital-acquired pneumonia. Infect Dis Clin North Am 2003;17:727-37, vi.

38. Septimus EJ. Nosocomial bacterial pneumonias. Semin Respir Infect 1989;4:245-52.

39. Alcón A, Fàbregas N, Torres A. Hospital-acquired pneumonia: Etiologic considerations. Infect Dis Clin North Am 2003;17:679-695.

40. Mandell LA, Marrie TJ, Niederman MS, The Canadian Hospital Acquired Pneumonia Consensus Conference Group. Initial antimicrobial treatment of hospital acquired pneumonia in adults: A conference report. Can J Infect Dis Med Microbiol $1993 ; 4: 317-21$
41. Lynch JP III. Hospital-acquired pneumonia: Risk factors, microbiology, and treatment. Chest 2001;119:373S-84S

42. Mandell LA, Campbell GD Jr. Nosocomial pneumonia guidelines: an international perspective. Chest 1998;113:188S-93S.

43. American Thoracic Society; Infectious Diseases Society of America. Guidelines for the management of adults with hospital-acquired, ventilator-associated, and healthcareassociated pneumonia. Am J Respir Crit Care Med 2005;171:388-416.

44. Louie M, Dyck B, Parker S, Sekla L, Nicolle LE. Nosocomia pneumonia in a Canadian tertiary care center: A prospective surveillance study. Infect Control Hosp Epidemiol 1991; 12:356-63

45. Stebbings AE, Ti TY, Tan WC. Hospital acquired pneumonia in the medical intensive care unit - a prospective study. Singapore Med J 1999;40:508-12.

46. Bartlett JG, O'Keefe P, Tally FP, Louie TJ, Gorbach SL. Bacteriology of hospital-acquired pneumonia. Arch Intern Med 1986;146:868-71.

47. Alvarez-Lerma F, Insausti-Ordeñana J, Jordá-Marcos R, et al. Efficacy and tolerability of piperacillin/tazobactam versus ceftazidime in association with amikacin for treating nosocomial pneumonia in intensive care patients: A prospective randomized multicenter trial. Intensive Care Med 2001;27:493-502

48. Baughman RP, Tapson V, McIvor A. The diagnosis and treatment challenges in nosocomial pneumonia. Diagn Microbiol Infect Dis 1999;33:131-9.

49. Berger R, Arango L. Etiologic diagnosis of bacterial nosocomial pneumonia in seriously ill patients. Crit Care Med 1985;13:833-6.

50. Berk SL, Verghese A. Emerging pathogens in nosocomial pneumonia. Eur J Clin Microbiol Infect Dis 1989;8:11-4.

51. Crabtree TD, Gleason TG, Pruett TL, Sawyer RG. Trends in nosocomial pneumonia in surgical patients as we approach the 21st century: A prospective analysis. Am Surg 1999;65:706-9.

52. Craven DE, Steger KA, Barat LM, Duncan RA. Nosocomial pneumonia: Epidemiology and infection control. Intensive Care Med 1992;18(Suppl 1):S3-S9.

53. Croce MA, Fabian TC, Stewart RM, et al. Empiric monotherapy versus combination therapy of nosocomial pneumonia in trauma patients. J Trauma 1993;35:303-9.

54. Cross JT Jr, Campbell GD Jr. Drug-resistant pathogens in community- and hospital-acquired pneumonia. Clin Chest Med 1999;20:499-506.

55. Cross JT Jr, Campbell GD Jr. Therapy of nosocomial pneumonia. Med Clin North Am 2001;85:1583-94.

56. Cunha BA. The antibiotic treatment of community-acquired, atypical, and nosocomial pneumonias. Med Clin North Am 1995;79:581-97.

57. Emori TG, Banerjee SN, Culver DH, et al. Nosocomial infections in elderly patients in the United States, 1986-1990. National Nosocomial Infections Surveillance System. Am J Med 1991;91:289S-93S.

58. Fagon JY, Chastre J, Hance AJ, Montravers P, Novara A, Gibert C. Nosocomial pneumonia in ventilated patients: A cohort study evaluating attributable mortality and hospital stay. Am J Med 1993;94:281-8

59. Fagon JY, Maillet JM, Novara A. Hospital-acquired pneumonia: methicillin resistance and intensive care unit admission. Am J Med 1998;104:17S-23S.

60. Fink MP, Snydman DR, Niederman MS, et al. Treatment of severe pneumonia in hospitalized patients: Results of a multicenter, randomized, double-blind trial comparing intravenous ciprofloxacin with imipenem-cilastatin. The Severe Pneumonia Study Group. Antimicrob Agents Chemother 1994;38:547-57.

61. Hanes SD, Demirkan K, Tolley E, et al. Risk factors for lateonset nosocomial pneumonia caused by Stenotrophomonas maltophilia in critically ill trauma patients. Clin Infect Dis 2002;35:228-35. 
62. Ioanas M, Cavalcanti M, Ferrer M, et al. Hospital-acquired pneumonia: Coverage and treatment adequacy of current guidelines. Eur Respir J 2003;22:876-82.

63. Ioanas M, Ewig S, Torres A. Treatment failures in patients with ventilator-associated pneumonia. Infect Dis Clin North Am 2003;17:753-71.

64. Iwahara T, Ichiyama S, Nada T, Shimokata K, Nakashima N. Clinical and epidemiologic investigations of nosocomial pulmonary infections caused by methicillin-resistant Staphylococcus aureus. Chest 1994;105:826-31.

65. Jiménez $\mathrm{P}$, Torres A, Rodríguez-Roisin R, et al. Incidence and etiology of pneumonia acquired during mechanical ventilation. Crit Care Med 1989;17:882-5.

66. LaForce FM. Hospital-acquired gram-negative rod pneumonias: An overview. Am J Med 1981;70:664-9.

67. Leroy O, Giradie P, Yazdanpanah Y, et al. Hospital-acquired pneumonia: Microbiological data and potential adequacy of antimicrobial regimens. Eur Respir J 2002;20:432-9.

68. Napolitano LM. Hospital-acquired and ventilator-associated pneumonia: What's new in diagnosis and treatment? Am J Surg 2003;186:4S-14S.

69. Niederman MS. An antimicrobial approach to nosocomial pneumonia. Contemp Intern Med 1995;7:9-23.

70. Nielsen SL, Røder B, Magnussen P, Engquist A, Frimodt-M $\varnothing$ ller N. Nosocomial pneumonia in an intensive care unit in a Danish university hospital: Incidence, mortality and etiology. Scand J Infect Dis 1992;24:65-70.

71. Palmer DL. Microbiology of pneumonia in the patient at risk. Am J Med 1984;76:53-60.

72. Potgieter PD, Hammond JM. Etiology and diagnosis of pneumonia requiring ICU admission. Chest 1992;101:199-203.

73. Pugliese G, Lichtenberg DA. Nosocomial bacterial pneumonia: an overview. Am J Infect Control 1987;15:249-65.

74. Ramirez JA. The choice of empirical antibiotic therapy for nosocomial pneumonia. J Chemother 1994;6(Suppl 2):47-50.

75. Rello J, Quintana E, Ausina V et al. Incidence, etiology, and outcome of nosocomial pneumonia in mechanically ventilated patients. Chest 1991;100:439-44.

76. Rello J, Lorente C, Diaz E, et al. Incidence, etiology, and outcome of nosocomial pneumonia in ICU patients requiring percutaneous tracheotomy for mechanical ventilation. Chest 2003;124:2239-43

77. Schleupner CJ, Cobb DK. A study of the etiologies and treatment of nosocomial pneumonia in a community-based teaching hospital. Infect Control Hosp Epidemiol 1992;13:515-25

78. Rouby JJ. Histology and microbiology of ventilator-associated pneumonias. Semin Respir Infect 1996;11:54-61.

79. Robert R, Grollier G, Doré P, Hira M, Ferrand E, Fauchère JL. Nosocomial pneumonia with isolation of anaerobic bacteria in ICU patients: Therapeutic considerations and outcome. J Crit Care 1999;14:114-9.

80. Ruiz-Santana S, García Jimenez A, Esteban A, et al. ICU pneumonias: A multi-institutional study. Crit Care Med 1987; 15:930-2.

81. Scheld WM, Mandell GL. Nosocomial pneumonia: Pathogenesis and recent advances in diagnosis and therapy. Rev Infect Dis 1991;13(Suppl 9):S743-51.

82. Sieger B, Berman SJ, Geckler RW, Farkas SA. Empiric treatment of hospital-acquired lower respiratory tract infections with meropenem or ceftazidime with tobramycin: A randomized study. Meropenem Lower Respiratory Infection Group. Crit Care Med 1997;25:1663-70

83. Silvestri L, Sarginson RE, Hughes J, Milanese M, Gregori D, van Saene HK. Most nosocomial pneumonias are not due to nosocomial bacteria in ventilated patients. Evaluation of the accuracy of the $48 \mathrm{~h}$ time cut-off using carriage as gold standard. Anaesth Intensive Care 2002;30:275-82.

84. Simsek S, Yurtseven N, Gerçekogalu H, et al. Ventilatorassociated pneumonias in a cardiothoracic surgery centre postoperative intensive care unit. J Hosp Infect $2001 ; 47: 321-4$
85. Torres A, Bauer TT, León-Gil C, et al. Treatment of severe nosocomial pneumonia: a prospective randomised comparison of intravenous ciprofloxacin with imipenem/cilastatin Thorax 2000;55:1033-9.

86. Vanhems P, Lepape A, Savey A, Jambou P, Fabry J. Nosocomial pulmonary infection by antimicrobial-resistant bacteria of patients hospitalized in intensive care units: Risk factors and survival. J Hosp Infect 2000;45:98-106.

87. Weber DJ, Raasch R, Rutala WA. Nosocomial infections in the ICU: The growing importance of antibiotic-resistant pathogens. Chest 1999;115:34S-41S.

88. West M, Boulanger BR, Fogarty C, et al. Levofloxacin compared with imipenem/cilastatin followed by ciprofloxacin in adult patients with nosocomial pneumonia: A multicenter, prospective, randomized, open-label study. Clin Ther 2003;25:485-506.

89. Wiblin RT, Wenzel RP. Hospital-acquired pneumonia. Curr Clin Top Infect Dis 1996;16:194-214.

90. Wunderink RG. Therapy for nosocomial pneumonia. Curr Opin Pulm Med 1997;3:120-4.

91. Zanetti G, Bally F, Greub G, et al. Cefepime versus imipenemcilastatin for treatment of nosocomial pneumonia in intensive care unit patients: A multicenter, evaluator-blind, prospective, randomized study. Antimicrob Agents Chemother 2003;47:3442-7.

92. DeCorby M, Laing N, Weshnoweski B et al. Antimicrobial resistance in pathogens isolated from Canadian intensive care units: Results of the Canadian National Intensive Care Unit (CAN-ICU) Study 2005.

93. Mulvey MR, Bryce E, Boyd D, et al. Ambler class A extendedspectrum beta-lactamase-producing Escherichia coli and Klebsiella spp. in Canadian hospitals. Antimicrob Agents Chemother 2004:48:1204-14

94. Simor AE, Ofner-Agostini M, Bryce E, et al. The evolution of methicillin-resistant Staphylococcus aureus in Canadian hospitals: 5 years of national surveillance. CMAJ 2001;165:21-6.

95. Zhanel GG, Simor AE, Vercaigne L, Mandell LA, Canadian Carbapenem Discussion Group. Imipenem and meropenem: Comparison of in vitro activity, pharmacokinetics, clinical trials and adverse effects. Can J Infect Dis Med Microbiol 1998;9:215-26.

96. Zhanel GG, Dueck M, Hoban DJ, et al. Review of macrolides and ketolides: Focus on respiratory tract infections. Drugs 2001;61:443-98.

97. Zhanel GG, Schroeder C, Vercaigne L, Gin AS, Embil J, Hoban DJ. A critical review of oxazolidinones: An alternative or replacement for glycopeptides and streptogramins? Can J Infect Dis Med Microbiol 2001;12:379-90.

98. Zhanel GG, Ennis K, Vercaigne L, et al. A critical review of the fluoroquinolones: Focus on respiratory infections. Drugs 2002;62:13-59.

99. Zhanel GG, Laing NM, Nichol KA, et al. Antibiotic activity against urinary tract infection (UTI) isolates of vancomycinresistant enterococci (VRE): Results from the 2002 North American Vancomycin Resistant Enterococci Susceptibility Study (NAVRESS). J Antimicrob Chemother 2003;52:382-8.

100. Zhanel GG, DeCorby M, Laing $\mathrm{N}$ et al. Activity of the glycylcycline-tigecycline against resistant pathogens obtained from Canadian intensive care units: Results of the Canadian National Intensive Care Unit (CAN-ICU) Study 2005.

101. Zhanel GG, Laing N, Hisanaga T et al. Comparing antibiotic resistance patterns in outpatient and inpatient urinary isolates: Results from the North American Urinary Infection Collaborative Alliance (NAUTICA).

102. Carratala J, Gudiol F, Pallares R, et al. Risk factors for nosocomial Legionella pneumophila pneumonia. Am J Respir Crit Care Med 1994;149:625-9.

103. Chen KY, Ko SC, Hsueh PR, Luh KT, Yang PC. Pulmonary fungal infection: Emphasis on microbiological spectra, patient outcome, and prognostic factors. Chest 2001;120:177-84. 
104. Dotson RG, Pingleton SK. The effect of antibiotic therapy on recovery of intracellular bacteria from bronchoalveolar lavage in suspected ventilator-associated nosocomial pneumonia. Chest 1993;103:541-6.

105. Roig J, Sabria M, Pedro-Botet ML. Legionella spp.: Community acquired and nosocomial infections. Curr Opin Infect Dis 2003;16:145-51

106. Seifert H, Strate A, Pulverer G. Nosocomial bacteremia due to Acinetobacter baumannii. Clinical features, epidemiology, and predictors of mortality. Medicine (Baltimore) 1995;74:340-9.

107. Mahul P, Auboyer C, Jospe R, et al. Prevention of nosocomial pneumonia in intubated patients: Respective role of mechanical subglottic secretions drainage and stress ulcer prophylaxis. Intensive Care Med 1992;18:20-5.

108. Muto CA, Jernigan JA, Ostrowsky BE, et al. SHEA guideline for preventing nosocomial transmission of multidrug-resistant strains of Staphylococcus aureus and enterococcus. Infect Control Hosp Epidemiol 2003;24:362-86.

109. Simor A, Loeb M, and the CIDS/CAMM Guidelines Committee. The management of infection and colonization due to methicillin-resistant Staphylococcus aureus: A CIDS/CAMM position paper. Can J Infect Dis 2004;15:39-48.

110. Salgado CD, Farr BM. Outcomes associated with vancomycin resistant enterococci: A meta-analysis. Infect Control Hosp Epidemiol 2003;24:690-8

111. Lucas GM, Lechtzin N, Puryear DW, Yau LL, Flexner CW, Moore RD. Vancomycin-resistant and vancomycin-susceptible enterococcal bacteremia: Comparison of clinical features and outcomes. Clin Infect Dis 1998;26:1127-33.

112. Kim T, Oh PI, Simor AE. The economic impact of methicillinresistant Staphylococcus aureus in Canadian hospitals. Infect Control Hosp Epidemiol 2001;22:99-104.

113. Barton M, Hawkes M, Moore D, et al. Guidelines for the prevention and management of community-associated methicillin-resistant Staphylocccous aureus: A perspective for Canadian health care practitioners. Can J Infect Dis Microbiol 2006;17(Suppl C):4C-24C.

114. Laing FP, Ramotar K, Read RR, et al. Molecular epidemiology of Xanthomonas maltophilia colonization and infection in the hospital environment. J Clin Microbiol 1995;33:513-8.

115. Chastre J, Trouillet JL. Problem pathogens (Pseudomonas aeruginosa and Acinetobacter). Semin Respir Infect 2000;15:287-98.

116. Paterson DL, Bonomo RA. Extended-spectrum beta-lactamases: A clinical update. Clin Microbiol Rev 2005;18:657-86.

117. Kollef MH. The prevention of ventilator-associated pneumonia. N Engl J Med 1999;340:627-34.

118. Cook DJ, Kollef MH. Risk factors for ICU-acquired pneumonia. JAMA 1998;279:1605-6.

119. Mehta RM, Niederman MS. Nosocomial pneumonia in the intensive care unit: Controversies and dilemmas. J Intensive Care Med 2003;18:175-88.

120. El-Solh AA, Pietrantoni C, Bhat A, et al. Colonization of dental plaques: A reservoir of respiratory pathogens for hospital-acquired pneumonia in institutionalized elders. Chest 2004;126:1575-82

121. Pesola GR. Ventilator-associated pneumonia in institutionalized elders: Are teeth a reservoir for respiratory pathogens? Chest 2004;126:1401-3.

122. Garibaldi RA, Britt MR, Coleman ML, Reading JC, Pace NL. Risk factors for postoperative pneumonia. Am J Med 1981;70:677-80

123. Cunnion KM, Weber DJ, Broadhead WE, Hanson LC, Pieper CF, Rutala WA. Risk factors for nosocomial pneumonia: Comparing adult critical-care populations. Am J Respir Crit Care Med 1996;153:158-62.

124. Craven DE, Steger KA. Nosocomial pneumonia in mechanically ventilated adult patients: Epidemiology and prevention in 1996. Semin Respir Infect 1996;11:32-53.

125. Weinstein RA. Epidemiology and control of nosocomial infections in adult intensive care units. Am J Med 1991;91:179S-84S
126. Torres A, Gatell JM, Aznar E, et al. Re-intubation increases the risk of nosocomial pneumonia in patients needing mechanical ventilation. Am J Respir Crit Care Med 1995;152:137-41.

127. de Lassence A, Alberti C, Azoulay E, et al. Impact of unplanned extubation and reintubation after weaning on nosocomial pneumonia risk in the intensive care unit: A prospective multicenter study. Anesthesiology 2002;97:148-56.

128. Drakulovic MB, Torres A, Bauer TT, Nicolas JM, Nogué S, Ferrer M. Supine body position as a risk factor for nosocomial pneumonia in mechanically ventilated patients: a randomised trial. Lancet 1999;354:1851-8.

129. Dodek P, Keenan S, Cook D, et al. Evidence-based clinical practice guideline for the prevention of ventilator-associated pneumonia. Ann Intern Med 2004;141:305-13.

130. Sugerman HJ, Wolfe L, Pasquale MD, et al. Multicenter randomized, prospective trial of early tracheostomy. J Trauma 1997:43:741-7.

131. Sirvent JM, Torres A, Vidaur L, Armengol J, de Batlle J, Bonet A. Tracheal colonisation within $24 \mathrm{~h}$ of intubation in patients with head trauma: Risk factor for developing earlyonset ventilator-associated pneumonia. Intensive Care Med 2000;26:1369-72.

132. Joshi N, Localio AR, Hamory BH. A predictive risk index for nosocomial pneumonia in the intensive care unit. Am J Med 1992;93:135-42.

133. Ferrer M, Bauer TT, Torres A, Hernández C, Piera C. Effect of nasogastric tube size on gastroesophageal reflux and microaspiration in intubated patients. Ann Intern Med 1999;130:991-4.

134. Holzapfel L, Chevret S, Madinier G, et al. Influence of longterm oro- or nasotracheal intubation on nosocomial maxillary sinusitis and pneumonia: Results of a prospective, randomized, clinical trial. Crit Care Med 1993;21:1132-8.

135. Rouby JJ, Laurent P, Gosnach M, et al. Risk factors and clinical relevance of nosocomial maxillary sinusitis in the critically ill. Am J Respir Crit Care Med 1994;150:776-83.

136. Deppe SA, Kelly JW, Thoi LL, et al. Incidence of colonization, nosocomial pneumonia, and mortality in critically ill patients using a Trach Care closed-suction system versus an opensuction system: Prospective, randomized study. Crit Care Med 1990; 18:1389-93.

137. Kollef MH, Von Harz B, Prentice D, et al. Patient transport from intensive care increases the risk of developing ventilatorassociated pneumonia. Chest 1997;112:765-73.

138. Kollef MH. Ventilator-associated pneumonia. A multivariate analysis. JAMA 1993;270:1965-70.

139. George DL, Falk PS, Wunderink RG, et al. Epidemiology of ventilator-acquired pneumonia based on protected bronchoscopic sampling. Am J Respir Crit Care Med 1998;158:1839-47.

140. Bonten MJ, Gaillard CA, van Tiel FH, Smeets HG, van der Geest S, Stobberingh EE. The stomach is not a source for colonization of the upper respiratory tract and pneumonia in ICU patients. Chest 1994;105:878-84.

141. Bonten MJ, Gaillard CA, van der Geest S, et al. The role of intragastric acidity and stress ulcus prophylaxis on colonization and infection in mechanically ventilated ICU patients. A stratified, randomized, double-blind study of sucralfate versus antacids. Am J Respir Crit Care Med 1995;152:1825-34.

142. Cook D, Guyatt G, Marshall J, et al. A comparison of sucralfate and ranitidine for the prevention of upper gastrointestinal bleeding in patients requiring mechanical ventilation. Canadian Critical Care Trials Group. N Engl J Med 1998;338:791-7.

143. Niederman MS, Craven DE. Devising strategies for preventing nosocomial pneumonia - should we ignore the stomach? Clin Infect Dis 1997;24:320-3

144. Prod'hom G, Leuenberger P, Koerfer J, et al. Nosocomial pneumonia in mechanically ventilated patients receiving antacid, ranitidine, or sucralfate as prophylaxis for stress ulcer. A randomized controlled trial. Ann Intern Med 1994;120:653-62. 
145. Driks MR, Craven DE, Celli BR, et al. Nosocomial pneumonia in intubated patients given sucralfate as compared with antacids or histamine type 2 blockers. The role of gastric colonization. N Engl J Med 1987;317:1376-82.

146. Donowitz GR, Mandell GL. Acute pneumonia. In: Mandell GL, Bennett JE, Dolin R, eds. Principles and Practice of Infectious Diseases, 6th edn. New York: Churchill Livingstone 2005:819-45.

147. Fagon JY, Chastre J, Hance AJ, Domart Y, Trouillet JL, Gibert C. Evaluation of clinical judgment in the identification and treatment of nosocomial pneumonia in ventilated patients. Chest 1993;103:547-53.

148. Wunderink RG. Clinical criteria in the diagnosis of ventilatorassociated pneumonia. Chest 2000;117(Suppl S):191S-4S.

149. Shah PM, Stille W. Cefotaxime versus ceftriaxone for the treatment of nosocomial pneumonia. Results of a multicenter study. Diagn Microbiol Infect Dis 1995;22:171-2.

150. Colardyn F, Faulkner KL. Intravenous meropenem versus imipenem/cilastatin in the treatment of serious bacterial infections in hospitalized patients. Meropenem Serious Infection Study Group. J Antimicrob Chemother 1996;38:523-37.

151. Brun-Buisson C, Sollet JP, Schweich H, Brière S, Petit C. Treatment of ventilator-associated pneumonia with piperacillintazobactam/amikacin versus ceftazidime/amikacin: A multicenter, randomized controlled trial. VAP Study Group. Clin Infect Dis 1998;26:346-54.

152. Sutherland KR, Steinberg KP, Maunder RJ, Milberg JA, Allen DL, Hudson LD. Pulmonary infection during the acute respiratory distress syndrome. Am J Respir Crit Care Med 1995;152:550-6.

153. Wunderink RG, Woldenberg LS, Zeiss J, Day CM, Ciemins J, Lacher DA. The radiologic diagnosis of autopsy-proven ventilator-associated pneumonia. Chest 1992;101:458-63.

154. Winer-Muram HT, Rubin SA, Ellis JV, et al. Pneumonia and ARDS in patients receiving mechanical ventilation: Diagnostic accuracy of chest radiography. Radiology 1993;188:479-85.

155. Lefcoe MS, Fox GA, Leasa DJ, Sparrow RK, McCormack DG. Accuracy of portable chest radiography in the critical care setting. Diagnosis of pneumonia based on quantitative cultures obtained from protected brush catheter. Chest 1994;105:885-7.

156. Pugin J, Auckenthaler R, Mili N, Janssens JP, Lew PD, Suter PM. Diagnosis of ventilator-associated pneumonia by bacteriologic analysis of bronchoscopic and nonbronchoscopic "blind" bronchoalveolar lavage fluid. Am Rev Respir Dis 1991;143:1121-9.

157. Fartoukh M, Maitre B, Honoré S, Cerf C, Zahar JR, Brun-Buisson C. Diagnosing pneumonia during mechanical ventilation: The clinical pulmonary infection score revisited. Am J Respir Crit Care Med 2003;168:173-9.

158. Blot F, Raynard B, Chachaty E, Tancrède C, Antoun S, Nitenberg G. Value of gram stain examination of lower respiratory tract secretions for early diagnosis of nosocomial pneumonia. Am J Respir Crit Care Med 2000;162:1731-7.

159. el-Ebiary M, Torres A, González J, et al. Quantitative cultures of endotracheal aspirates for the diagnosis of ventilatorassociated pneumonia. Am Rev Respir Dis 1993;148:1552-7.

160. Sauaia A, Moore FA, Moore EE, Haenel JB, Kaneer L, Read RA. Diagnosing pneumonia in mechanically ventilated trauma patients: Endotracheal aspirate versus bronchoalveolar lavage. J Trauma 1993;35:512-7.

161. Torres A, Puig de la Bellacasa J, Xaubet A, et al. Diagnostic value of quantitative cultures of bronchoalveolar lavage and telescoping plugged catheters in mechanically ventilated patients with bacterial pneumonia. Am Rev Respir Dis 1989;140:306-10.

162. Lambert RS, Vereen LE, George RB. Comparison of tracheal aspirates and protected brush catheter specimens for identifying pathogenic bacteria in mechanically ventilated patients. Am J Med Sci 1989;297:377-82.

163. Shepherd KE, Lynch KE, Wain JC, Brown EN, Wilson RS. Elastin fibers and the diagnosis of bacterial pneumonia in the adult respiratory distress syndrome. Crit Care Med 1995;23:1829-34

164. Marquette CH, Copin MC, Wallet F, et al. Diagnostic tests for pneumonia in ventilated patients: Prospective evaluation of diagnostic accuracy using histology as a diagnostic gold standard. Am J Respir Crit Care Med 1995;151:1878-88.

165. Papazian L, Thomas P, Garbe L, et al. Bronchoscopic or blind sampling techniques for the diagnosis of ventilator-associated pneumonia. Am J Respir Crit Care Med 1995;152:1982-91.

166. Timsit JF, Misset B, Goldstein FW, Vaury P, Carlet J. Reappraisal of distal diagnostic testing in the diagnosis of ICUacquired pneumonia. Chest 1995;108:1632-9.

167. Vallés J, Rello J, Fernández R, et al. Role of bronchoalveolar lavage in mechanically ventilated patients with suspected pneumonia. Eur J Clin Microbiol Infect Dis 1994;13:549-58.

168. Torres A, Martos A, Puig de la Bellacasa J, et al. Specificity of endotracheal aspiration, protected specimen brush, and bronchoalveolar lavage in mechanically ventilated patients. Am Rev Respir Dis 1993;147:952-7.

169. Chastre J, Fagon JY, Soler P, et al. Diagnosis of nosocomial bacterial pneumonia in intubated patients undergoing ventilation: Comparison of the usefulness of bronchoalveolar lavage and the protected specimen brush. Am J Med 1988;85:499-506.

170. Wimberley N, Faling LJ, Bartlett JG. A fiberoptic bronchoscopy technique to obtain uncontaminated lower airway secretions for bacterial culture. Am Rev Respir Dis 1979;119:337-43.

171. Niederman MS, Torres A, Summer W. Invasive diagnostic testing is not needed routinely to manage suspected ventilatorassociated pneumonia. Am J Respir Crit Care Med 1994;150:565-9

172. Chastre J, Fagon JY. Invasive diagnostic testing should be routinely used to manage ventilated patients with suspected pneumonia. Am J Respir Crit Care Med 1994;150:570-4.

173. Baughman RP, Thorpe JE, Staneck J, Rashkin M, Frame PT. Use of the protected specimen brush in patients with endotracheal or tracheostomy tubes. Chest 1987;91:233-6.

174. Marquette CH, Herengt F, Mathieu D, Saulnier F, Courcol R, Ramon P. Diagnosis of pneumonia in mechanically ventilated patients. Repeatability of the protected specimen brush. Am Rev Respir Dis 1993;147:211-4.

175. Timsit JF, Misset B, Renaud B, Goldstein FW, Carlet J. Effect of previous antimicrobial therapy on the accuracy of the main procedures used to diagnose nosocomial pneumonia in patients who are using ventilation. Chest 1995;108:1036-40.

176. Chastre J, Viau F, Brun P, et al. Prospective evaluation of the protected specimen brush for the diagnosis of pulmonary infections in ventilated patients. Am Rev Respir Dis 1984;130:924-9.

177. Jordá R, Parras F, Ibañez J, Reina J, Bergadá J, Raurich JM. Diagnosis of nosocomial pneumonia in mechanically ventilated patients by the blind protected telescoping catheter. Intensive Care Med 1993;19:377-82.

178. Papazian L, Martin C, Albanese J, Saux P, Charrel J, Gouin F Comparison of two methods of bacteriologic sampling of the lower respiratory tract: A study in ventilated patients with nosocomial bronchopneumonia. Crit Care Med 1989;17:461-4

179. Rouby JJ, Martin De Lassale E, Poete P, et al. Nosocomial bronchopneumonia in the critically ill. Histologic and bacteriologic aspects. Am Rev Respir Dis 1992;146:1059-66.

180. Torres A, Puig de la Bellacasa J, Rodriguez-Roisin R, Jimenez de Anta MT, Agusti-Vidal A. Diagnostic value of telescoping plugged catheters in mechanically ventilated patients with bacterial pneumonia using the Metras catheter. Am Rev Respir Dis 1988;138:117-20.

181. Marik PE, Brown WJ. A comparison of bronchoscopic vs blind protected specimen brush sampling in patients with suspected ventilator-associated pneumonia. Chest 1995;108:203-7.

182. Middleton R, Broughton WA, Kirkpatrick MB. Comparison of four methods for assessing airway bacteriology in intubated, 
mechanically ventilated patients. Am J Med Sci 1992;304:239-45.

183. Leal-Noval SR, Alfaro-Rodríguez E, Murillo-Cabeza F, Garnacho-Montero J, Rey-Perez J, Múñoz-Sánchez MA. Diagnostic value of the blind brush in mechanically ventilated patients with nosocomial pneumonia. Intensive Care Med 1992;18:410-4.

184. Bonten MJ, Bergmans DC, Stobberingh EE, et al. Implementation of bronchoscopic techniques in the diagnosis of ventilator-associated pneumonia to reduce antibiotic use. Am J Respir Crit Care Med 1997;156:1820-4.

185. Singh N, Rogers P, Atwood CW, Wagener MM, Yu VL. Shortcourse empiric antibiotic therapy for patients with pulmonary infiltrates in the intensive care unit. A proposed solution for indiscriminate antibiotic prescription. Am J Respir Crit Care Med 2000;162:505-11.

186. Souweine B, Veber B, Bedos JP, et al. Diagnostic accuracy of protected specimen brush and bronchoalveolar lavage in nosocomial pneumonia: Impact of previous antimicrobial treatments. Crit Care Med 1998;26:236-44.

187. Sanchez-Nieto JM, Torres A, Garcia-Cordoba F, et al. Impact of invasive and noninvasive quantitative culture sampling on outcome of ventilator-associated pneumonia: A pilot study. Am J Respir Crit Care Med 1998;157:371-6.

188. Fagon JY, Chastre J, Wolff M, et al. Invasive and noninvasive strategies for management of suspected ventilator-associated pneumonia. A randomized trial. Ann Intern Med 2000;132:621-30.

189. Ruiz M, Torres A, Ewig S, et al. Noninvasive versus invasive microbial investigation in ventilator-associated pneumonia: Evaluation of outcome. Am J Respir Crit Care Med 2000;162:119-25.

190. Solé Violán J, Fernández JA, Benítez AB, Cardeñosa Cendrero JA, Rodríguez de Castro F. Impact of quantitative invasive diagnostic techniques in the management and outcome of mechanically ventilated patients with suspected pneumonia. Crit Care Med 2000;28:2737-41.

191. Canadian Critical Care Trials Group. A randomized trial of diagnostic techniques for ventilator-associated pneumonia. N Engl J Med 2006;355:2619-30.

192. Baldwin DR, Honeybourne D, Wise R. Pulmonary disposition of antimicrobial agents: in vivo observations and clinical relevance. Antimicrob Agents Chemother 1992;36:1176-80.

193. Drusano GL, Preston SL, Gotfried MH, Danziger LH, Rodvold KA. Levofloxacin penetration into epithelial lining fluid as determined by population pharmacokinetic modeling and monte carlo simulation. Antimicrob Agents Chemother 2002;46:586-9.

194. Boselli E, Breilh D, Rimmelé T, et al. Pharmacokinetics and intrapulmonary diffusion of levofloxacin in critically ill patients with severe community-acquired pneumonia. Crit Care Med 2005;33:104-9.

195. Nightingale CH. Moxifloxacin, a new antibiotic designed to treat community-acquired respiratory tract infections: A review of microbiologic and pharmacokinetic-pharmacodynamic characteristics. Pharmacotherapy 2000;20:245-56.

196. Boselli E, Breilh D, Rimmelé T, et al. Pharmacokinetics and intrapulmonary concentrations of linezolid administered to critically ill patients with ventilator-associated pneumonia. Crit Care Med 2005;33:1529-33.

197. Conte JE Jr, Golden JA, Kipps J, Zurlinden E. Intrapulmonary pharmacokinetics of linezolid. Antimicrob Agents Chemother 2002;46:1475-80.

198. Honeybourne D, Tobin C, Jevons G, Andrews J, Wise R. Intrapulmonary penetration of linezolid. J Antimicrob Chemother 2003;51:1431-4.

199. Boselli E, Breilh D, Duflo F, et al. Steady-state plasma and intrapulmonary concentrations of cefepime administered in continuous infusion in critically ill patients with severe nosocomial pneumonia. Crit Care Med 2003;31:2102-6.

200. Boselli E, Breilh D, Cannesson M, et al. Steady-state plasma and intrapulmonary concentrations of piperacillin/tazobactam
$4 \mathrm{~g} / 0.5 \mathrm{~g}$ administered to critically ill patients with severe nosocomial pneumonia. Intensive Care Med 2004;30:976-9.

201. Honeybourne D. Antibiotic penetration into lung tissues. Thorax 1994;49:104-6.

202. Tomaselli F, Maier A, Matzi V, Smolle-Jüttner FM, Dittrich P. Penetration of meropenem into pneumonic human lung tissue as measured by in vivo microdialysis. Antimicrob Agents Chemother 2004;48:2228-32.

203. Drusano GL, Sorgel F, Ma L. Pharmacokinetics and penetration into epithelial lining fluid as determined by poplation phamacokinetic modeling and Monte Carlo simulation. In: The Proceedings of the 44th Interscience Conference on Antimicrobial Agents and Chemotherapy 2004, Washington, DC: Abstract 1861 .

204. Cruciani M, Gatti G, Lazzarini L, et al. Penetration of vancomycin into human lung tissue. J Antimicrob Chemother 1996;38:865-9.

205. Lamer C, de Beco V, Soler P, et al. Analysis of vancomycin entry into pulmonary lining fluid by bronchoalveolar lavage in critically ill patients. Antimicrob Agents Chemother 1993;37:281-6.

206. Wunderink RG, Rello J, Cammarata SK, Croos-Dabrera RV, Kollef MH. Linezolid vs vancomycin: Analysis of two doubleblind studies of patients with methicillin-resistant Staphylococcus aureus nosocomial pneumonia. Chest 2003;124:1789-97.

207. Forrest A, Nix DE, Ballow CH, Goss TF, Birmingham MC, Schentag JJ. Pharmacodynamics of intravenous ciprofloxacin in seriously ill patients. Antimicrob Agents Chemother 1993;37:1073-81.

208. Drusano GL, Preston SL, Fowler C, Corrado M, Weisinger B, Kahn J. Relationship between fluoroquinolone area under the curve: Minimum inhibitory concentration ratio and the probability of eradication of the infecting pathogen, in patients with nosocomial pneumonia. J Infect Dis 2004;189:1590-7.

209. Highet VS, Forrest A, Ballow CH, Schentag JJ. Antibiotic dosing issues in lower respiratory tract infection: Populationderived area under inhibitory curve is predictive of efficacy. J Antimicrob Chemother 1999;43(Suppl A):55-63.

210. Moore RD, Smith CR, Lietman PS. Association of aminoglycoside plasma levels with therapeutic outcome in gram-negative pneumonia. Am J Med 1984;77:657-62.

211. Moore RD, Lietman PS, Smith CR. Clinical response to aminoglycoside therapy: Importance of the ratio of peak concentration to minimal inhibitory concentration. J Infect Dis 1987;155:93-9.

212. Moise-Broder PA, Forrest A, Birmingham MC, Schentag JJ. Pharmacodynamics of vancomycin and other antimicrobials in patients with Staphylococcus aureus lower respiratory tract infections. Clin Pharmacokinet 2004;43:925-42.

213. Yu VL, Singh N. Excessive antimicrobial usage causes measurable harm to patients with suspected ventilatorassociated pneumonia. Intensive Care Med 2004;30:735-8.

214. Dennesen PJ, van der Ven AJ, Kessels AG, Ramsay G, Bonten MJ. Resolution of infectious parameters after antimicrobial therapy in patients with ventilator-associated pneumonia. Am J Respir Crit Care Med 2001;163:1371-5.

215. Paramythiotou E, Lucet JC, Timsit JF, et al. Acquisition of multidrug-resistant Pseudomonas aeruginosa in patients in intensive care units: Role of antibiotics with antipseudomonal activity. Clin Infect Dis 2004;38:670-7.

216. Höffken G, Niederman MS. Nosocomial pneumonia: The importance of a de-escalating strategy for antibiotic treatment of pneumonia in the ICU. Chest 2002;122:2183-96.

217. Paterson DL, Rice LB. Empirical antibiotic choice for the seriously ill patient: Are minimization of selection of resistant organisms and maximization of individual outcome mutually exclusive? Clin Infect Dis 2003;36:1006-12.

218. Rello J, Vidaur L, Sandiumenge A, et al. De-escalation therapy in ventilator-associated pneumonia. Crit Care Med 2004;32:2183-90

219. McQuillen DP, Duncan RA, Craven DE. Ventilator-associated pneumonia: Emerging principles of management. Infect Med 2005;22:104-18. 
220. Bailey TC, Ritchie DJ, McMullin ST, et al. A randomized, prospective evaluation of an interventional program to discontinue intravenous antibiotics at two tertiary care teaching institutions. Pharmacotherapy 1997;17:277-81.

221. Evans RS, Pestotnik SL, Classen DC, et al. A computer-assisted management program for antibiotics and other antiinfective agents. N Engl J Med 1998;338:232-8.

222. Ibrahim EH, Ward S, Sherman G, Schaiff R, Fraser VJ, Kollef MH. Experience with a clinical guideline for the treatment of ventilator-associated pneumonia. Crit Care Med 2001;29:1109-15.

223. Leibovici L, Gitelman V, Yehezkelli Y, et al. Improving empirical antibiotic treatment: Prospective, nonintervention testing of a decision support system. J Intern Med 1997;242:395-400

224. Micek ST, Ward S, Fraser VJ, Kollef MH. A randomized controlled trial of an antibiotic discontinuation policy for clinically suspected ventilator-associated pneumonia. Chest 2004;125:1791-9.

225. Soo Hoo GW, Wen YE, Nguyen TV, Goetz MB. Impact of clinical guidelines in the management of severe hospitalacquired pneumonia. Chest 2005;128:2778-87.

226. Evans RS, Classen DC, Pestotnik SL, Lundsgaarde HP, Burke JP. Improving empiric antibiotic selection using computer decision support. Arch Intern Med 1994;154:878-84.

227. Luna CM, Blanzaco D, Niederman MS, et al. Resolution of ventilator-associated pneumonia: Prospective evaluation of the clinical pulmonary infection score as an early clinical predictor of outcome. Crit Care Med 2003;31:676-82.

228. Chastre J, Wolff M, Fagon JY, et al. Comparison of 8 vs 15 days of antibiotic therapy for ventilator-associated pneumonia in adults: a randomized trial. JAMA 2003;290:2588-98.

229. Evans ME, Feola DJ, Rapp RP. Polymyxin B sulfate and colistin: Old antibiotics for emerging multiresistant gramnegative bacteria. Ann Pharmacother 1999;33:960-7.

230. Conway SP, Pond MN, Watson A, Etherington C, Robey HL, Goldman $\mathrm{MH}$. Intravenous colistin sulphomethate in acute respiratory exacerbations in adult patients with cystic fibrosis. Thorax 1997;52:987-93

231. Conway SP, Etherington C, Munday J, Goldman MH, Strong JJ, Wootton M. Safety and tolerability of bolus intravenous colistin in acute respiratory exacerbations in adults with cystic fibrosis. Ann Pharmacother 2000;34:1238-42.

232. Berlana D, Llop JM, Fort E, Badia MB, Jódar R. Use of colistin in the treatment of multiple-drug-resistant gram-negative infections. Am J Health Syst Pharm 2005;62:39-47.

233. Garnacho-Montero J, Ortiz-Leyba C, Jiménez-Jiménez FJ, et al. Treatment of multidrug-resistant Acinetobacter baumannii ventilator-associated pneumonia (VAP) with intravenous colistin: A comparison with imipenem-susceptible VAP. Clin Infect Dis 2003;36:1111-8.

234. Hamer DH. Treatment of nosocomial pneumonia and tracheobronchitis caused by multidrug-resistant Pseudomonas aeruginosa with aerosolized colistin. Am J Respir Crit Care Med 2000;162:328-30.

235. Levin AS, Barone AA, Penço J, et al. Intravenous colistin as therapy for nosocomial infections caused by multidrug-resistant Pseudomonas aeruginosa and Acinetobacter baumannii. Clin Infect Dis 1999;28:1008-11.

236. Linden PK, Kusne S, Coley K, Fontes P, Kramer DJ, Paterson D. Use of parenteral colistin for the treatment of serious infection due to antimicrobial-resistant Pseudomonas aeruginosa. Clin Infect Dis 2003;37:e154-e160.

237. Markou N, Apostolakos H, Koumoudiou C, et al. Intravenous colistin in the treatment of sepsis from multiresistant Gramnegative bacilli in critically ill patients. Crit Care 2003;7:R78-83.

238. Cole PJ. The role of nebulized antibiotics in treating serious respiratory infections. J Chemother 2001;13:354-62.

239. Drobnic ME, Suñé P, Montoro JB, Ferrer A, Orriols R. Inhaled tobramycin in non-cystic fibrosis patients with bronchiectasis and chronic bronchial infection with Pseudomonas aeruginosa. Ann Pharmacother 2005;39:39-44.
240. Mukhopadhyay S, Singh M, Cater JI, Ogston S, Franklin M, Olver RE. Nebulised antipseudomonal antibiotic therapy in cystic fibrosis: A meta-analysis of benefits and risks. Thorax 1996;51:364-8.

241. Scheinberg P, Shore E. A pilot study of the safety and efficacy of tobramycin solution for inhalation in patients with severe bronchiectasis. Chest 2005;127:1420-6.

242. Brown RB, Kruse JA, Counts GW, Russell JA, Christou NV, Sands ML. uble-blind study of endotracheal tobramycin in the treatment of gram-negative bacterial pneumonia. The Endotracheal Tobramycin Study Group. Antimicrob Agents Chemother 1990;34:269-72.

243. Le Conte P, Potel G, Clémenti E, et al. Administration of tobramycin aerosols in patients with nosocomial pneumonia: A preliminary study. Presse Med 2000;29:76-8.

244. Iregui M, Ward S, Sherman G, Fraser VJ, Kollef MH. Clinical importance of delays in the initiation of appropriate antibiotic treatment for ventilator-associated pneumonia. Chest 2002;122:262-8.

245. Crouch Brewer S, Wunderink RG, Jones CB, Leeper KV Jr. Ventilator-associated pneumonia due to Pseudomonas aeruginosa. Chest 1996;109:1019-29.

246. Rello J, Rué M, Jubert P, et al. Survival in patients with nosocomial pneumonia: Impact of the severity of illness and the etiologic agent. Crit Care Med 1997;25:1862-7.

247. Sankaran RT, Mattana J, Pollack S, et al. Laboratory abnormalities in patients with bacterial pneumonia. Chest 1997;111:595-600.

248. Alvarez-Lerma F. Modification of empiric antibiotic treatment in patients with pneumonia acquired in the intensive care unit. ICU-Acquired Pneumonia Study Group. Intensive Care Med 1996;22:387-94.

249. Rello J, Gallego M, Mariscal D, Soñora R, Valles J. The value of routine microbial investigation in ventilator-associated pneumonia. Am J Respir Crit Care Med 1997;156:196-200.

250. Luna CM, Vujacich P, Niederman MS, et al. Impact of BAL data on the therapy and outcome of ventilator-associated pneumonia. Chest 1997;111:676-85.

251. Clec'h C, Timsit JF, De Lassence A, et al. Efficacy of adequate early antibiotic therapy in ventilator-associated pneumonia: Influence of disease severity. Intensive Care Med 2004;30:1327-33.

252. Kollef MH, Ward S. The influence of mini-BAL cultures on patient outcomes: implications for the antibiotic management of ventilator-associated pneumonia. Chest 1998;113:412-20.

253. Babcock HM, Zack JE, Garrison T, Trovillion E, Kollef MH, Fraser VJ. Ventilator-associated pneumonia in a multi-hospital system: differences in microbiology by location. Infect Control Hosp Epidemiol 2003;24:853-8.

254. Fowler RA, Flavin KE, Barr J, Weinacker AB, Parsonnet J, Gould MK. Variability in antibiotic prescribing patterns and outcomes in patients with clinically suspected ventilatorassociated pneumonia. Chest 2003;123:835-44.

255. Bodey GP, Jadeja L, Elting L. Pseudomonas bacteremia. Retrospective analysis of 410 episodes. Arch Intern Med 1985; 145:1621-9.

256. Hilf M, Yu VL, Sharp J, Zuravleff JJ, Korvick JA, Muder RR. Antibiotic therapy for Pseudomonas aeruginosa bacteremia: Outcome correlations in a prospective study of 200 patients. Am J Med 1989;87:540-6.

257. Paul M, Benuri-Silbiger I, Soares-Weiser K, Leibovici L. Beta lactam monotherapy versus beta lactam-aminoglycoside combination therapy for sepsis in immunocompetent patients: Systematic review and meta-analysis of randomised trials. BMJ 2004;328:668.

258. Bliziotis IA, Samonis G, Vardakas KZ, Chrysanthopoulou S, Falagas ME. Effect of aminoglycoside and beta-lactam combination therapy versus beta-lactam monotherapy on the emergence of antimicrobial resistance: A meta-analysis of randomized, controlled trials. Clin Infect Dis 2005;41:149-58.

259. Mangi RJ, Greco T, Ryan J, Thornton G, Andriole VT. Cefoperazone versus combination antibiotic therapy of hospital-acquired pneumonia. Am J Med 1988;84:68-74. 
260. Fernández-Guerrero M, Gudiol F, Rodriguez-Torres A, Arnau C, Valdés L, Vallvé C. Nosocomial pneumonia: comparative multicentre trial between monotherapy with cefotaxime and treatment with antibiotic combinations. Infection 1991;19(Suppl 6):S320-5.

261. Rapp RP, Young B, Foster TS, Tibbs PA, O’Neal W. Ceftazidime versus tobramycin/ticarcillin in treating hospital acquired pneumonia and bacteremia. Pharmacotherapy 1984:4:211-5.

262. Cometta A, Baumgartner JD, Lew D, et al. Prospective randomized comparison of imipenem monotherapy with imipenem plus netilmicin for treatment of severe infections in nonneutropenic patients. Antimicrob Agents Chemother 1994;38:1309-13.

263. Rubinstein E, Lode H, Grassi C. Ceftazidime monotherapy vs ceftriaxone/tobramycin for serious hospital-acquired gramnegative infections. Antibiotic Study Group. Clin Infect Dis 1995;20:1217-28.

264. Joshi M, Bernstein J, Solomkin J, Wester BA, Kuye O. Piperacillin/tazobactam plus tobramycin versus ceftazidime plus tobramycin for the treatment of patients with nosocomial lower respiratory tract infection. Piperacillin/tazobactam Nosocomial Pneumonia Study Group. J Antimicrob Chemother 1999;43:389-97.

265. Reeves JH, Russell GM, Cade JF, McDonald M. Comparison of ceftriaxone with cefotaxime in serious chest infections. Chest 1989;96:1292-7.

266. Kollef MH, Rello J, Cammarata SK, Croos-Dabrera RV, Wunderink RG. Clinical cure and survival in Gram-positive ventilator-associated pneumonia: Retrospective analysis of two double-blind studies comparing linezolid with vancomycin. Intensive Care Med 2004;30:388-94

267. Micek ST, Lloyd AE, Ritchie DJ, Reichley RM, Fraser VJ, Kollef MH. Pseudomonas aeruginosa bloodstream infection: Importance of appropriate initial antimicrobial treatment. Antimicrob Agents Chemother 2005;49:1306-11

268. Wunderink RG, Cammarata SK, Oliphant TH, Kollef MH; Linezolid Nosocomial Pneumonia Study Group. Continuation of a randomized, double-blind, multicenter study of linezolid versus vancomycin in the treatment of patients with nosocomial pneumonia. Clin Ther 2003;25:980-92

269. Rubinstein E, Cammarata S, Oliphant T, Wunderink R; Linezolid Nosocomial Pneumonia Study Group. Linezolid (PNU-100766) versus vancomycin in the treatment of hospitalized patients with nosocomial pneumonia: A randomized, double-blind, multicenter study. Clin Infect Dis 2001;32:402-12

270. Fagon J, Patrick H, Haas DW, et al. Treatment of gram-positive nosocomial pneumonia. Prospective randomized comparison of quinupristin/dalfopristin versus vancomycin. Nosocomial Pneumonia Group. Am J Respir Crit Care Med 2000:161:753-62

271. Talcott JA, Siegel RD, Finberg R, Goldman L. Risk assessment in cancer patients with fever and neutropenia: A prospective, two-center validation of a prediction rule. J Clin Oncol 1992;10:316-22.

272. Talcott JA, Whalen A, Clark J, Rieker PP, Finberg R. Home antibiotic therapy for low-risk cancer patients with fever and neutropenia: A pilot study of 30 patients based on a validated prediction rule. J Clin Oncol 1994:12:107-14.

273. Evans ME. Selection of oxacillin resistance in oxacillinsensitive Staphylococcus aureus through exposure to ciprofloxacin but not piperacillin/tazobactam. Eur J Clin Microbiol Infect Dis 2002;21:621-3.

274. Rivers E, Nguyen B, Havstad S, et al. Early goal-directed therapy in the treatment of severe sepsis and septic shock. N Engl J Med 2001;345:1368-77.

275. Antonelli M, Conti G, Rocco M, et al. A comparison of noninvasive positive-pressure ventilation and conventional mechanical ventilation in patients with acute respiratory failure. N Engl J Med 1998;339:429-35.
276. Delclaux C, L'Her E, Alberti C, et al. Treatment of acute hypoxemic nonhypercapnic respiratory insufficiency with continuous positive airway pressure delivered by a face mask: A randomized controlled trial. JAMA 2000;284:2352-60.

277. Hilbert G, Gruson D, Vargas F, et al. Noninvasive ventilation in immunosuppressed patients with pulmonary infiltrates, fever, and acute respiratory failure. N Engl J Med 2001;344:481-7

278. Brower RG, Lanken PN, MacIntyre N, et al. Higher versus lower positive end-expiratory pressures in patients with the acute respiratory distress syndrome. N Engl J Med 2004;351:327-36.

279. Angus DC, Birmingham MC, Balk RA, et al. E5 murine monoclonal antiendotoxin antibody in gram-negative sepsis: A randomized controlled trial. E5 Study Investigators. JAMA 2000;283:1723-30.

280. Ziegler EJ, Fisher CJ Jr, Sprung CL, et al. Treatment of gramnegative bacteremia and septic shock with HA-1A human monoclonal antibody against endotoxin. A randomized, doubleblind, placebo-controlled trial. The HA-1A Sepsis Study Group. N Engl J Med 1991;324:429-36.

281. Abraham E, Wunderink R, Silverman H, et al. Efficacy and safety of monoclonal antibody to human tumor necrosis factor alpha in patients with sepsis syndrome. A randomized, controlled, double-blind, multicenter clinical trial. TNF-alpha MAb Sepsis Study Group. JAMA 1995;273:934-41.

282. Fisher CJ Jr, Dhainaut JF, Opal SM, et al. Recombinant human interleukin 1 receptor antagonist in the treatment of patients with sepsis syndrome. Results from a randomized, double-blind, placebo-controlled trial. Phase III rhIL-1ra Sepsis Syndrome Study Group. JAMA 1994;271:1836-43.

283. Opal SM, Fisher CJ Jr, Dhainaut JF, et al. Confirmatory interleukin-1 receptor antagonist trial in severe sepsis: A phase III, randomized, double-blind, placebo-controlled, multicenter trial. The Interleukin-1 Receptor Antagonist Sepsis Investigator Group. Crit Care Med 1997;25:1115-24.

284. Sprung CL, Caralis PV, Marcial EH, et al. The effects of highdose corticosteroids in patients with septic shock. A prospective, controlled study. N Engl J Med 1984;311:1137-43.

285. Bone RC, Fisher CJ Jr, Clemmer TP, Slotman GJ, Metz CA, Balk RA. A controlled clinical trial of high-dose methylprednisolone in the treatment of severe sepsis and septic shock. N Engl J Med 1987;317:653-8.

286. Bernard GR, Wheeler AP, Russell JA, et al. The effects of ibuprofen on the physiology and survival of patients with sepsis. The Ibuprofen in Sepsis Study Group. N Engl J Med 1997;336:912-8.

287. Cheng AC, Stephens DP, Currie BJ. Granulocyte-Colony Stimulating Factor (G-CSF) as an adjunct to antibiotics in the treatment of pneumonia in adults. Cochrane Database Syst Rev 2004;(3):CD004400

288. Bernard GR, Vincent JL, Laterre PF, et al. Efficacy and safety of recombinant human activated protein $\mathrm{C}$ for severe sepsis. N Engl J Med 2001;344:699-709.

289. Laterre PF, Garber G, Levy H, et al. Severe communityacquired pneumonia as a cause of severe sepsis: Data from the PROWESS study. Crit Care Med 2005;33:952-61.

290. Hash RB, Stephens JL, Laurens MB, Vogel RL. The relationship between volume status, hydration, and radiographic findings in the diagnosis of community-acquired pneumonia. J Fam Pract 2000;49:833-7.

291. Sakr Y, Vincent JL, Reinhart K, et al. High tidal volume and positive fluid balance are associated with worse outcome in acute lung injury. Chest 2005;128:3098-108.

292. National Heart, Lung, and Blood Institute Acute Respiratory Distress Syndrome (ARDS) Clinical Trials Network, Wiedemann HP, Wheeler AP, Bernard GR, et al. Comparison of two fluid-management strategies in acute lung injury. N Engl J Med 2006;354:2564-75.

293. Heyland DK, Dhaliwal R, Drover JW, Gramlich L, Dodek P; Canadian Critical Care Clinical Practice Guidelines 
Committee. Canadian clinical practice guidelines for nutrition support in mechanically ventilated, critically ill adult patients. JPEN J Parenter Enteral Nutr 2003;27:355-73.

294. Multz AS, Chalfin DB, Samson IM, et al. A "closed" medical intensive care unit (MICU) improves resource utilization when compared with an "open” MICU. Am J Respir Crit Care Med 1998;157:1468-73.

295. Carson SS, Stocking C, Podsadecki T, et al. Effects of organizational change in the medical intensive care unit of a teaching hospital: a comparison of 'open' and 'closed' formats. JAMA 1996;276:322-8

296. Haley RW. Surveillance by objective: a new priority-directed approach to the control of nosocomial infections. The National Foundation for Infectious Diseases lecture. Am J Infect Control 1985; 13:78-89.

297. Haley RW, Culver DH, White JW, et al. The efficacy of infection surveillance and control programs in preventing nosocomial infections in US hospitals. Am J Epidemiol 1985;121:182-205.

298. Fleming CA, Balaguera HU, Craven DE. Risk factors for nosocomial pneumonia. Focus on prophylaxis. Med Clin North Am 2001;85:1545-63.

299. Gardner P. A need to update and revise the pneumococcal vaccine recommendations for adults. Ann Intern Med 2003;138:999-1000.

300. Sisk JE, Whang W, Butler JC, Sneller VP, Whitney CG. Costeffectiveness of vaccination against invasive pneumococcal disease among people 50 through 64 years of age: Role of comorbid conditions and race. Ann Intern Med 2003;138:960-8.

301. Bonten MJ. Controversies on diagnosis and prevention of ventilator-associated pneumonia. Diagn Microbiol Infect Dis 1999;34:199-204.

302. Kollef MH, Sherman G, Ward S, Fraser VJ. Inadequate antimicrobial treatment of infections: A risk factor for hospital mortality among critically ill patients. Chest 1999;115:462-74.

303. Pittet D, Hugonnet S, Harbarth S, et al. Effectiveness of a hospital-wide programme to improve compliance with hand hygiene. Infection Control Programme. Lancet 2000;356:1307-12

304. Infection control guideline for the prevention of health careassociated pneumonia. Nosocomial and Occupational Infections Section. Health Care Acquired Infection Division, Centre for Infectious Disease Prevention and Control, Public Health Agency of Canada. (in press)

305. Kollef MH. Epidemiology and risk factors for nosocomial pneumonia. Emphasis on prevention. Clin Chest Med 1999;20:653-70.

306. Albert RK, Condie F. Hand-washing patterns in medical intensive-care units. N Engl J Med 1981;304:1465-6.

307. Weinstein RA. Failure of infection control in intensive care units: Can sucralfate improve the situation? Am J Med 1991;91:132S-4S.

308. Pittet D. Improving adherence to hand hygiene practice: A multidisciplinary approach. Emerg Infect Dis 2001;7:234-40.

309. Wade JJ, Desai N, Casewell MW. Hygienic hand disinfection for the removal of epidemic vancomycin-resistant Enterococcus faecium and gentamicin-resistant Enterobacter cloacae. J Hosp Infect 1991;18:211-8.

310. Esteban A, Frutos-Vivar F, Ferguson ND, et al. Noninvasive positive-pressure ventilation for respiratory failure after extubation. N Engl J Med 2004;350:2452-60.

311. Nava S, Ambrosino N, Clini E, et al. Noninvasive mechanical ventilation in the weaning of patients with respiratory failure due to chronic obstructive pulmonary disease. A randomized, controlled trial. Ann Intern Med 1998;128:721-8

312. Carlucci A, Richard JC, Wysocki M, Lepage E, Brochard L; SRLF Collaborative Group on Mechanical Ventilation. Noninvasive versus conventional mechanical ventilation. An epidemiologic survey. Am J Respir Crit Care Med 2001;163:874-80.
313. Brochard L, Mancebo J, Wysocki M, et al. Noninvasive ventilation for acute exacerbations of chronic obstructive pulmonary disease. N Engl J Med 1995;333:817-22.

314. Nourdine K, Combes P, Carton MJ, Beuret P, Cannamela A, Ducreux JC. Does noninvasive ventilation reduce the ICU nosocomial infection risk? A prospective clinical survey. Intensive Care Med 1999;25:567-73.

315. Keenan SP. Noninvasive positive pressure ventilation in acute respiratory failure. JAMA 2000;284:2376-8.

316. Collard HR, Saint S, Matthay MA. Prevention of ventilatorassociated pneumonia: An evidence-based systematic review. Ann Intern Med 2003;138:494-501.

317. Guérin C, Girard R, Chemorin C, De Varax R, Fournier G. Facial mask noninvasive mechanical ventilation reduces the incidence of nosocomial pneumonia. A prospective epidemiological survey from a single ICU. Intensive Care Med 1997;23:1024-32.

318. Brook AD, Ahrens TS, Schaiff R, et al. Effect of a nursingimplemented sedation protocol on the duration of mechanical ventilation. Crit Care Med 1999;27:2609-15.

319. Kress JP, Pohlman AS, O'Connor MF, Hall JB. Daily interruption of sedative infusions in critically ill patients undergoing mechanical ventilation. $\mathrm{N}$ Engl J Med 2000;342:1471-7.

320. Marelich GP, Murin S, Battistella F, Inciardi J, Vierra T, Roby M. Protocol weaning of mechanical ventilation in medical and surgical patients by respiratory care practitioners and nurses: Effect on weaning time and incidence of ventilatorassociated pneumonia. Chest 2000;118:459-67.

321. Needleman J, Buerhaus P, Mattke S, Stewart M, Zelevinsky K. Nurse-staffing levels and the quality of care in hospitals. N Engl J Med 2002;346:1715-22.

322. Thorens JB, Kaelin RM, Jolliet P, Chevrolet JC. Influence of the quality of nursing on the duration of weaning from mechanical ventilation in patients with chronic obstructive pulmonary disease. Crit Care Med 1995;23:1807-15.

323. Holzapfel L, Chastang C, Demingeon G, Bohe J, Piralla B, Coupry A. A randomized study assessing the systematic search for maxillary sinusitis in nasotracheally mechanically ventilated patients. Influence of nosocomial maxillary sinusitis on the occurrence of ventilator-associated pneumonia. Am J Respir Crit Care Med 1999;159:695-701.

324. Hubmayr RD, Burchardi H, Elliot M, et al. Statement of the 4th International Consensus Conference in Critical Care on ICU-Acquired Pneumonia - Chicago, Illinois, May 2002. Intensive Care Med 2002;28:1521-36.

325. Cook D, De Jonghe B, Brochard L, Brun-Buisson C. Influence of airway management on ventilator-associated pneumonia: Evidence from randomized trials. JAMA 1998;279:781-7.

326. Rello J, Soñora R, Jubert P, Artigas A, Rué M, Vallés J. Pneumonia in intubated patients: Role of respiratory airway care. Am J Respir Crit Care Med 1996;154:111-5.

327. Ferrer M, Torres A, González J, et al. Utility of selective digestive decontamination in mechanically ventilated patients. Ann Intern Med 1994;120:389-95.

328. Craven DE, Goularte TA, Make BJ. Contaminated condensate in mechanical ventilator circuits. A risk factor for nosocomial pneumonia? Am Rev Respir Dis 1984;129:625-8.

329. Kollef MH, Shapiro SD, Boyd V, et al. A randomized clinical trial comparing an extended-use hygroscopic condenser humidifier with heated-water humidification in mechanically ventilated patients. Chest 1998;113:759-67.

330. Pneumatikos I, Koulouras V, Nathanail C, Goe D, Nakos G. Selective decontamination of subglottic area in mechanically ventilated patients with multiple trauma. Intensive Care Med 2002;28:432-7.

331. Vallés J, Artigas A, Rello J, et al. Continuous aspiration of subglottic secretions in preventing ventilator-associated pneumonia. Ann Intern Med 1995;122:179-86.

332. Torres A, Serra-Batlles J, Ros E, et al. Pulmonary aspiration of gastric contents in patients receiving mechanical ventilation: The effect of body position. Ann Intern Med 1992;116:540-3. 
333. Orozco-Levi M, Torres A, Ferrer M, et al. Semirecumbent position protects from pulmonary aspiration but not completely from gastroesophageal reflux in mechanically ventilated patients. Am J Respir Crit Care Med 1995;152:1387-90.

334. Davis K Jr, Johannigman JA, Campbell RS, et al. The acute effects of body position strategies and respiratory therapy in paralyzed patients with acute lung injury. Crit Care 2001;5:81-7.

335. Pingleton SK, Hinthorn DR, Liu C. Enteral nutrition in patients receiving mechanical ventilation. Multiple sources of tracheal colonization include the stomach. Am J Med 1986;80:827-32.

336. Delaney A, Gray H, Laupland KB, Zuege DJ. Kinetic bed therapy to prevent nosocomial pneumonia in mechanically ventilated patients: A systematic review and meta-analysis. Crit Care 2006;10:R70.

337. Craven DE, Lichtenberg DA, Goularte TA, Make BJ, McCabe WR. Contaminated medication nebulizers in mechanical ventilator circuits. Source of bacterial aerosols. Am J Med 1984;77:834-8.

338. Dreyfuss D, Djedaini K, Weber P, et al. Prospective study of nosocomial pneumonia and of patient and circuit colonization during mechanical ventilation with circuit changes every 48 hours versus no change. Am Rev Respir Dis 1991;143:738-43.

339. Kollef MH, Shapiro SD, Fraser VJ, et al. Mechanical ventilation with or without 7-day circuit changes. A randomized controlled trial. Ann Intern Med 1995;123:168-74.

340. Craven DE, Connolly MG Jr, Lichtenberg DA, Primeau PJ, McCabe WR. Contamination of mechanical ventilators with tubing changes every 24 or 48 hours. N Engl J Med 1982;306:1505-9.

341. Long MN, Wickstrom G, Grimes A, Benton CF, Belcher B, Stamm AM. Prospective, randomized study of ventilatorassociated pneumonia in patients with one versus three ventilator circuit changes per week. Infect Control Hosp Epidemiol 1996;17:14-9.

342. Hess D. Prolonged use of heat and moisture exchangers: Why do we keep changing things? Crit Care Med 2000;28:1667-8.

343. Kirton OC, DeHaven B, Morgan J, Morejon O, Civetta J. A prospective, randomized comparison of an in-line heat moisture exchange filter and heated wire humidifiers: Rates of ventilator-associated early-onset (community-acquired) or lateonset (hospital-acquired) pneumonia and incidence of endotracheal tube occlusion. Chest 1997;112:1055-9.

344. Bonten MJ, Bergmans DC, Ambergen AW, et al. Risk factors for pneumonia, and colonization of respiratory tract and stomach in mechanically ventilated ICU patients. Am J Respir Crit Care Med 1996;154:1339-46.

345. DeRiso AJ 2nd, Ladowski JS, Dillon TA, Justice JW, Peterson AC. Chlorhexidine gluconate $0.12 \%$ oral rinse reduces the incidence of total nosocomial respiratory infection and nonprophylactic systemic antibiotic use in patients undergoing heart surgery. Chest 1996;109:1556-61.

346. Abele-Horn M, Dauber A, Bauernfeind A, et al. Decrease in nosocomial pneumonia in ventilated patients by selective oropharyngeal decontamination (SOD). Intensive Care Med 1997;23:187-95.

347. Bergmans DC, Bonten MJ, Gaillard CA, et al. Prevention of ventilator-associated pneumonia by oral decontamination: $\mathrm{A}$ prospective, randomized, double-blind, placebo-controlled study. Am J Respir Crit Care Med 2001;164:382-8.

348. D’Amico R, Pifferi S, Leonetti C, Torri V, Tinazzi A, Liberati A. Effectiveness of antibiotic prophylaxis in critically ill adult patients: Systematic review of randomised controlled trials. BMJ 1998;316:1275-85.

349. Pugin J, Auckenthaler R, Lew DP, Suter PM. Oropharyngeal decontamination decreases incidence of ventilator-associated pneumonia. A randomized, placebo-controlled, double-blind clinical trial. JAMA 1991;265:2704-10.

350. Rodríguez-Roldán JM, Altuna-Cuesta A, López A, et al. Prevention of nosocomial lung infection in ventilated patients:
Use of an antimicrobial pharyngeal nonabsorbable paste. Crit Care Med 1990;18:1239-42.

351. van Nieuwenhoven CA, Buskens E, van Tiel FH, Bonten MJ Relationship between methodological trial quality and the effects of selective digestive decontamination on pneumonia and mortality in critically ill patients. JAMA 2001;286:335-40.

352. Krueger WA, Lenhart FP, Neeser G, et al. Influence of combined intravenous and topical antibiotic prophylaxis on the incidence of infections, organ dysfunctions, and mortality in critically ill surgical patients: A prospective, stratified, randomized, double-blind, placebo-controlled clinical trial. Am J Respir Crit Care Med 2002;166:1029-37.

353. de Jonge E, Schultz MJ, Spanjaard L, et al. Effects of selective decontamination of digestive tract on mortality and acquisition of resistant bacteria in intensive care: A randomised controlled trial. Lancet 2003;362:1011-6.

354. Gastinne H, Wolff M, Delatour F, Faurisson F, Chevret S. A controlled trial in intensive care units of selective decontamination of the digestive tract with nonabsorbable antibiotics. The French Study Group on Selective Decontamination of the Digestive Tract. N Engl J Med 1992;326:594-9.

355. Hammond JM, Potgieter PD, Saunders GL, Forder AA. Double-blind study of selective decontamination of the digestive tract in intensive care. Lancet 1992;340:5-9.

356. Lingnau W, Berger J, Javorsky F, Fille M, Allerberger F, Benzer $\mathrm{H}$. Changing bacterial ecology during a five-year period of selective intestinal decontamination. J Hosp Infect 1998;39:195-206.

357. Misset B, Kitzis MD, Mahe P, et al. Bacteriological side effects of gut decontamination with polymyxin $\mathrm{E}$, gentamicin, and amphotericin B. Infect Control Hosp Epidemiol 1993;14:62-4.

358. Misset B, Kitzis MD, Conscience G, Goldstein F, Fourrier A, Carlet J. Mechanisms of failure to decontaminate the gut with polymixin $\mathrm{E}$, gentamicin and amphotericin $\mathrm{B}$ in patients in intensive care. Eur J Clin Microbiol Infect Dis 1994;13:165-70.

359. Verwaest C, Verhaegen J, Ferdinande P, et al. Randomized, controlled trial of selective digestive decontamination in 600 mechanically ventilated patients in a multidisciplinary intensive care unit. Crit Care Med 1997;25:63-71.

360. Wiener J, Itokazu G, Nathan C, Kabins SA, Weinstein RA. A randomized, double-blind, placebo-controlled trial of selective digestive decontamination in a medical-surgical intensive care unit. Clin Infect Dis 1995;20:861-7.

361. Hindré T, Didelot S, Le Pennec JP, Haras D, Dufour A, Vallée-Réhel K. Bacteriocin detection from whole bacteria by matrix-assisted laser desorption ionization-time of flight mass spectrometry. Appl Environ Microbiol 2003;69:1051-8.

362. Maquelin K, Kirschner C, Choo-Smith LP, et al. Prospective study of the performance of vibrational spectroscopies for rapid identification of bacterial and fungal pathogens recovered from blood cultures. J Clin Microbiol 2003;41:324-9.

363. Dennis P, Edwards EA, Liss SN, Fulthorpe R. Monitoring gene expression in mixed microbial communities by using DNA microarrays. Appl Environ Microbiol 2003;69:769-78.

364. Fuqua C, Greenberg EP. Listening in on bacteria: Acylhomoserine lactone signalling. Nat Rev Mol Cell Biol 2002;3:685-95.

365. Adair CG, Gorman SP, Byers LM, et al. Eradication of endotracheal tube biofilm by nebulised gentamicin. Intensive Care Med 2002;28:426-31.

366. Wood GC, Boucher BA, Croce MA, Hanes SD, Herring VL, Fabian TC. Aerosolized ceftazidime for prevention of ventilator-associated pneumonia and drug effects on the proinflammatory response in critically ill trauma patients. Pharmacotherapy 2002;22:972-82.

367. Solomkin JS, Mazuski JE, Baron EJ, et al. Guidelines for the selection of anti-infective agents for complicated intraabdominal infections. Clin Infect Dis 2003;37:997-1005. 
368. Clinical and Laboratory Standards Institute (CLSI). Performance standards for antimicrobial susceptibility testing, Fifteenth Informational Supplement M100-S15. 2005.

369. National Committee for Clinical Laboratory Standards (NCCLS). Performance standards for antimicrobial susceptibility testing: Supplemental tables. 2002.

370. Schentag JJ, Vari AJ, Winslade NE, et al. Treatment with aztreonam or tobramycin in critical care patients with nosocomial gram-negative pneumonia. Am J Med 1985;78:34-41.

371. Jaccard C, Troillet N, Harbarth S, et al. Prospective randomized comparison of imipenem-cilastatin and piperacillin-tazobactam in nosocomial pneumonia or peritonitis. Antimicrob Agents Chemother 1998;42:2966-72.

372. Hoepelman AI, Kieft H, Aoun M, et al. International comparative study of cefepime and ceftazidime in the treatment of serious bacterial infections. J Antimicrob Chemother 1993;32(Suppl B):175-86.

373. Niederman M, Hoeffken G, Hampel B. Efficacy and safety of moxifloxacin versus ceftriaxone / ceftriaxone-azetil (IV / PO) in patients with nosocomial pneumonia. In: 2006

374. Torres A, de Celis R, Rabinad E, et al. Therapeutic efficacy of the combination of aztreonam with cefotaxime in the treatment of severe nosocomial pneumonia. Comparative study against amikacin combined with cefotaxime. Chemotherapy 1989;35(Suppl 1):15-24.
375. Rapp RP, Billeter M, Hatton J, Young AB, Tibbs PA, Dempsey RJ. Intravenous ciprofloxacin versus ceftazidime for treatment of nosocomial pneumonia and urinary tract infection. Clin Pharm 1991;10:49-55.

376. Saginur R, Garber G, Darling G, et al. Prospective, randomized comparison of intravenous and oral ciprofloxacin with intravenous ceftazidime in the treatment of nosocomial pneumonia. Can J Infect Dis 1997;8:89-94.

377. Barckow D, Schwigon CD. Cefepime versus cefotaxime in the treatment of lower respiratory tract infections. J Antimicrob Chemother 1993;32(Suppl B):187-93.

378. Garau J, Blanquer J, Cobo L, et al. Prospective, randomised, multicentre study of meropenem versus imipenem/cilastatin as empiric monotherapy in severe nosocomial infections. Eur J Clin Microbiol Infect Dis 1997;16:789-96.

379. Cade JF, Presneill J, Sinickas V, Hellyar A. The optimal dosage of ceftazidime for severe lower respiratory tract infections. J Antimicrob Chemother 1993;32:611-22.

380. Nicolau DP, McNabb J, Lacy MK, Quintiliani R, Nightingale CH. Continuous versus intermittent administration of ceftazidime in intensive care unit patients with nosocomial pneumonia. Int J Antimicrob Agents 2001;17:497-504.

381. Shorr AF, Zadeikis N, Jackson WL, et al. Levofloxacin for treatment of ventilator-associated pneumonia: A subgroup analysis from a randomized trial. Clin Infect Dis 2005;40(Suppl 2):S123-9.

\section{ASSOCIATION OF MEDICAL MICROBIOLOGY AND INFECTIOUS DISEASE CANADA GUIDELINES COMMITTEE}

Drs Gerald Evans (Chair), David Haldane, Elizabeth Lee Ford-Jones, Michel Laverdiere, Lindsay Nicolle, Corinna Quan, Kathryn Suh 


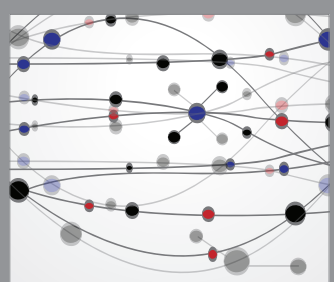

The Scientific World Journal
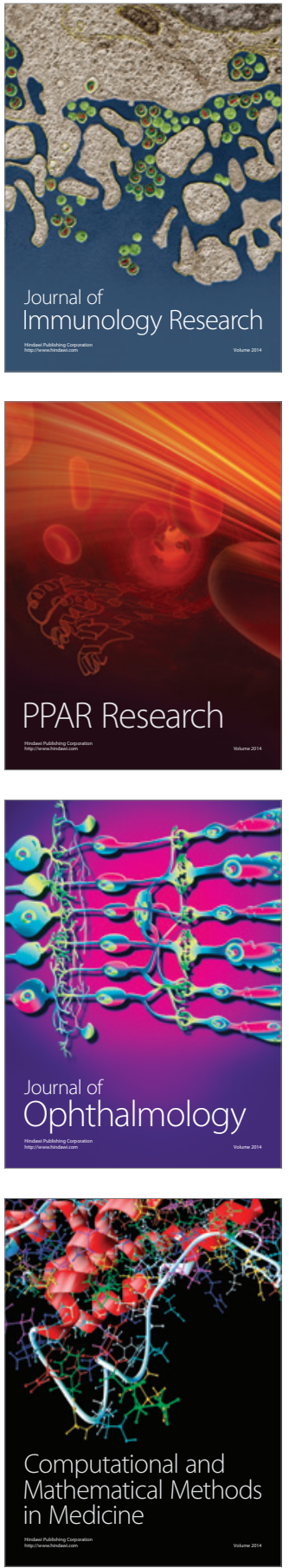

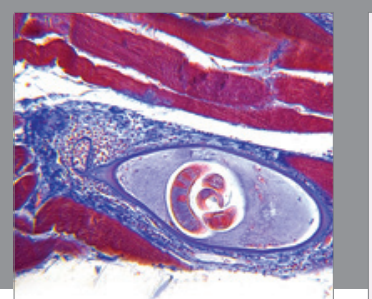

Gastroenterology Research and Practice

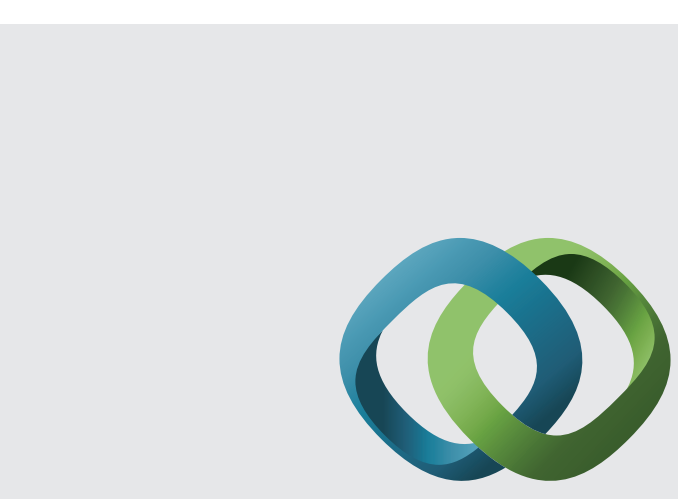

\section{Hindawi}

Submit your manuscripts at

http://www.hindawi.com
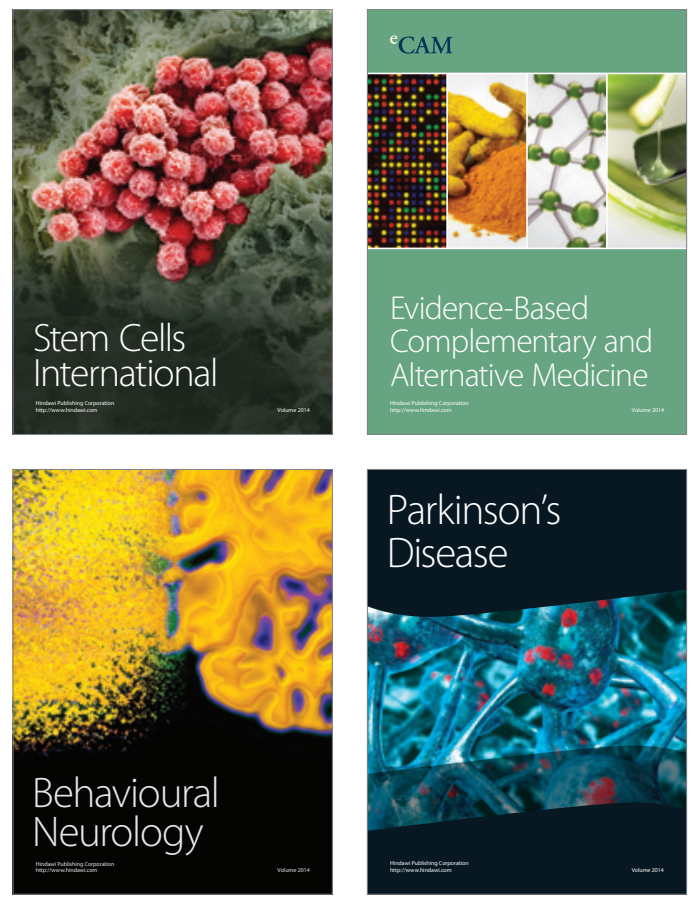
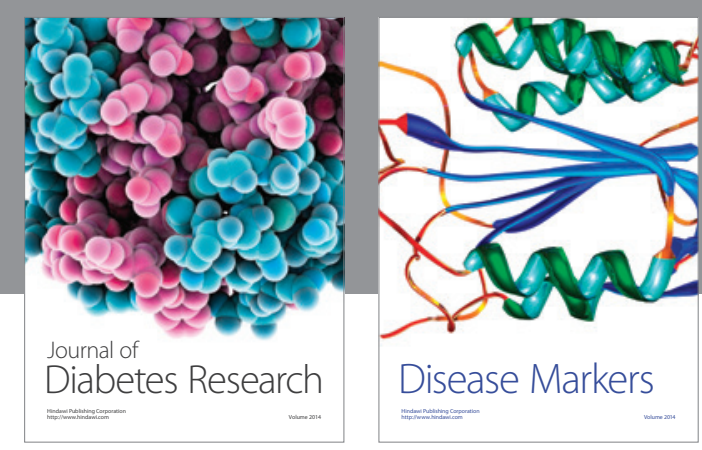

Disease Markers
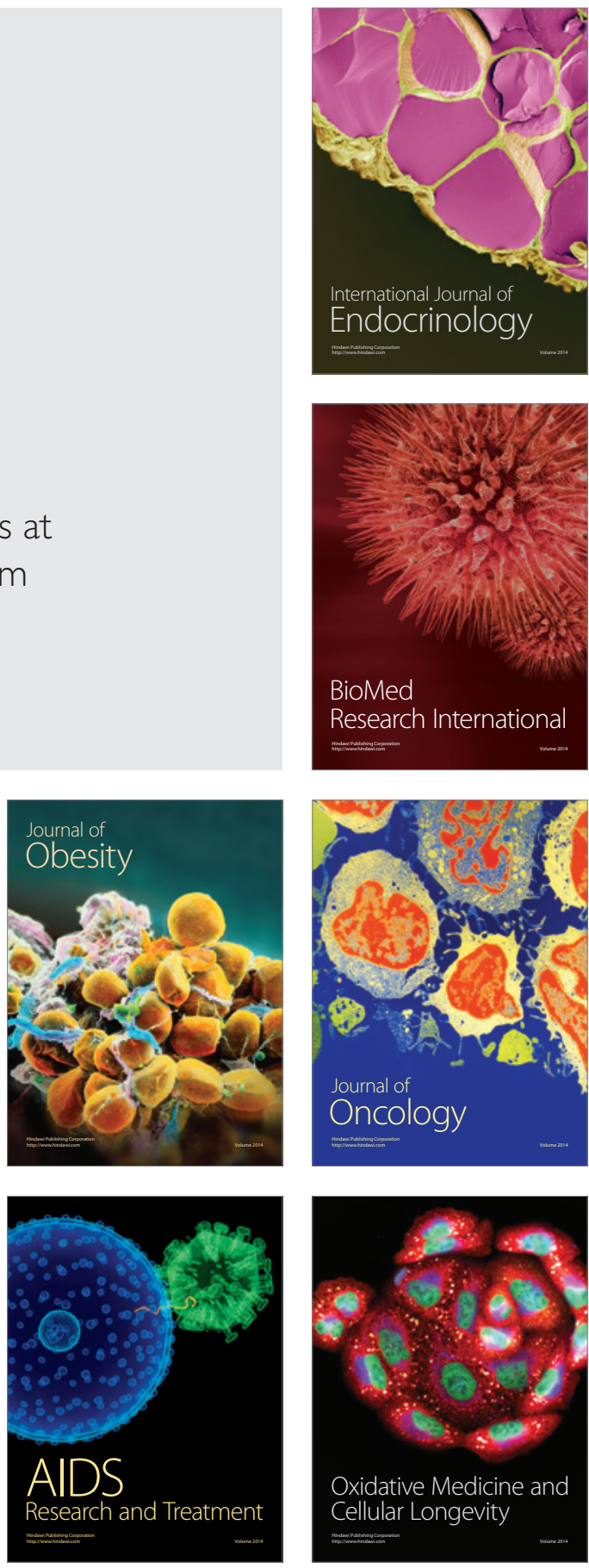